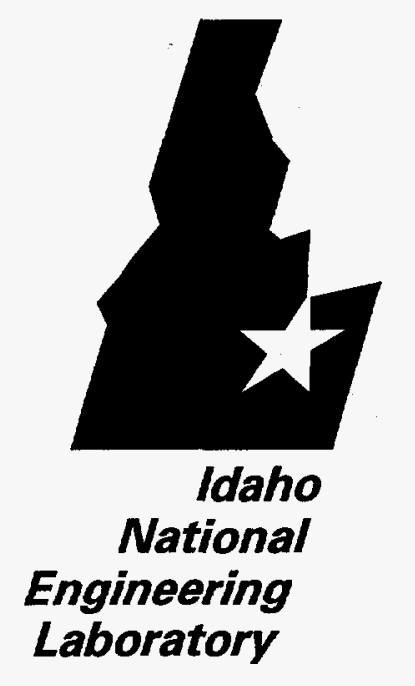

INEL-95/0530

October 1995

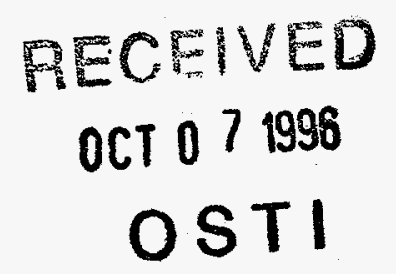

Noncontacting NDE for Materials Characterization

K. L. Telschow

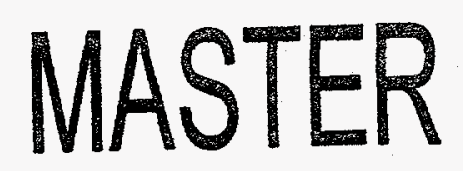

DSTRBBUTON OF THIS DOCUMENT IS UMLMITED

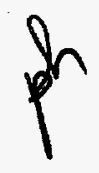

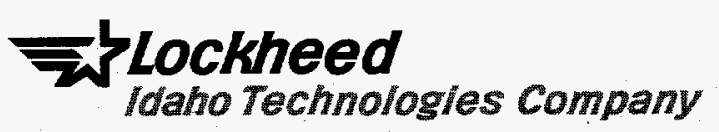




\title{
Noncontacting NDE for Materials Characterization
}

\author{
K. L. Telschow
}

Published October 1995

\section{Idaho National Engineering Laboratory Materials Physics Department Lockheed Idaho Technologies Company Idaho Falls, Idaho 83415}




\section{DISCLAIMER}

This report was prepared as an account of work sponsored by an agency of the United States Government. Neither the United States Government nor any agency thereof, nor any of their employees, makes any warranty, express or implied, or assumes any legal liability or responsibility for the accuracy, completeness, or usefulness of any information, apparatus, product, or process disclosed, or represents that its use would not infringe privately owned rights. Reference herein to any specific commercial product, process, or service by trade name, trademark, manufacturer, or otherwise does not necessarily constitute or imply its endorsement, recommendation, or favoring by the United States Government or any agency thereof. The views and opinions of authors expressed herein do not necessarily state or reflect those of the United States Government or any agency thereof. 


\section{DISCLAIMER}

Portions of this document may be illegible in electronic image products. Images are produced from the best available original document. 


\begin{abstract}
This report describes research performed at the Idaho National Engineering Laboratory from May 1983 to September 1995, funded by the Interior Department's Bureau of Mines, on ultrasonic methods (particularly noncontacting methods) for nondestructive evaluation and process control. The abilities of ultrasonic techniques to measure microstructural features in metals, ceramics, and composite materials were demonstrated. A major emphasis in this project was the development of noncontacting ultrasonic techniques, based on laser generation and detection of elastic waves, for process monitoring and control in high-temperature, harsh environments without close coupling to the material being processed. Laser ultrasonic measurements were utilized for in situ process monitoring during ceramic sintering, high temperature annealing, and molten metal solidification.
\end{abstract}




\section{ACKNOWLEDGMENTS}

This project would not have been possible without the dedicated efforts of J. B. Walter, L. S. Koo, and G. V. Garcia at the Idaho National Engineering Laboratory. In addition, collaborations with Montana State University and the University of Idaho contributed greatly to the program's success. Four theses resulted from this research. University collaborators include:

\section{Montana State University}

Professor R. J. Conant, Department of Mechanical Engineering

Master's Thesis: David Hurley, Harischandra Prasad Cherukuri, Amitava Roy

Ph.D. Thesis: Hemin Yang

\section{University of Idaho}

Professors T. Alan Place and R. F. Gibson, Department of Mechanical Engineering 


\section{CONTENTS}

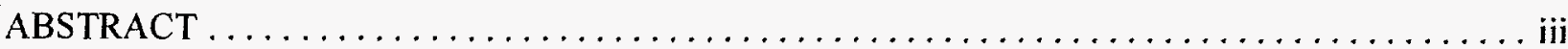

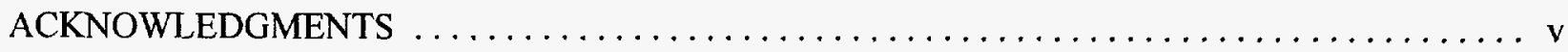

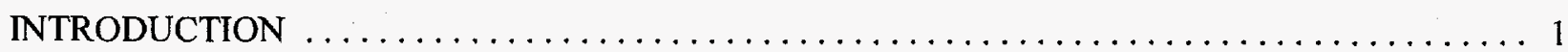

ULTRASONIC SCATTERING AS A PROBE OF MATERIAL MICROSTRUCTURE $\ldots \ldots \ldots \ldots 2$

INTERNAL FRICTION MEASUREMENTS $\ldots \ldots \ldots \ldots \ldots \ldots \ldots \ldots \ldots \ldots \ldots \ldots \ldots, \ldots$

LASER GENERATION AND DETECTION OF ULTRASOUND $\ldots \ldots \ldots \ldots \ldots \ldots \ldots \ldots \ldots$

Optical Ultrasound Detection $\ldots \ldots \ldots \ldots \ldots \ldots \ldots \ldots \ldots \ldots \ldots \ldots \ldots \ldots \ldots \ldots \ldots \ldots$

Laser Ultrasound Generation $\ldots \ldots \ldots \ldots \ldots \ldots \ldots \ldots \ldots \ldots \ldots \ldots \ldots \ldots \ldots \ldots$

LASER ULTRASONIC MONITORING OF SINTERING $\ldots \ldots \ldots \ldots \ldots \ldots \ldots \ldots \ldots \ldots \ldots \ldots \ldots$

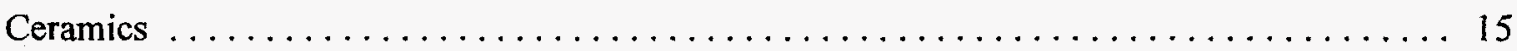

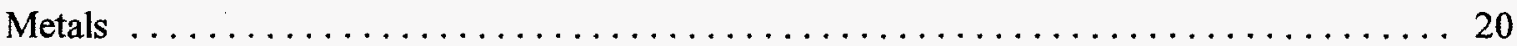

CARBON STEEL PHASE TRANSITION MEASUREMENTS $\ldots \ldots \ldots \ldots \ldots \ldots \ldots \ldots \ldots \ldots$

SURFACE WAVES IN SHEETS/FOILS AND SPHERES $\ldots \ldots \ldots \ldots \ldots \ldots \ldots \ldots \ldots \ldots \ldots$

MICROELECTRONIC APPLICATIONS OF LASER ULTRASONICS $\ldots \ldots \ldots \ldots \ldots \ldots \ldots 28$

MOLTEN METAL SOLIDIFICATION MONITORING $\ldots \ldots \ldots \ldots \ldots \ldots \ldots \ldots \ldots \ldots \ldots \ldots \ldots$

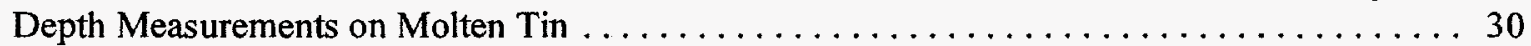

Liquid Mercury Laser Source Characterization $\ldots \ldots \ldots \ldots \ldots \ldots \ldots \ldots \ldots \ldots, \ldots \ldots \ldots$

Radiation Pattern ..................................... 31

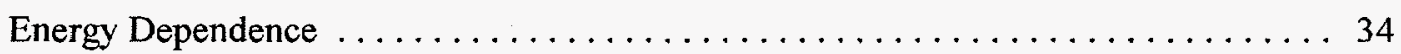

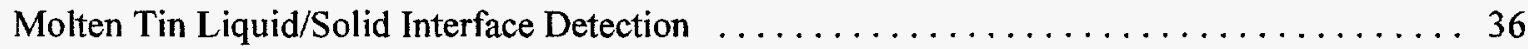

Stationary Solidification Front Measurements $\ldots \ldots \ldots \ldots \ldots \ldots \ldots \ldots \ldots \ldots, 36$

Moving Solidification Front $\ldots \ldots \ldots \ldots \ldots \ldots \ldots \ldots \ldots \ldots \ldots, \ldots \ldots \ldots$

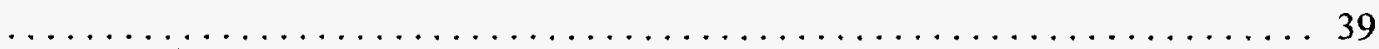

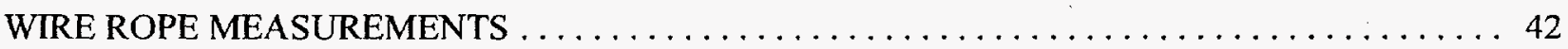

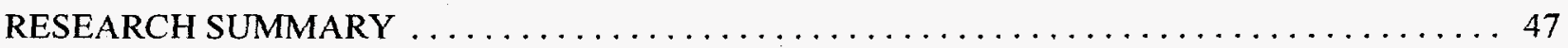

TECHNOLOGY TRANSFER $\ldots \ldots \ldots \ldots \ldots \ldots \ldots \ldots \ldots \ldots \ldots \ldots \ldots \ldots \ldots \ldots, 48$

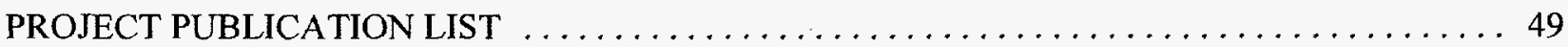

Inconel Grain Scattering and the Single Scatterer Model $\ldots \ldots \ldots \ldots \ldots \ldots \ldots \ldots . \ldots 49$

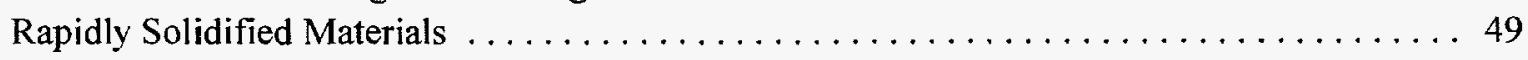

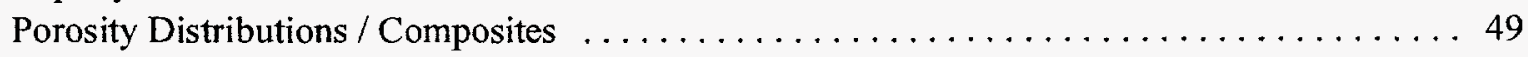


Laser Generation . . . . . . . . . . . . . . . . . . . . . . . . . . . 49

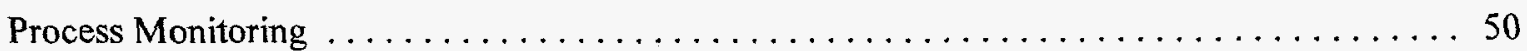

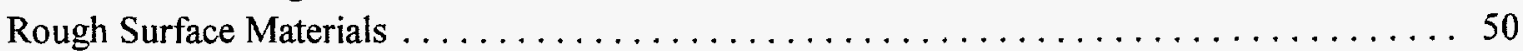

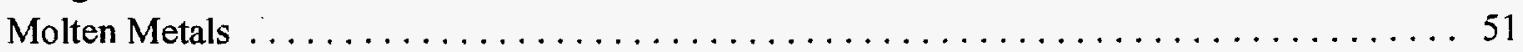

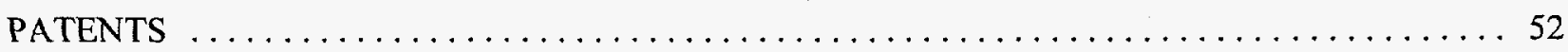

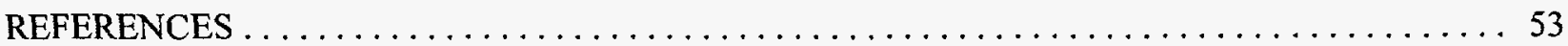

\section{FIGURES}

1. Measured attenuations of three Inconel samples having the grain sizes indicated and micrographs of

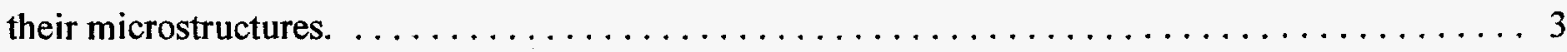

2. Measured attenuations of three Inconel samples having the grain sizes indicated and micrographs of

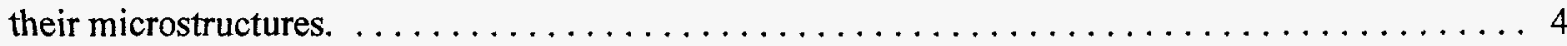

3. Measured backscatter power spectra for the three Inconel samples and micrographs of their

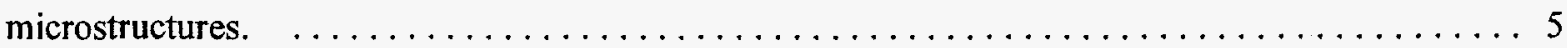

4. Ultrasonic transducer above a material sample showing the inspection method. $\ldots \ldots \ldots \ldots 7$

5. Test rigs for the impulse measurements using (a) flexural and (b) torsional vibrations. . . . . . 9

6. Measured torsional oscillation loss factor versus the microstructural particle size fraction. . . . . 10

7. Schematic of the confocal Fabry-Perot interferometer used for detection of the sample surface

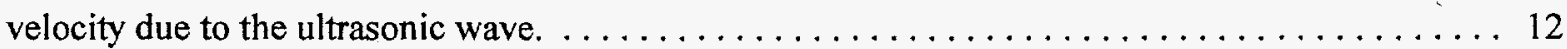

8. Schematic of the optical ultrasonic setup for high temperature measurements. $\ldots \ldots \ldots \ldots \ldots 12$

9. Ultrasonic waveforms recorded with the capacitive detector and the optical for the pulsed laser source

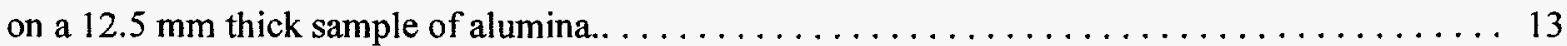

10. Attenuation in three samples of Inconel with different grain sizes as measured with the piezoelectric

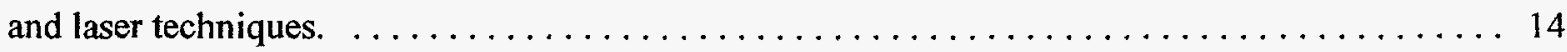

11. Real-time laser ultrasonic measurements in the through transmission mode taken while heating zinc

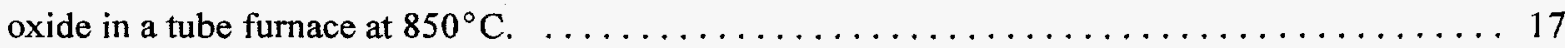

12. Longitudinal wave velocities of the presintered zinc oxide sample set measured both with the contact

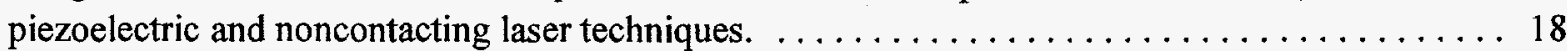

13. The relative densities of samples $\# 43$ and $\# 49$ sintered at 900 and $975^{\circ} \mathrm{C}$, respectively. . . . . 19

14. Longitudinal wave velocities measured in partially sintered copper powder. . . . . . . . 20

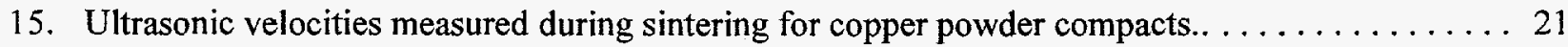

16. Ultrasonic velocities measured during sintering for copper and copper $/ 10 \%$ tin compacts. . . . . 22

17. Ultrasonic signal magnitude waveforms taken at the points indicated in the text for the copper/10\%tin compact. . . . . . . . . . . . . . . . . . . . . . . . . 22

18. Ultrasonic wave velocity hysteresis recorded during the microstructural phase transition in carbon

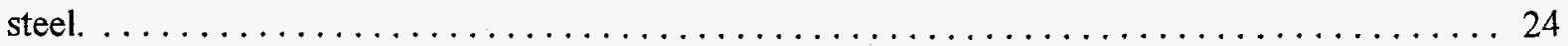

19. Block diagram of the experimental setup for recording surface waves on plates and spheres using

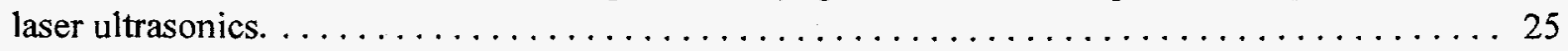

20. Lamb waves measured by the laser ultrasonic technique in aluminum. $\ldots \ldots \ldots \ldots \ldots \ldots$

21. Surface waves recorded on a $17.5 \mathrm{~mm}$ diameter stainless steel sphere using laser ultrasonics. . . 27

22. Setup for high frequency surface wave measurements to evaluate bonding in microelectronic

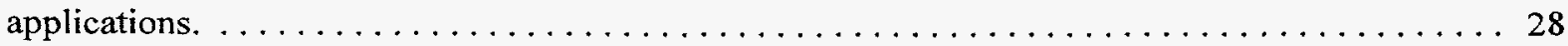

23. Surface wave measurement at high frequencies for a source-to-detector distance of $100 \mu \mathrm{m} . \ldots 29$ 
24. Laser ultrasonic measurement apparatus for acoustic wave generation and detection at the liquid metal

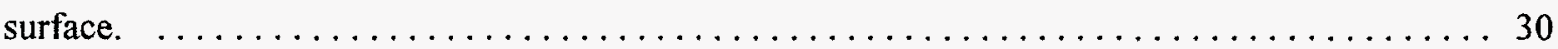

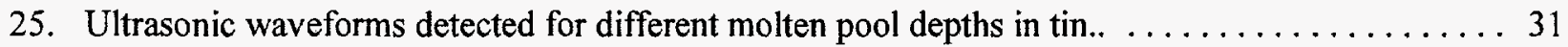

26. Angular radiation measurement geometry for liquid mercury. $\ldots \ldots \ldots \ldots \ldots \ldots \ldots \ldots \ldots \ldots$

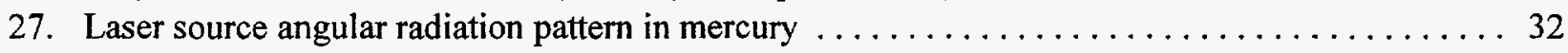

28. Surface waves on mercury for a source-to-detector separation of $7.5 \mathrm{~mm} . \ldots \ldots \ldots \ldots \ldots$

29. Ultrasonic amplitude as a function of the Nd-YAG pulse energy in both the thermoelastic and

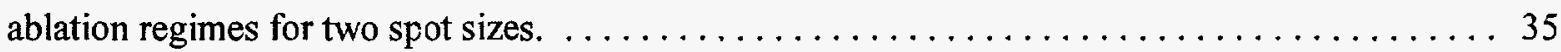

30. The ablation model, shown as the dashed curve, displays the essential physics for the transition from thermoelastic expansion to ablation ultrasound production mechanisms. $\ldots \ldots \ldots \ldots \ldots \ldots$

31. Molten metal casting furnace for laser/piezoelectric experiments. $\ldots \ldots \ldots \ldots \ldots \ldots \ldots \ldots \ldots$

32. Solidification front reflection echoes recorded at the surface of the liquid with the laser technique and

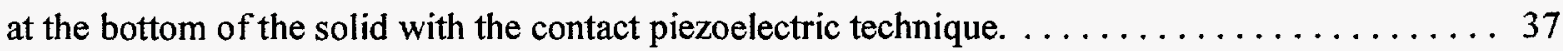

33. The solidification front in tin measured by the laser ultrasonic method. $\ldots \ldots \ldots \ldots \ldots \ldots \ldots$

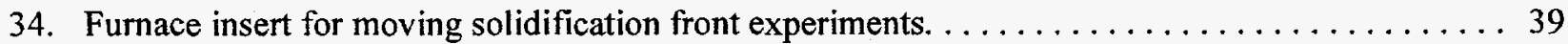

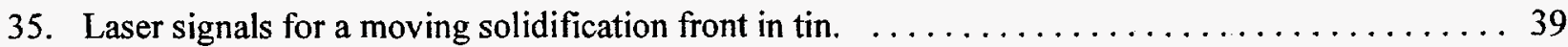

36. Laser signals from a moving solidification front in a tin-lead alloy. $\ldots \ldots \ldots \ldots \ldots \ldots \ldots$

37. Comparison of solidification front echoes for 8 and $12 \mathrm{~mm}$ mushy zones with that of a moving front

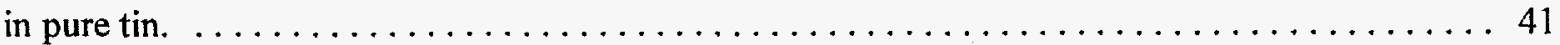

38. Waveforms recorded along the unfatigued rope. $\ldots \ldots \ldots \ldots \ldots \ldots \ldots \ldots \ldots \ldots \ldots \ldots \ldots$

39. Wave velocity comparison between the two ropes tested at INEL. $\ldots \ldots \ldots \ldots \ldots \ldots \ldots \ldots$

40. Wave velocities measured on six rope sections under high load. $\ldots \ldots \ldots \ldots \ldots \ldots \ldots \ldots$

41. Wave velocity comparison between the least and most fatigued sections at high load. ....... 45

42. Longitudinal wave signals measured along the rope with magnetic and piezoelectric transducers. . 46 


\section{Noncontacting NDE for Materials Characterization}

\section{INTRODUCTION}

Advanced materials require an entirely new range of nondestructive evaluation (NDE) capabilities to ensure their fitness for purpose. Existing NDE techniques must be extended to meet these new requirements as well as new techniques developed to measure characteristics unique to these materials. For example, rapidly solidified alloys rely on unique microstructural features for their improved properties, and critical flaw sizes in ceramics are typically much smaller than those found in metals. The quality of materials produced, by basic processes such as melting and casting of metals or advanced processes such as sintering of high-temperature ceramic composites, could be greatly improved by incorporating in situ process-control sensors. Key microstructural and thermal parameters need to be measured in real time, nondestructively, and at very high temperatures. Ultrasonics is particularly useful as it probes the interior of materials and is sensitive to most critical process-control parameters.

This report describes the results of a research project at the Idaho National Engineering Laboratory (INEL), funded by the Interior Department's Bureau of Mines, that studied ultrasonic methods for nondestructive evaluation (NDE) and process control. The goal of the project, which ran from May 1983 to September 1995, was to develop methods for monitoring microstructure with ultrasonics that would allow improvements in materials processing. The capabilities of ultrasonics for microstructure measurements in metals, ceramics and composite materials were demonstrated. Historically, a drawback to ultrasonics for process-control monitoring is that the techniques required close coupling (usually contact) of transducers to the material being investigated. A major emphasis on this project has been the development of noncontacting ultrasonic techniques, based on laser generation and detection of elastic waves, for process-control monitoring in high-temperature, harsh environments that do not require close coupling to the material being processed. A modified Fabry-Perot confocal interferometer was constructed and used to measure ultrasonic waveforms from materials with rough surfaces during a variety of processing conditions. In situ measurements were performed on the sintering of ceramics, high temperature annealing of metals, materials with curved surfaces and unusual geometries, and molten metal solidification. Applications of laser ultrasonics in microelectronics and ultrasonic methods for wire rope inspections were also investigated. 


\section{ULTRASONIC SCATTERING AS A PROBE OF MATERIAL MICROSTRUCTURE}

Many important physical properties of metal alloys depend strongly on microstructure, and particularly on grain size, shape, and distribution. The goal of ultrasonic characterization is to determine, nondestructively, as many parameters of the grain structure as possible. Scattering of ultrasonic waves from grain boundaries and anisotropies is the primary source of information for these types of measurements. Experimentally, scattering leads to attenuation and backscattered radiation that are characteristic of the grains and are readily measured. The most common method involves placing a piezoelectric transducer in contact with the material and producing an ultrasonic wave packet that propagates into the material. Reverberation of this wave packet from the end faces of the part yields a decaying envelope of echoes that depict the attenuation of the wave as it propagates, see Figure 1.

Attenuation is caused by both irreversible heat transfer and scattering. In metals, at moderate frequencies normally used in the laboratory, the major attenuation mechanism is scattering from grains and inhomogeneities in the microstructure.

A correlation of grain size with attenuation has been established in the literature and in this work (see Reference 1 and works cited therein). Attenuation was used here as a standard for material property determination and for comparison between different materials. A set of Inconel Alloy 718 samples was prepared with varying grain sizes and evidence of twinning and precipitate formation--all characteristics that affect attenuation. Figure 2 shows the measured attenuations in three samples with mean grain sizes of 22,76 , and $107 \mu \mathrm{m}$, as determined from optical metallographic inspection. A large increase in attenuation corresponding to the increase the grain size was recorded.

A potentially more useful technique for NDE is to record the radiation backscattered to the transducer as the ultrasonic wave passes through the material before encountering the part's back face. This signal is solely due to scattering off the microstructure and its detection does not require access to the back face of the sample. This is an enormous advantage for field use as often the back face is not accessible. However, the reduced signal amplitude places more stringent requirements for high sensitivity and low noise on the transducer and associated electronics. Figure 3 shows the backscatter radiation energy spectra recorded for the same set of Inconel samples used in the attenuation measurements.

To study backscatter radiation more closely, a model was developed based on scattering from a collection of small spherical particles inside a uniform host material.' ${ }^{\prime}$ This was meant to simulate grain scattering. Ultrasonic scattering from spherical inclusions or voids is known, ${ }^{2}$ which allows calculation of the total backscatter signal by summing contributions from all the particles, taking into account their locations in the incident beam. With suitable parameters, a variety of backscatter experiments can be simulated and various types of data processing routines compared. A limitation of this model is that multiple scattering, which does occur to some extent in materials, is not taken into account. The model ${ }^{3}$ was used to explain the upward shift in the backscatter signal power spectrum from that of the incident ultrasonic wave observed experimentally. ${ }^{4}$

In addition to model calculations, a set of test samples was prepared from a glassy material with secondary, less dense, inclusions precipitated from the melt. The size and number of the inclusions were controlled by the mixture of $\mathrm{SiO}_{2}, \mathrm{~B}_{2} \mathrm{O}_{3}$, and $\mathrm{CaO}$ components and the melt cooling rate. Nearly 


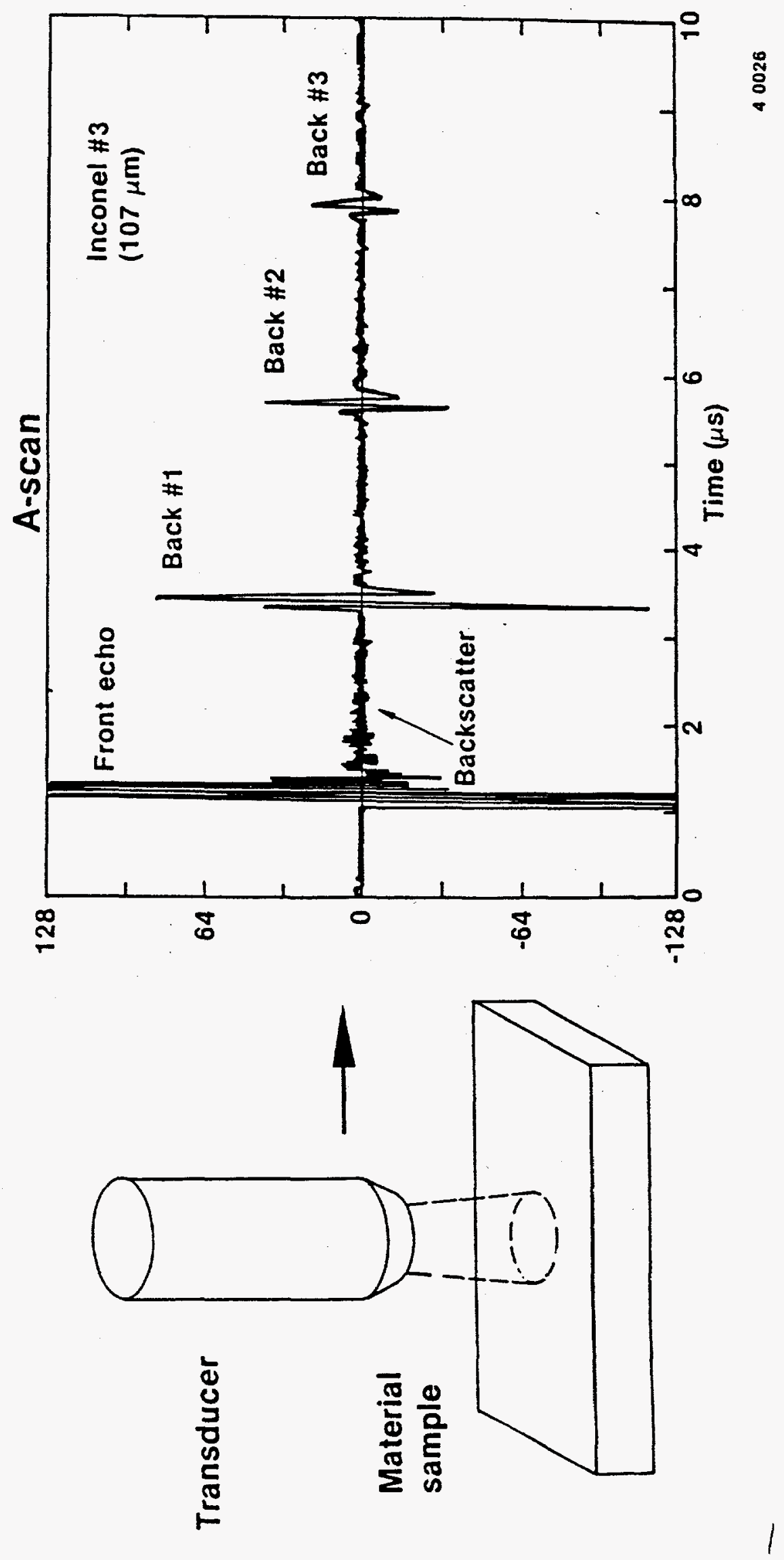

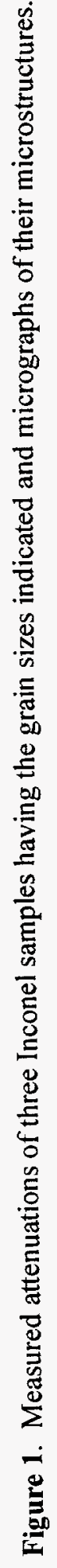



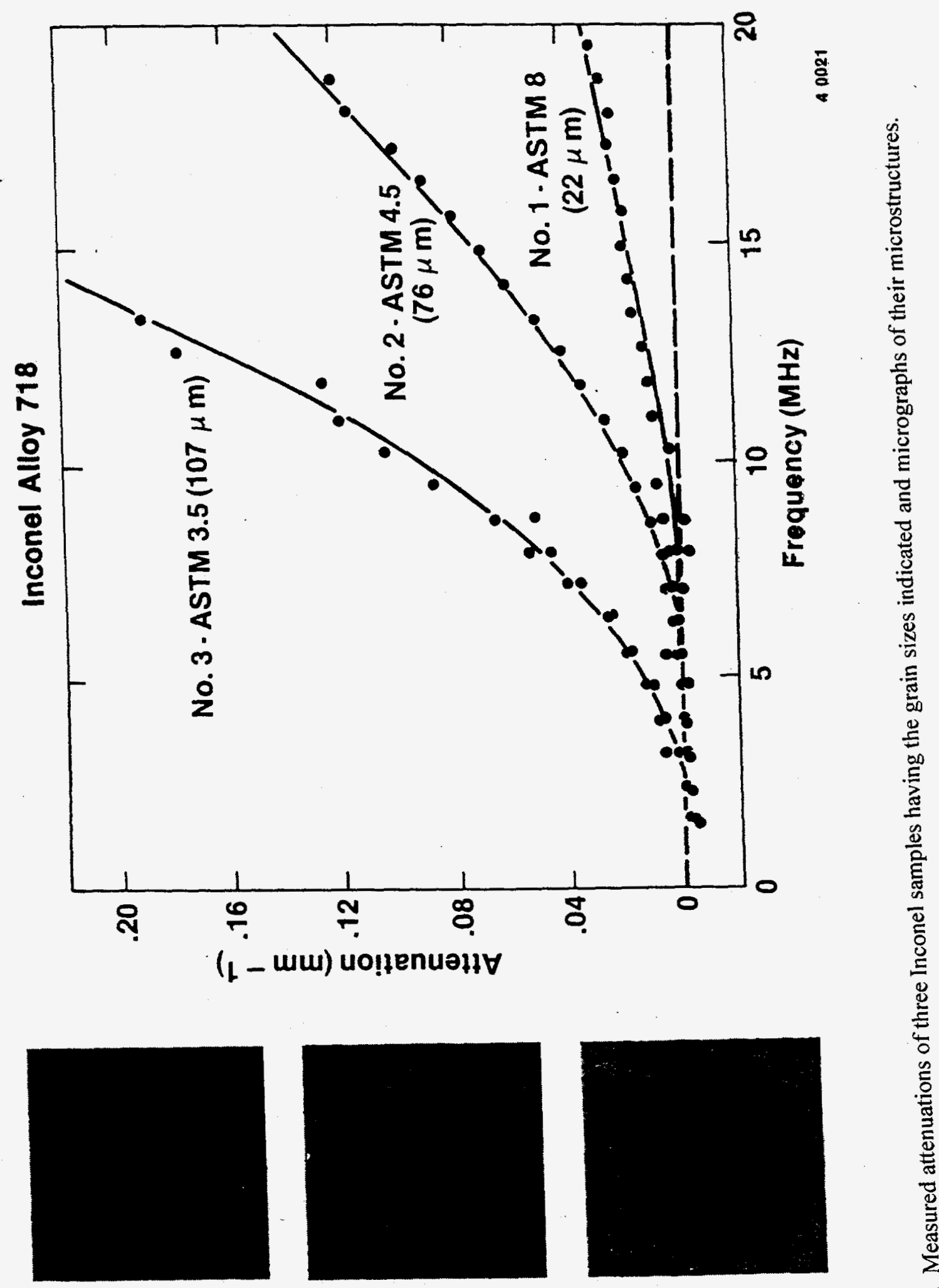

\&

j)

$\bar{i}$

倠 


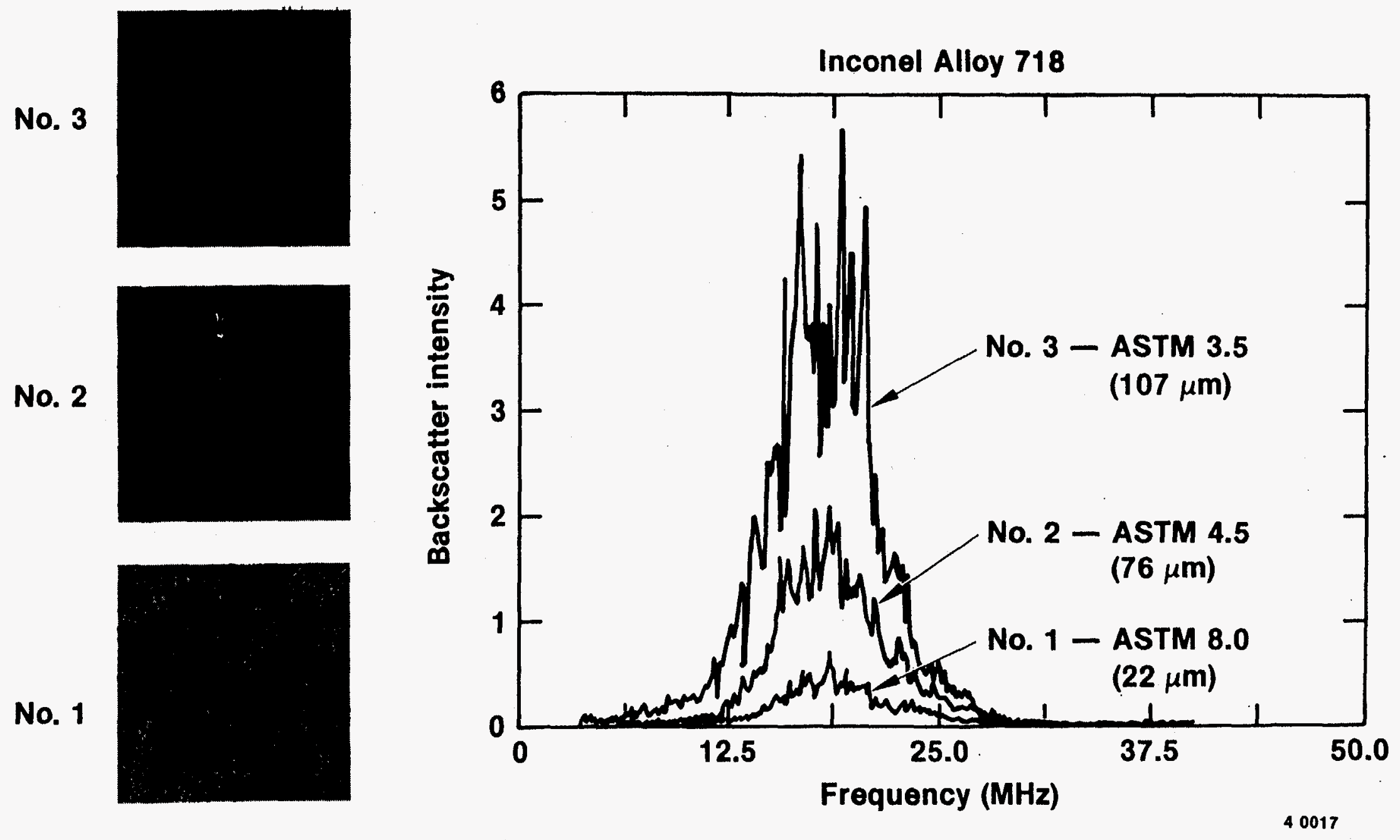

Figure 3. Measured backscatter power spectra for the three Inconel samples and micrographs of their microstructures. 
spherical inclusions resulted that allowed the individual particle scattering amplitude as well as the number density, size, and spatial distribution to be determined. The inclusions ranged from a high density $\left(10^{6} / \mathrm{mm}^{3}\right)$ with a mean size of $2.5 \mu \mathrm{m}$ and uniform distribution to a smaller density $\left(8 \times 10^{3} / \mathrm{mm}^{3}\right)$, mean size of $5.0 \mu \mathrm{m}$, and nonuniform distribution. The forward propagation of ultrasonic waves through these dense scattering samples could be described by multiple scattering theory. ${ }^{5}$ Although the attenuation due to scattering was too small to be measured, a decrease in propagation velocity approximately proportional to the inclusion volume fraction was observed in accordance with the theoretical expectations. In the reverse direction to the incident wave, the measured backscattered radiation was consistent with the "coherent scattering" regime predicted from the model calculation, with the backscattered energy scaling approximately with the mean interparticle distance. These measurements on glass samples with known inclusion size and distribution were an important step toward obtaining quantitative information about the microstructure directly from ultrasonic measurements.

Ultrasonic scattering was used to study the consolidation of rapidly solidified powders (RSP) of Type 304 stainless steel. Both extruded and explosively consolidated RSP 304 samples were obtained from the Metals Branch at INEL. The extruded sample exhibited very small attenuation and essentially no measurable backscatter due to the small grain size $(10 \mu \mathrm{m})$. The lack of scattering from voids indicated that nearly complete consolidation was achieved in this sample. In contrast, the explosively consolidated samples showed considerable attenuation and backscatter, which was subsequently found to be due to unconsolidated powder boundaries, resulting in tiny voids. Heat treating these samples for periods of one hour at temperatures from 200 to $1200^{\circ} \mathrm{C}$ produced a significant evolution of the microstructure which was well characterized by changes in the attenuation and backscatter. In particular, a large increase in attenuation and backscatter was observed at $600^{\circ} \mathrm{C}$ where recrystallization regions became evident in the microstructure. ${ }^{6,7,9}$ These results show that ultrasonic measurements provide significant information about material microstructures and form a valuable NDE tool for material evaluation.

Since ultrasonic backscatter measurements require access to only the front face of a sample, scanning the transducer over the surface can provide an image of the microstructure through a mapping of the backscatter energy or attenuation. This NDE approach is very useful in large structure analysis for inhomogeneities or other spatial variations in microstructure. Several measurements of this type were performed using immersion transducers, scanning hardware, and data acquisition and analysis software. Nonuniform distributions of porosity, ceramic composite fiber/matrix bonding, and ceramic joint interfaces were studied by the backscatter scanning method with the results successfully correlating with the known or measured microstructure properties. ${ }^{10,11,12,13,14}$

Joining ceramic materials is a critical aspect of producing composite parts with prescribed mechanical properties. A nondestructive means of characterizing joint properties is needed to identify acceptable joints and extend service lifetimes. The goal of this task was to evaluate, through nondestructive ultrasonic measurements, the integrity of a ceramic joint prepared by brazing with a glass joining compound. A variety of joints prepared under different conditions were compared. ${ }^{14}$ The ultrasonic images of the joint plane showed regions of large scattering signals. These signals corresponded to several properties of the joint such as thickness, constitution of the joining material, and the presence of voids, cracks, or crystallized glass in the joint plane. Joints were produced whose thickness could be accurately determined, and good correlation was found between joint reflection signal energy and joint thickness. These joints provided a means to calibrate the reflection signals. 
Figure 4 shows the measured joint reflection signal energy as a function of joint thickness for regions in several joints where reliable thickness estimates could be obtained. Most of the joints exhibited significant thickness variations across the joint plane, which would account for the scatter observed. The energy reflected from the interface was calculated based on the reflection coefficients from the joint and the impedance mismatch between the host ceramic and joint using a continuum model. For joint thicknesses greater than the ultrasonic wavelength, the signal energy provides a clear measure of the impedance of the joint. For thinner joints, signal energy depends greatly on both the thickness and the impedance. The signal energy scalcs approximately quadratically with joint thickness over the range of thicknesses to $50 \mu \mathrm{m}$ or greater. This behavior shows that for these relatively thick joints, thickness is the primary characteristic measured by the ultrasonic reflection signal, assuming a glass joining compound of uniform thickness. The actual measurement is capable of resolving significantly smaller reflected signals (about two orders of magnitude) than shown. Almost all of the stronger joints exhibited reflections in this range that cannot be accounted for by thickness dependence alone. These reflections are possibly due to microcracking near the joint plane or spreading of the joint region from diffusion of the joining glass into the host ceramic. Ultrasonic imaging has been very successful in locating voids and other defects in the joint plane which yield large reflection signals. These results have been useful for determining which areas of a joint are worthy of fracture testing as opposed to those where the glass joining compound had not filled the joint gap or some other serious defect was present.

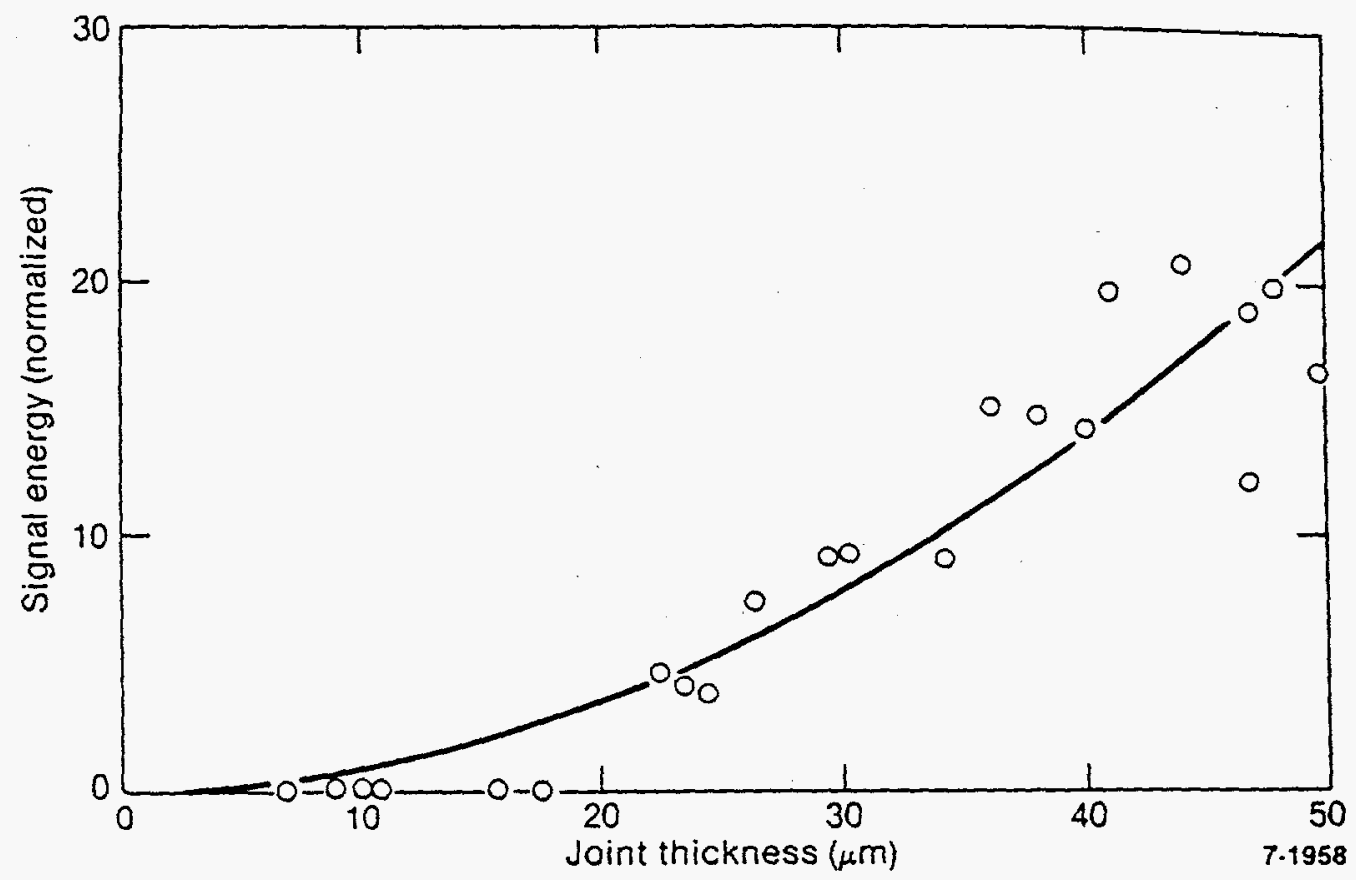

Figure 4. Ultrasonic transducer above a material sample showing the inspection methnd. The A-scan shows the signals received from echoes reverberating within the material part. 


\section{INTERNAL FRICTION MEASUREMENTS}

Internal friction measurements were performed by Professors T. Alan Place and R. F. Gibson at the University of Idaho to determine the extent to which this measurement technique produces data that correlate with mechanical properties. The purpose of this task was to assist in the evaluation of rapidly solidified alloys as replacements for strategic materials. The impulse vibration technique was used for characterizing the material's internal friction through damping for both flexural and torsional motions. Figure 5 shows the test rigs used. ${ }^{6,15}$ The flexural vibration specimens were designed to give the loss factor at the thermoelastic peak with frequency for various stages of thermal degradation. The relatively high shear strains in the torsional vibrations made that method more sensitive to degradation than the flexural mode. The apparatus also had added mass assemblies for decreasing the resonant frequency to the experimentally accessible range.

The extent of thermal degradation on rapidly solidified Devitrium $7025^{\mathrm{a}}$ was determined by torsional damping measurements. The original ribbon material was comminuted to a powder and extruded into a rod. The specimens blanks were cut by electrical discharge machining with a wire cutter and then heat treated for 0,24 , and $240 \mathrm{~h}$ at $1100^{\circ} \mathrm{C}$. The microstructure consisted of many small Ni-Mo2-B2 particles. The matrix was amorphous-no grain boundaries were observed using either optical or scanning electron microscopy. Quantitative metallography showed that particle volume fraction, particle size, and mean free path between particles increased as the heat treatment time increased. The strength of the alloy decreased as these particle characteristics increased. It has been shown that the ordered structure present in as-consolidated alloys of this type becomes disordered after treatment at $900^{\circ} \mathrm{C}$ and that the material softens somewhat. Disordering occurred at the high temperature used for this work, which accounts for the softening that occurred with increasing time at $1100^{\circ} \mathrm{C}$.

Figure 6 shows that the measured loss factor (torsional damping capacity) increases significantly as a function of the particle size, which increased with heat treatment time. The loss factors measured were very small, approaching the resolution of the equipment. Since the loss factor increases with the heat treatment time, a correlation was found between loss factor and strength, ductility, and hardness. Softer and more pliant materials generally show higher loss factors, so this trend in the results was expected. Many microstructural features contribute to damping, including interfacial effects, dislocations, impurities, and thermal currents between phases or grains. The individual contributions of these effects cannot be separated with the information available from the present work, but the overall effect on damping is consistent enough to indicate a correlation may be made between mechanical properties and loss factor. The thermal stability of this alloy is remarkable. After $240 \mathrm{~h}$ at $1100^{\circ} \mathrm{C}$, the hardness value only declined by some 11 points (Rockwell C) despite the particle coarsening that took place. This, coupled with previous work on wear resistance and hot hardness, indicates that this alloy system could be the source of excellent substitutes for chromium-bearing steels presently used for heat and wear resistance.

a. Ni53-Mo35-Fe9-B2, produced by Allied Corporation. 


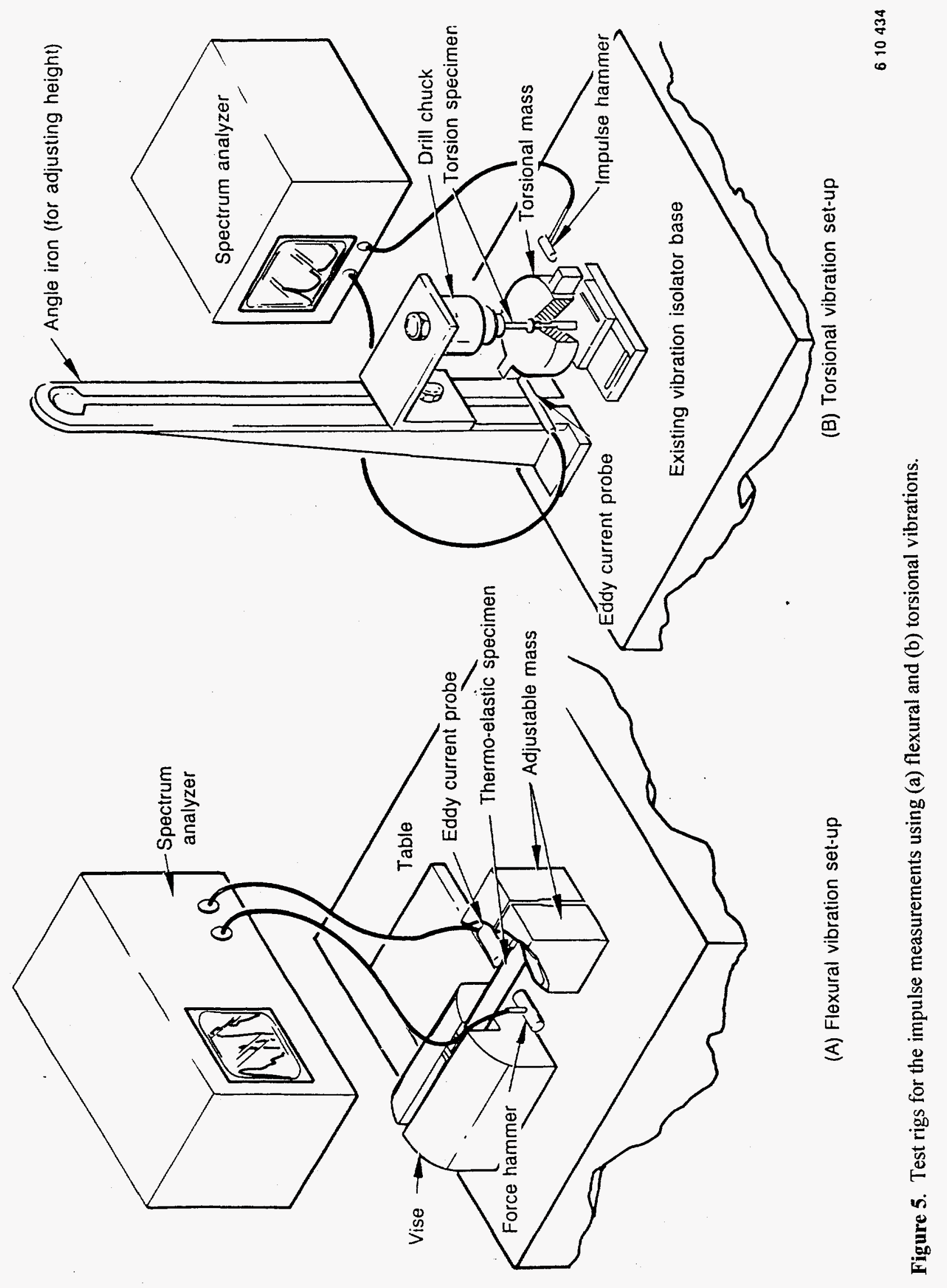




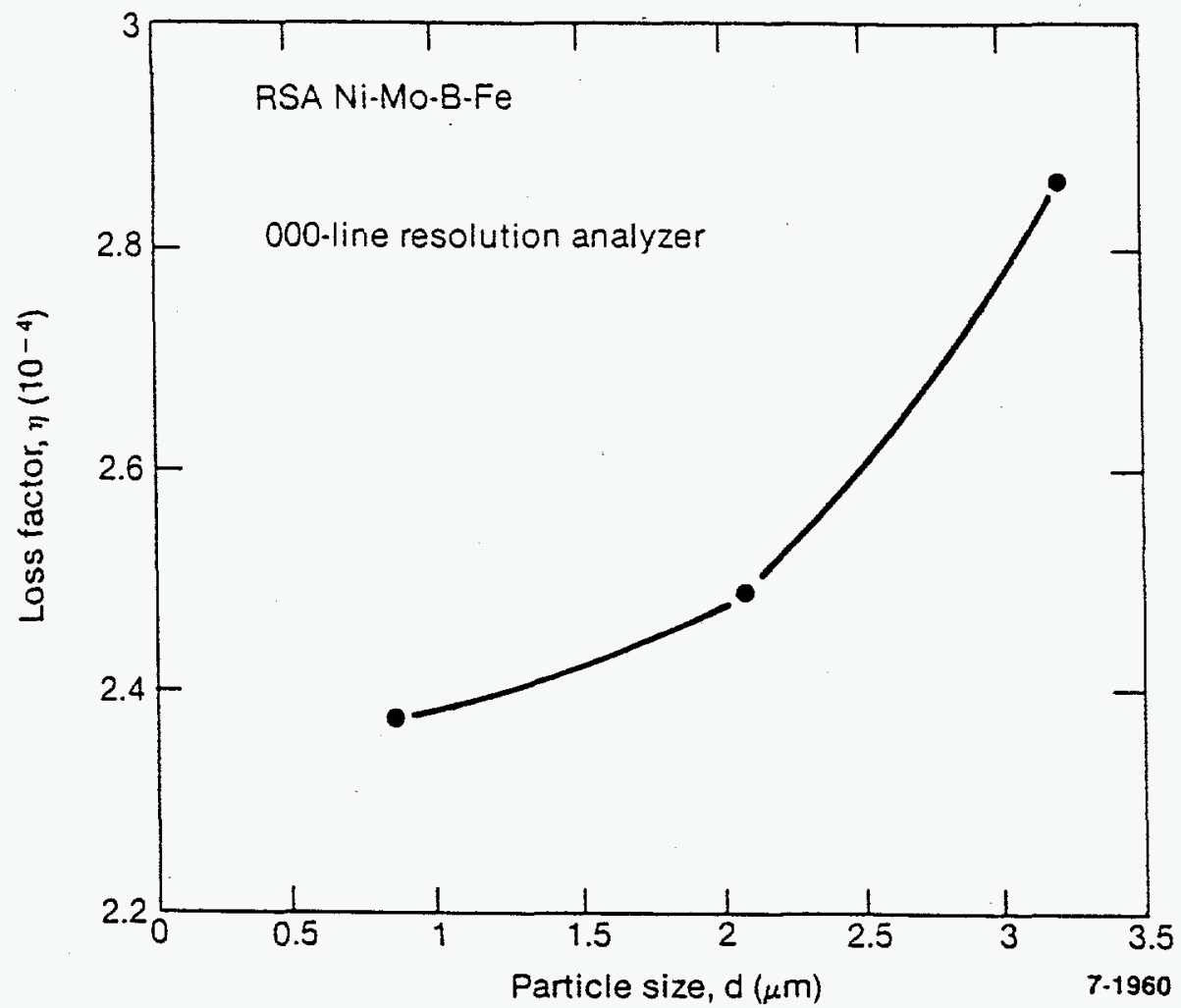

Figure 6. Measured torsional oscillation loss factor versus the microstructural particle size fraction. 


\section{LASER GENERATION AND DETECTION OF ULTRASOUND}

Several advances have been made in use of lasers for both generation and detection of ultrasonic waves in a totally noncontacting manner for material microstructure evaluation. One of the goals was to develop the pulsed laser as a noncontacting method of determining a material's microstructure by mapping its ultrasonic characteristics as a function of position.

\section{Optical Ultrasound Detection}

During FY 1988 it was determined that optical techniques could be implemented in a manner suitable for application to materials with rough surfaces, as are found in industrial materials processing and NDE. There are several criteria that an optical detector must satisfy to be applicable to material microstructure determination and in situ measurements in, for example, a processing furnace. These criteria are high sensitivity, wide bandwidth, ease of alignment, and ability to obtain signals from rough sample surfaces. The design chosen ${ }^{16,17}$ allowed for optimization in all these areas. The detector works on the principle that light reflected from a moving surface is Doppler shifted in frequency in direct proportion to the velocity of the surface. The instrument optically demodulates the laser light reflected from the sample surface by passing it through a confocal Fabry-Perot interferometer. Additional feedback signals were generated to lock the interferometer to the unmodulated laser light frequency. The instrument is a surface velocity detector and has a bandwidth of about $20 \mathrm{MHz}$ in transmission and more than $100 \mathrm{MHz}$ in reflection. Since it demodulates the light intensity and is insensitive to phase, alignment is relatively simple compared to phase-sensitive optical detection schemes. The intensity sensitivity of this device makes it ideal for materials with rough surfaces, as would be encountered in most processing applications. Figure 7 is a schematic of the optical detecting ultrasonic equipment used at INEL. The sample is shown inside of the tube furnace in the geometry to be used for in situ sintering measurements. The argon laser was found to be somewhat unstable and prone to drift; however, electronic stabilization corrected for this behavior.

\section{Laser Ultrasound Generation}

A high energy pulsed Nd:YAG laser was used to excite ultrasonic waves by locally heating or ablating material at the surface. Figure 8 shows the all-optical measurement geometry for investigating materials at high temperature. The effect of the incident laser pulse penetrating to a significant depth in the sample, such as can be encountered with semi-transparent ceramic or glassy materials, on the ultrasonic displacements was investigated. Experimental measurements and analytical calculations showed that under suitable thermoelastic conditions a sharp precursor is generated in the material. This wave has considerable high frequency content $(20-40 \mathrm{MHz})$ and is very useful for probing the microstructure through ultrasonic scattering. A sharp precursor pulse is always obtained for an ablating source. 'The origin of this precursor wave was studied with thermoelastic models that include optical penetration and thermal diffusion into the material. The results showed that any subsurface elastic expansion source will produce a precursor displacement pulse due to the linear superposition of waves traveling directly to the detector and those reflecting from the free surface. ${ }^{18,19}$ Detailed analysis was carried out for the generation of Lamb elastic waves in plates of material with a large optical penetration depth, as found in ceramics. ${ }^{20}$ 


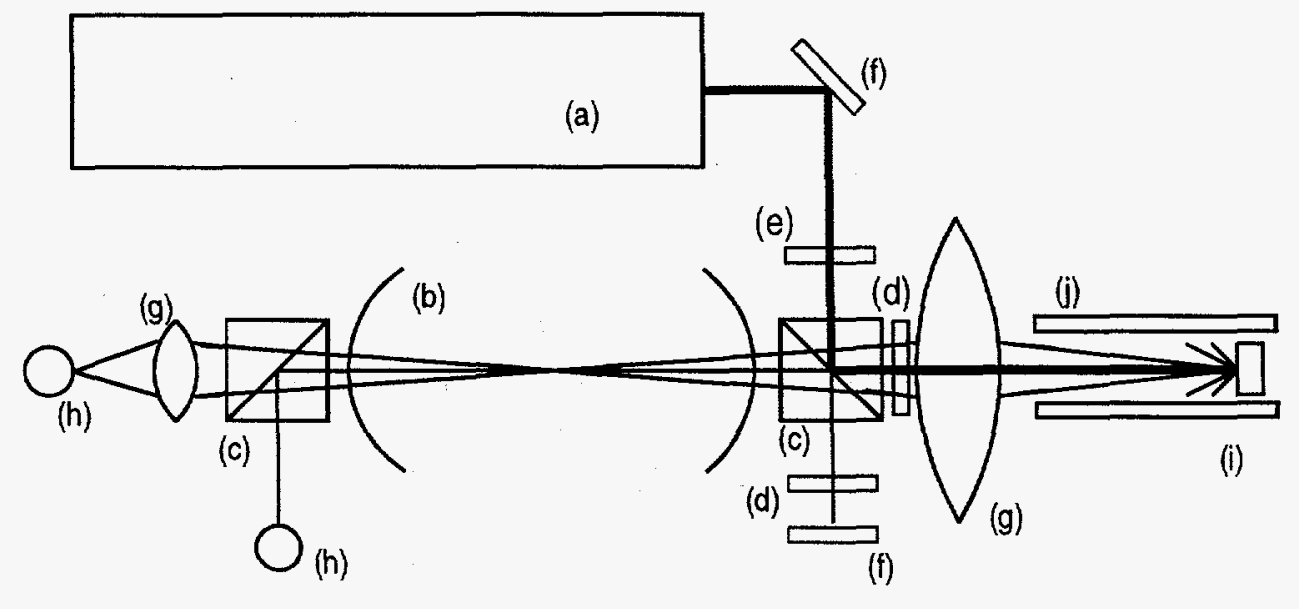

Figure 7. Schematic of the confocal Fabry-Perot interferometer used for detection of the sample surface velocity due to the ultrasonic wave. (a) argon laser, (b) Fabry-Perot interferometer, (c) polarized beam splitter cubes, (d) 1/4 wave plates, (e) $1 / 2$ wave plate, (f) mirrors, (g) lenses for collecting the scattered light, (h) photodiodes, (i) sample, and (j) the central tube of the furnace.

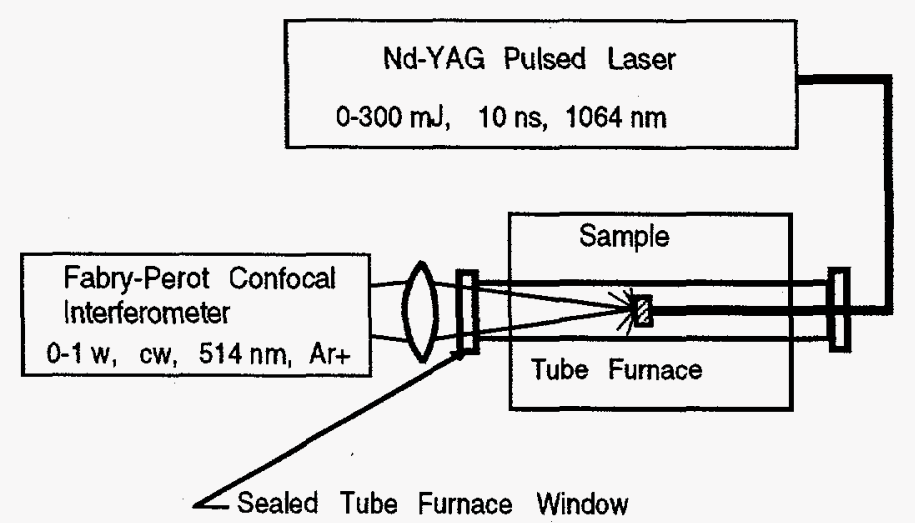

Figure 8. Schematic of the optical ultrasonic setup for high temperature measurements. 
Figure 9 shows the measured waveform at the bottom surface of an alumina sample in which the optical penetration is significant. The top trace is the displacement measured by the capacitive detector and the bottom trace is the surface velocity recorded by the optical detector for the same pulse. Thus the bottom trace is essentially the time derivative of the top trace, as it should be for a velocity detector. It is apparent that a positive spike is produced as a result of the heating with depth caused by the finite optical penetration into the material. Also, the precursor pulse shape reflects the source temperature distribution in the material. As the optical penetration depths of materials decrease to zero, the amplitude of the precursor signal decreases to zero also. Therefore, no observable precursor is predicted for materials, such as stainless steel, where the penetration depth is only nanometers.

One of the first measurements taken with the laser source was attenuation in the Inconel test samples. ${ }^{21}$ Figure 10 shows the measured attenuation found with the laser source plotted with that previously measured with the piezoelectric source. These results show that higher attenuations could be measured with the laser due to its wider bandwidth.

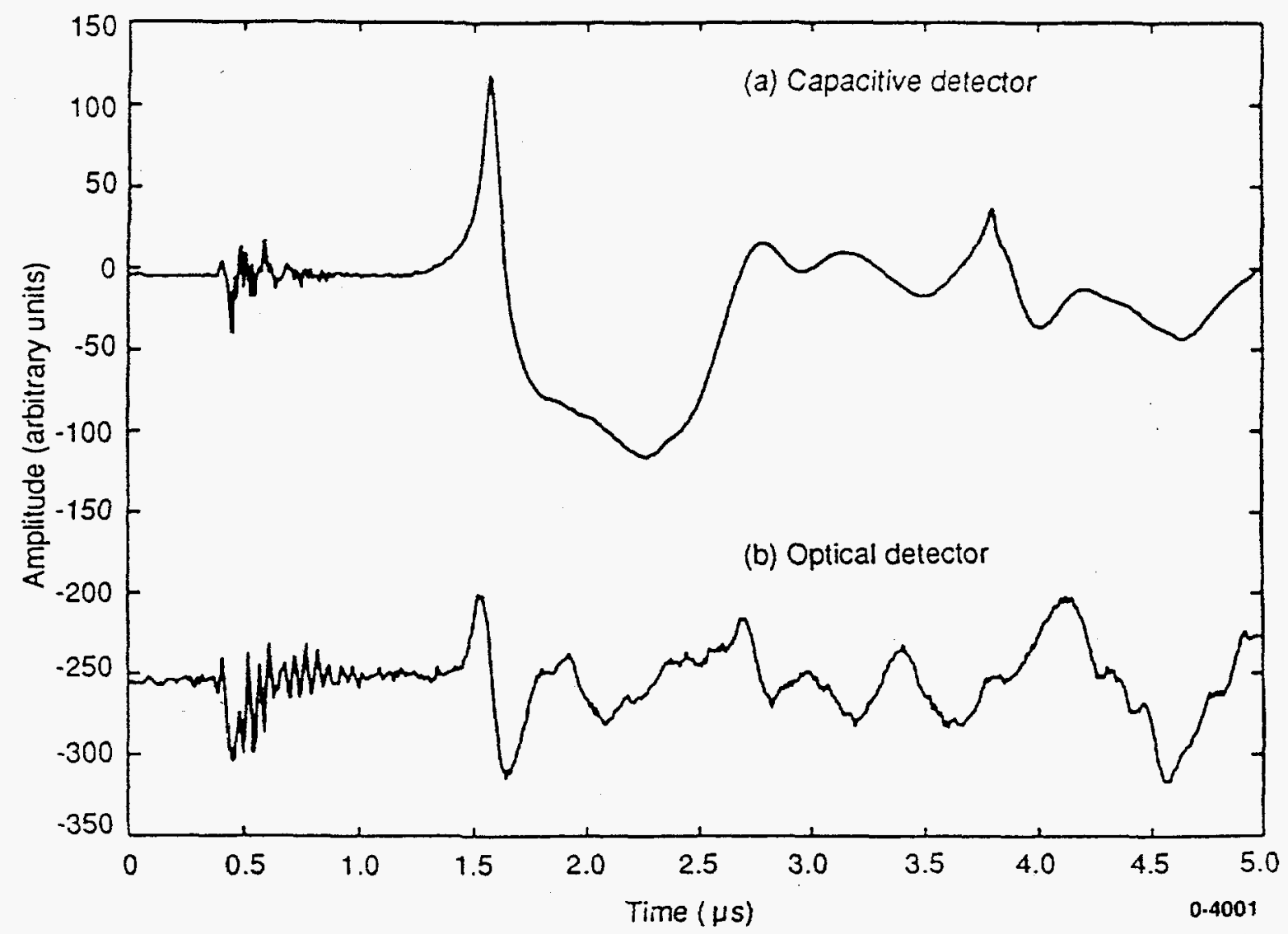

Figure 9. Ultrasonic waveforms recorded with the capacitive detector (top trace) and the optical detector (bottom trace) for the pulsed laser source on a $12.5 \mathrm{~mm}$ thick sample of alumina. The large initial displacement peak seen in the top trace is the "precursor" waveform resulting from significant optical penetration into the material. The optically detected signal is essentially the time derivative of the displacement waveform, which is consistent with the optical detector being a surface velocity detector. 


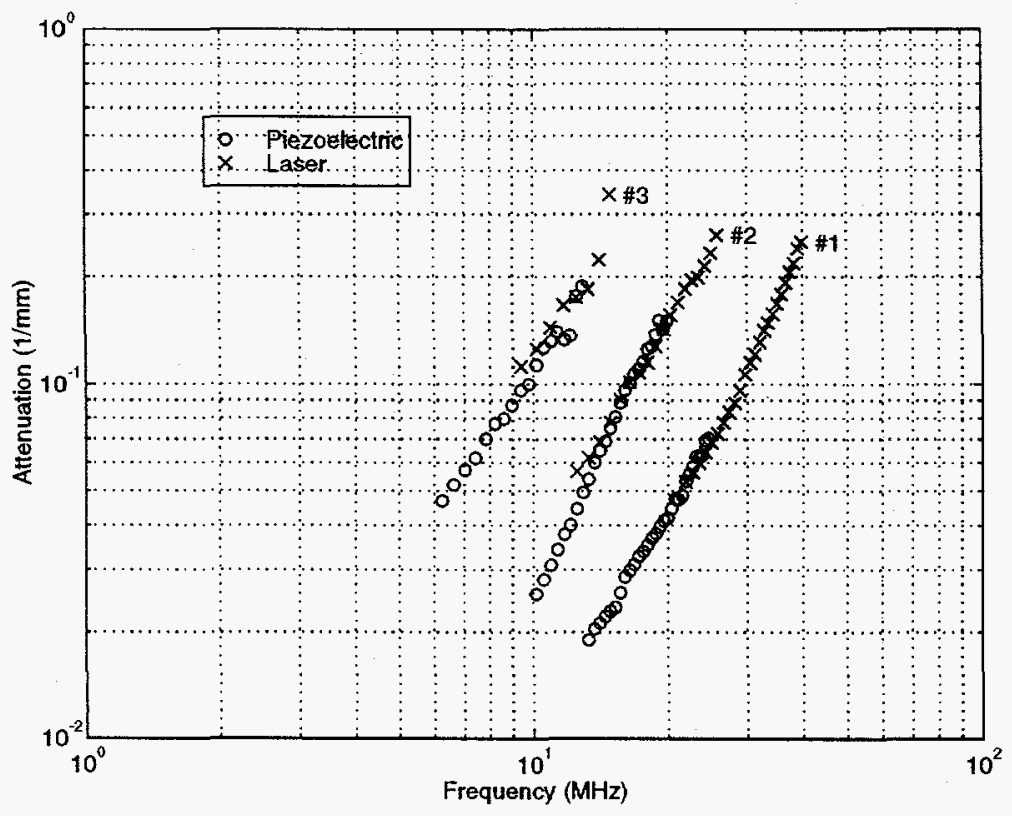

Figure 10. Attenuation in three samples of Inconel with different grain sizes as measured with the piezoelectric and laser techniques. 


\section{LASER ULTRASONIC MONITORING OF SINTERING}

\section{Ceramics}

Ceramic components are normally consolidated from powder compacts by sintering at high temperatures. Often the properties of these components are determined by their residual porosity. Improvements in efficiency of production and in the consistency of properties of ceramics could be achieved if the porosity could be monitored, and controlled, during the sintering stage. A noncontacting technique to monitor sintering by using laser generation and detection in situ during the consolidation was demonstrated.

In a material with porosity, the effective compliance is increased due to the presence of voids, which means that the elastic modulus and the velocity of ultrasonic wave propagation decrease with increasing porosity. The velocity of longitudinal waves in a solid material is given by $V=[M / \rho]^{1 / 2}$, where $M$ is the effective elastic modulus and $\rho$ is the sample density. In a porous ceramic, the elastic constants are complicated functions of the host material's Young's modulus and Poisson's ratio, and the number, size, and shape of the voids. ${ }^{22}$ However, for some materials, particularly sintered ceramics and metals, a monotonic increase of longitudinal wave velocity with porosity is found. ${ }^{23,24}$ Ultrasonic methods, therefore, have potential for determining porosity in ceramics in a nondestructive manner. However, a noncontacting measurement technique is required for monitoring the evolution of material microstructure during processing. Several researchers have applied laser ultrasonics to measuring microstructural properties of metals. ${ }^{25,26,27,28,29,30,31,32,33,34,35,36}$ The work reported here describes the successful application of laser ultrasonic techniques to the monitoring of sintering of zinc oxide at temperatures from 850 to $950^{\circ} \mathrm{C}$. Prior to this work, ultrasonic wave measurements of the sintering of ceramics used buffer rods that made direct contact with the material. ${ }^{37,38,39}$ Only optical access to the sample being sintered is required with the laser ultrasonic technique. ${ }^{40,41,42}$ Zinc oxide was chosen as the ceramic material to be studied as it sinters at varying rates at temperatures in the range of 700 to $1100^{\circ} \mathrm{C}$. Also, it does not require a sintering additive to reach full theoretical density. Laser ultrasonic measurements are presented for samples of zinc oxide with rough and/or optically diffusely reflecting surfaces, including in situ measurements taken within a tube furnace.

A pulsed Nd-YAG laser with a $10 \mathrm{~ns}$ pulse width and pulse energies up to $300 \mathrm{~mJ}$ was used as the ultrasound source and an argon laser coupled to the Fabry-Perot interferometer as the detector. The generation mechanism for ultrasound in ceramics generally includes both thermoelastic generation and ablation. Most ceramics have a significant optical penetration depth, which alters the thermoelastic generation mechanism. This was used to advantage. Thermoelastic generation at the surface produces an elastic wave radiation pattern with large directionality away from the surface normal, whereas ablation produces its largest wave motion in the direction of the surface normal. Therefore, for through transmission or for pulse echo measurements the ablation mechanism is preferred. Ablation is easily produced in ceramics due to their small thermal diffusivity compared to metals. However, material surface damage results from ablation, which may be undesirable. In ceramics that exhibit a sizable optical penetration depth, however, the thermoelastic mechanism itself produces a significant component of the ultrasonic wave in the direction of the surface normal because the thermoelastic expansion extends into the material.

The material used was commercial zinc oxide (Fisher Z52-500) with a very small particle size, around a micron, and some agglomeration. The green state samples were pressed to approximately $47 \% \mathrm{of}$ 
theoretical density in disks $25 \mathrm{~mm}$ in diameter and 8 to $10 \mathrm{~mm}$ thick. They were particularly soft with roughly the consistency of chalk. The green state samples were ablated significantly by the source laser at the energy levels required for adequate detection signal to noise ratio. Therefore, the ultrasonic response of the green state samples was recorded with a minimum of signal averaging, usually 10 pulses. Surface ablation was significantly reduced after the sample reached greater than $50 \%$ theoretical density. The zinc oxide samples exhibited nearly complete diffuse reflection from their surfaces, even after sintering. The optical collection of scattered light from the sample, the determining factor for the signal to noise ratio, was limited by the opening of the furnace tube.

Figure 11 shows typical waveforms recorded while a sample was being heated to $850^{\circ} \mathrm{C}$ during the sintering process. (The temperature of the sample as a function of time was not measured.) The signals represent longitudinal waves measured in a through transmission mode. Trace (a) was taken at room temperature before the sample was inserted into the furnace. Several minutes were used to insert the sample into the tube furnace; trace (b) was recorded upon completion of the insertion. At a furnace temperature of $850^{\circ} \mathrm{C}$, the sample sinters to nearly theoretical density in about $2 \mathrm{~h}$. Waveforms $\mathrm{C}$ and $\mathrm{D}$ show a rapid decrease in the ultrasonic time-of-flight after insertion. This is due to the bonding between powder particles, the changing sample thickness, and the increasing densification taking place. Sintering is a complicated dynamic process, and the results show that the laser ultrasonic technique can monitor the overall process as a function of time, but it does not distinguish between shrinkage, densification, and possible temperature dependencies in the material properties, such as elastic constants. However, for materials whose elastic constants are not highly dependent on temperature, the density can be directly determined from the ultrasonic data given suitable knowledge about the shrinkage of the sample as it sinters.

The procedure for sintering measurements was to insert a sample into the furnace and preheat it at $700^{\circ} \mathrm{C}$ for about $1 \mathrm{~h}$. This step was necessary because it was found that initially a large change in elastic constant occurred with very little change in average density, believed due to the powder particles beginning to join together. Measurements were of the time-of-flight of longitudinal ultrasonic waves propagating through the sample, as it sinters. To determine the sample average density from these measurements, it is necessary to know the sample thickness and the dependence of the ultrasonic velocity on density and temperature. In addition, there are most likely density and temperature gradients in the material as it sinters, since it is heated from the outside. There is no way to determine these gradients with the through transmission measurements reported here, so only average sample densities are considered below.

There is a connection between the sample thickness and its density, since many ceramics shrink uniformly during sintering if compacted uniformly. This assumption was checked for the zinc oxide samples by measuring initial and final masses and volumes. Uniform shrinkage assumes that the sample diameter shrinks in the same proportion as its thickness, which was confirmed. In addition, no mass loss occurred within a precision of $4 \%$. Densities are reported here in percent of the theoretical density for zinc oxide, $5.6 \mathrm{~g} / \mathrm{cm}^{3}$. The temperature dependence of the ultrasonic velocity in the zinc oxide compacts during sintering is unknown. Measurements have been performed on the temperature dependence of fully sintered samples; longitudinal wave velocity is essentially temperature independent (to within $5 \%$ ) 


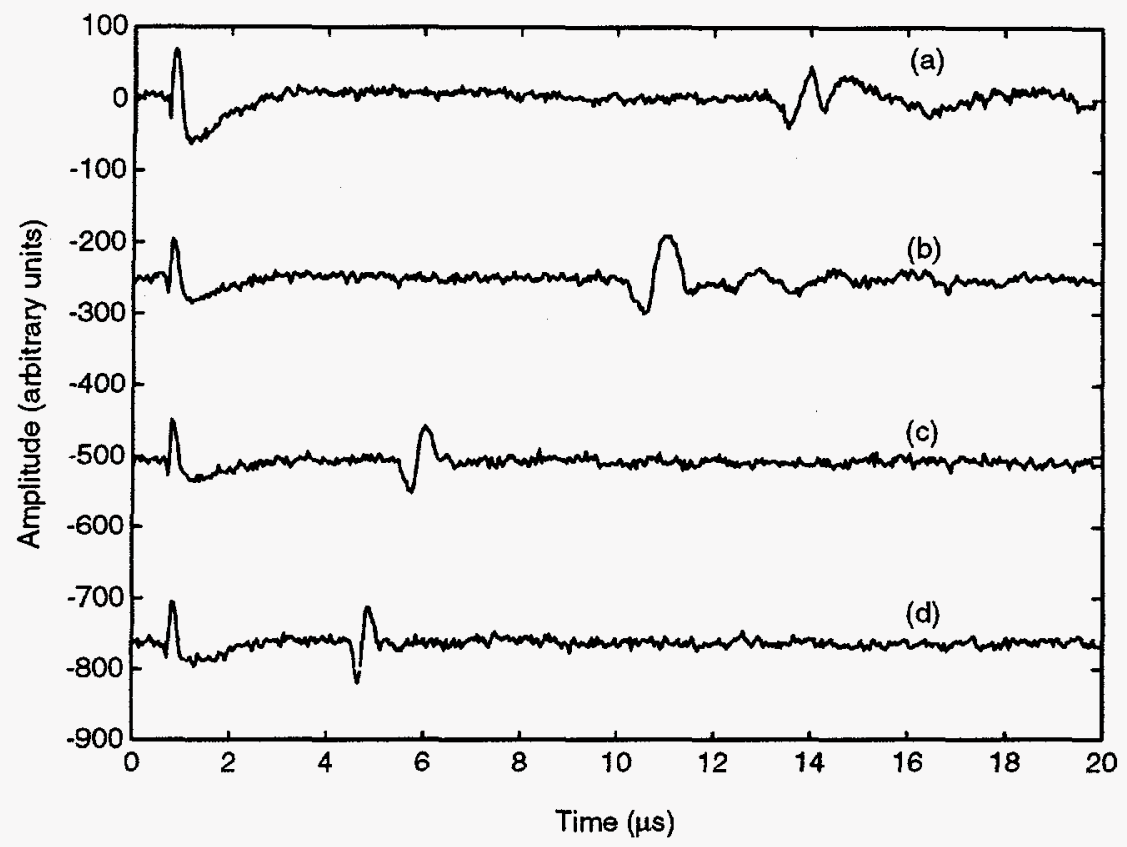

Figure 11. Real-time laser ultrasonic measurements in the through transmission mode taken while heating zinc oxide in a tube furnace at $850^{\circ} \mathrm{C}$. The firing of the pulsed laser is marked by the optical feed-through pulse near the origin for each A-scan.

over the range of temperatures used in these experiments. Therefore no correction for temperature dependence has been considered for the data presented here.

During sintering, the ultrasonic time-of-flight decreases significantly as the material's density increases and its thickness decreases. To complete the density determination algorithm, the dependence of the ultrasonic wave velocity on density must be known for the material. Several samples of zinc oxide were prepared in the "green" state and then sintered at various temperatures and times to produce a set of partially sintered samples with relative densities of from $52 \%$ to $97 \%$. Longitudinal ultrasonic wave velocities were recorded for this sample set to provide basic information on the effects of sample density. Measurements were taken with a $5 \mathrm{MHz}$ contact piezoelectric transducer, using a vacuum-coupled polymer film with gel couplant and pulse echo overlap, and the laser ultrasonic method. In the green state, the measured velocities were low, around $0.7 \mathrm{~mm} / \mu \mathrm{s}$, and not very dependent on the sample density. However, the velocity rises abruptly after a small amount of sintering, up to $52 \%$ density, probably due to bonding between the powder particles in the initial sintering. This results in a large change in elastic constant for the sample but in very little densification. Further sintering produces an approximately linear change in velocity, with relative density values approaching that of the bulk material as full densification is achieved, see Figure 12.

The assumption of conservation of mass yields the following relation between density and thickness before, during, and after sintering: $\rho_{i} L_{i}^{3}=\rho L^{3}=\rho_{f} L_{f}^{3}$ where $(i, f)$ refer to (before, after) sintering. This, 


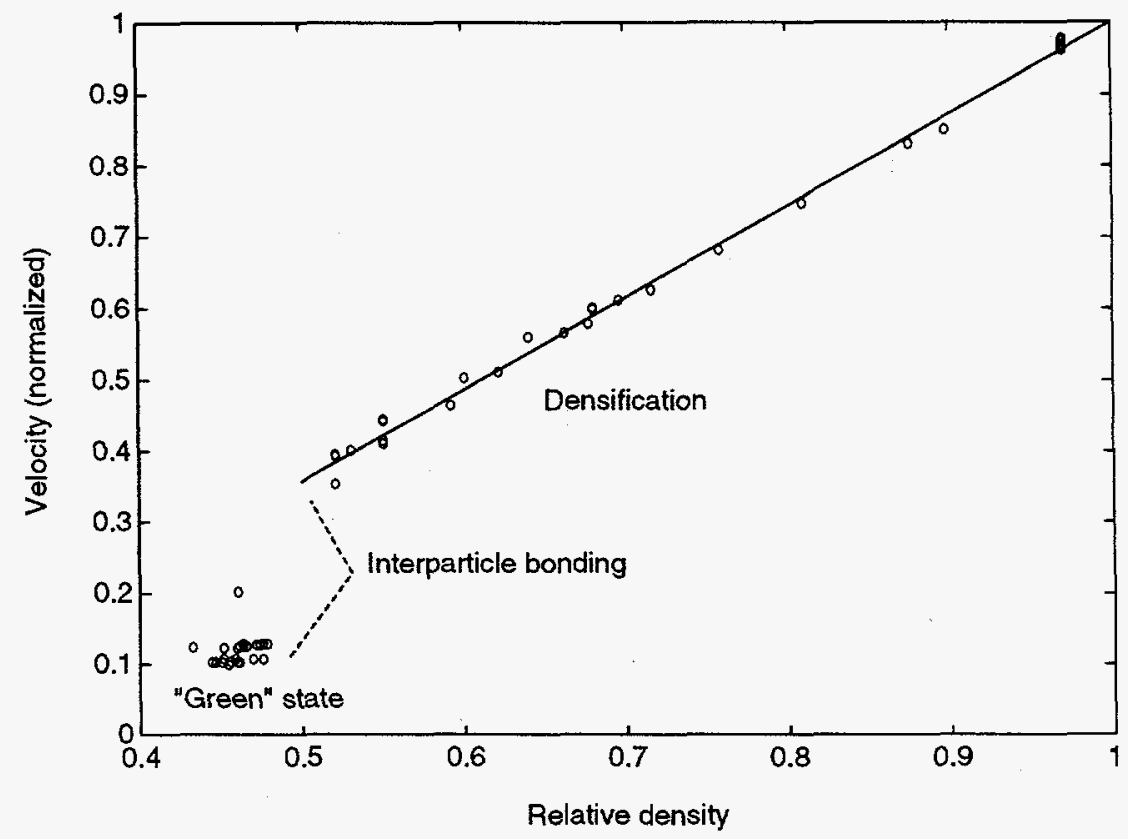

Figure 12. Longitudinal wave velocities of the presintered zinc oxide sample set measured both with the contact piezoelectric and noncontacting laser techniques.

coupled with the longitudinal velocity dependence on porosity, $\mathrm{C}(\rho)$, yields a relation between density and ultrasonic wave time-of-flight, $T$, of the following form: $\rho^{1 / 3} \mathrm{C}(\rho) \mathrm{T}=\rho_{\mathrm{m}}{ }^{1 / 3} \mathrm{C}_{\mathrm{m}} \mathrm{T}_{\mathrm{m}}$. Here " $\mathrm{m}^{\prime \prime}$ can refer to either before or after sintering values; $\rho$ is the average density. This equation can be inverted to obtain the density as a function of time-of-flight through a given sample. The size of different samples is taken into account by normalization, done either before or after the sample is sintered. The range of applicability for this algorithm is determined by the range over which the velocity as a function of density is reliably known. For the zinc oxide samples described here, only data recorded for samples with density greater than $50 \%$ theoretical density was used.

Figure 13 shows typical results obtained for zinc oxide samples \#43 and \#49, which had initial densities around $47 \%$ and were presintered by heat treating at $700^{\circ} \mathrm{C}$ for about $1 \mathrm{~h}$. At the time indicated in the graph, the temperature was raised quickly to a final temperature of 900 or $975^{\circ} \mathrm{C}$, respectively, and the longitudinal wave time-of-flight recorded as a function of time. Both the relative density and shrinkage can be calculated as a function of time using the above algorithm. Several samples with roughly the same starting density and size were monitored and sintered in this way to a variety of final temperatures ranging from 850 to $1050^{\circ} \mathrm{C}$. Similar results were obtained in all cases, except that the speed at which the sample sintered and the final density reached were monotonic functions of the final sample temperature. The slope of the densification and shrinkage curves becomes small after times of about 1.5 to $2.0 \mathrm{~h}$ for all the samples tested. The density of a sample after sintering was predictable from this procedure to a precision of about 2 to $3 \%$ theoretical density, which is about the precision to which the various parameters used in the algorithm are known. The fact that the final sample density seems to level off after some time, or at least increases very slowly, indicates that the furnace temperature is the most important parameter in determining the final density for zinc oxide. 


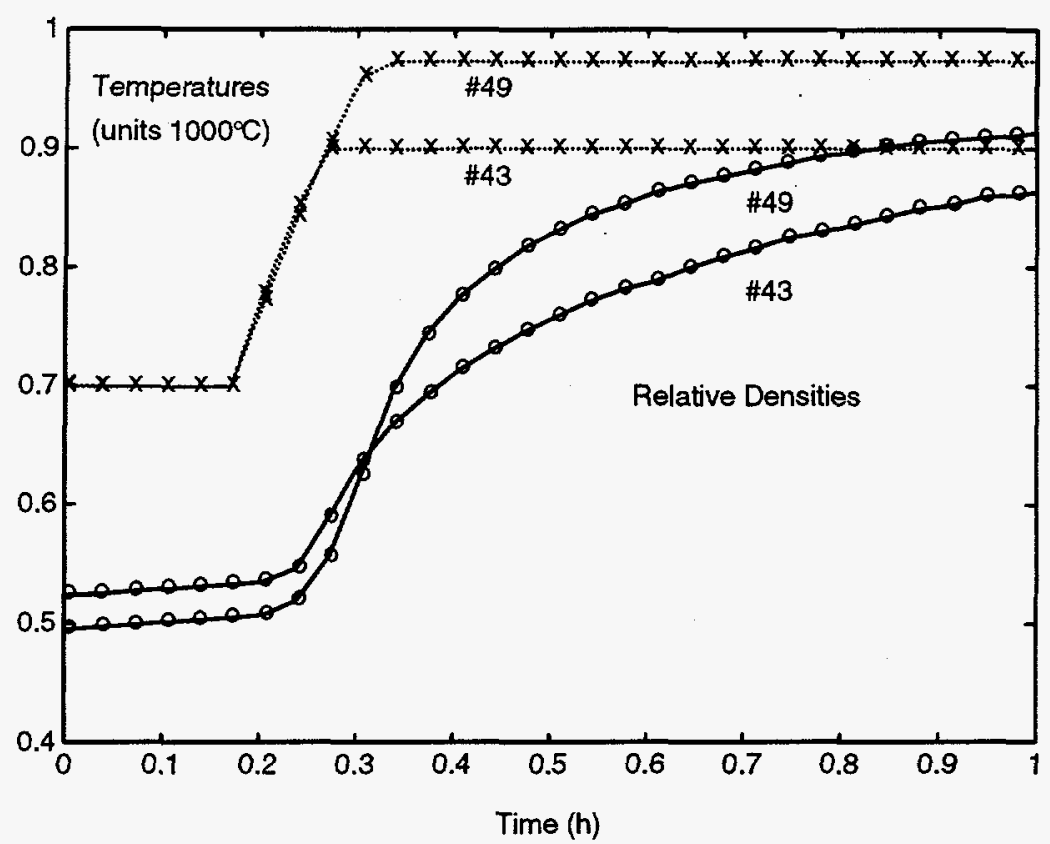

Figure 13. The relative densities of samples \#43 and \#49 sintered at 900 and $975^{\circ} \mathrm{C}$, respectively. 


\section{Metals}

Measurements on the sintering of copper and copper/tin powders was made. These tests probed the effects of powder size and mixture composition on sintering parameters. Copper powders of 100 and 325 mesh were pressed and sintered to varying densities and the longitudinal wave velocity measured. Figure 14 shows the longitudinal velocities for these two powder sizes. The results indicate that generally there are three regions of interest. First, the "green" state compacted powders exhibit a low ultrasonic velocity that is dependent on packing pressure and powder size. During the initial heating stages, the powder particles begin to join, causing the elastic modulus of the sample to rise quickly with little or no net change in sample shape. Finally, the compact densifies in a manner strongly dependent on sample temperature and sintering time. During this third regime the ultrasonic velocity appears to be proportional to the sample's relative density. This general behavior was observed for both the ceramic and metal powders. However, powder size plays a role also. In particular, the copper powders were of approximately $44 \mu \mathrm{m}$ (-325 mesh) and $150 \mu \mathrm{m}(-100 \mathrm{mesh})$ maximum size, which is large compared to the $1 \mu \mathrm{m}$ zinc oxide particles. The larger copper powder size influenced the ultrasonic wave propagation characteristics primarily through dispersion since the particle sizes are a larger fraction of the ultrasonic wavelengths $(\sim 1000$ to $2000 \mu \mathrm{m})$. These results suggest that ultrasonic velocity can be used as a reliable universal measure of relative sintered density if the appropriate wavelength is used.

The sintering process is often aided by adding a second material to the compact. This second material frequently melts at a lower temperature than the host material and increases the sintering rate of the compact. Laser ultrasonic measurements of the sintering of copper and copper/tin mixtures were performed to investigate liquid-phase sintering. The results clearly show several metallurgical changes

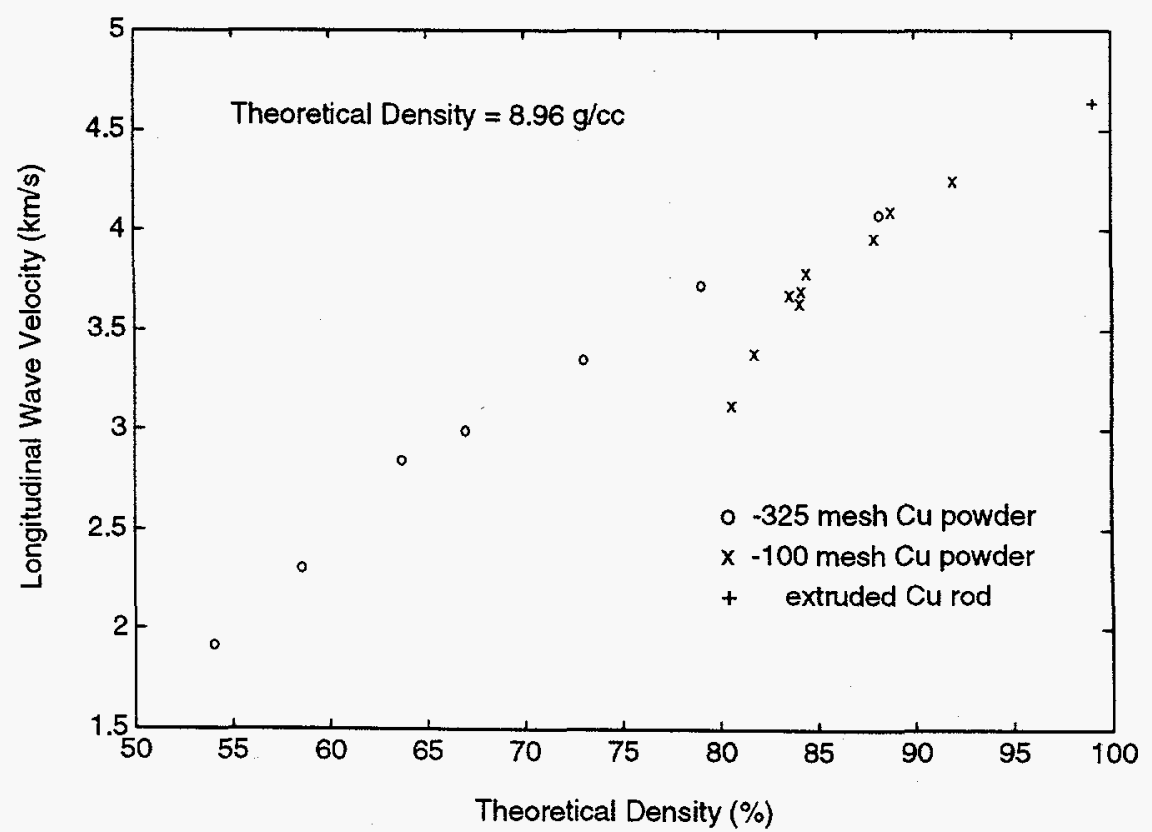

Figure 14. Longitudinal wave velocities measured in partially sintered copper powder. 
occurring in the sample as it sinters. The ultrasonic velocity vs. time history for both a pure copper compact and a 90\% copper $/ 10 \%$ tin compact (all -325 mesh) during the initial stages of sintering are shown in Figures 15 and 16; temperature increased linearly with time at the same rate for both figures. The pure copper data illustrate a typical one-component material sintering curve. Little change in the measured velocity is observed until a temperature is reached where significant diffusion bonding between the particles occurs, Figure 15 \#A. As the diffusion bonding increases, the ultrasonic velocity increases due to the "stiffening" of the compact, \#B and \#C. Finally, the compact begins to densify and the velocity increases more slowly, \#D.

A different sintering history was observed for the copper/tin mixture. The different starting velocities depict the different starting densities of the two samples. Solid state diffusion starts at a lower temperature in the CuSn compact than in the pure copper compact, as shown in Figure 16 \#E. As the sample heats up, the tin particles melt $\left(232^{\circ} \mathrm{C}\right)$, which causes a step in the velocity vs. time profile, \#F and \#G. Enhanced diffusion (or metallurgical) bonding between copper particles next occurs, causing the velocity to rise rapidly in a manner similar to the pure copper results, \#H. Subsequently, the compact sinters similarly to the pure copper compact, \#I; however, an overall increase in net sintering rate and densification at lower temperatures were achieved with the tin additive.

Ultrasonic signal magnitudes recorded at different times during the sintering cycle are shown in Figure 17 for the copper/tin mixture; similar waveforms were recorded for the pure copper powder. Before significant diffusion bonding occurs, there is a very large amount of scattering of the ultrasonic wave from the many mechanical bonds between particles in the compact. Waveforms \#E and \#F show the ultrasonic signal energy spread out over a large time span after the first signal arrival, indicating a large amount of

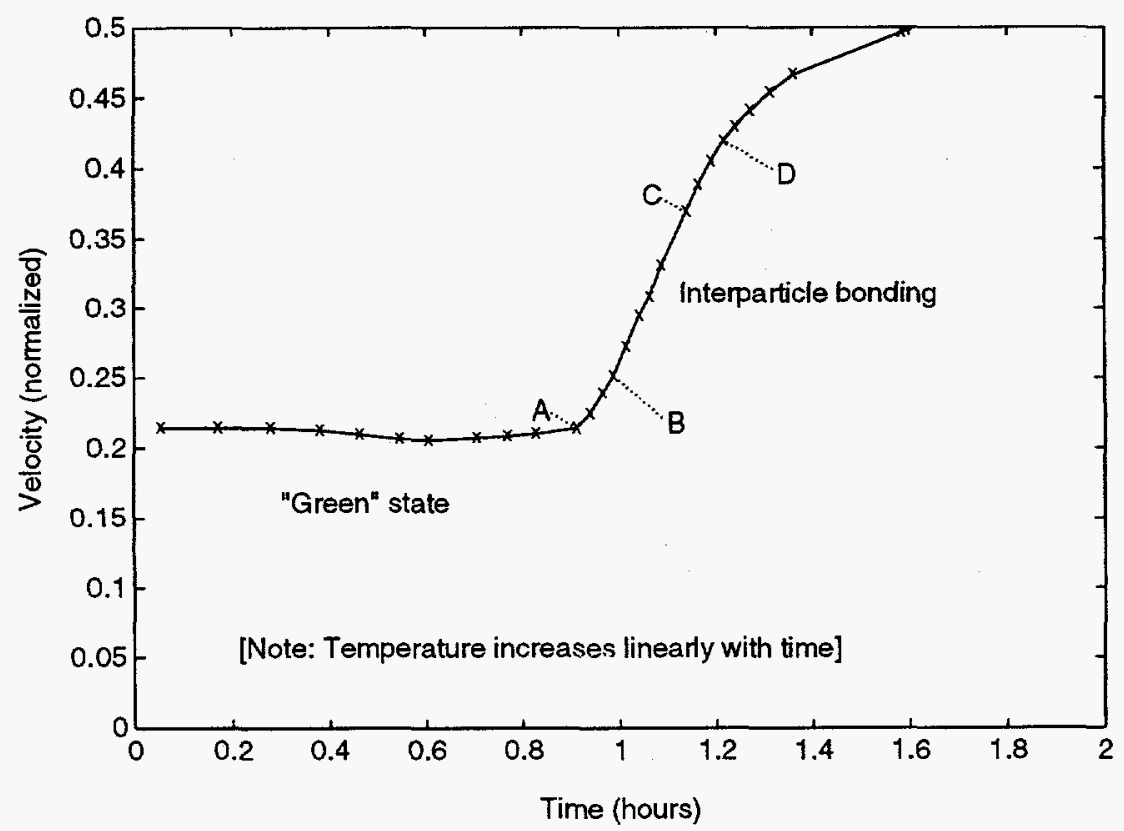

Figure 15. Ultrasonic velocities measured during sintering for copper powder compacts. The letters refer to specific regions in the sintering cycle. 


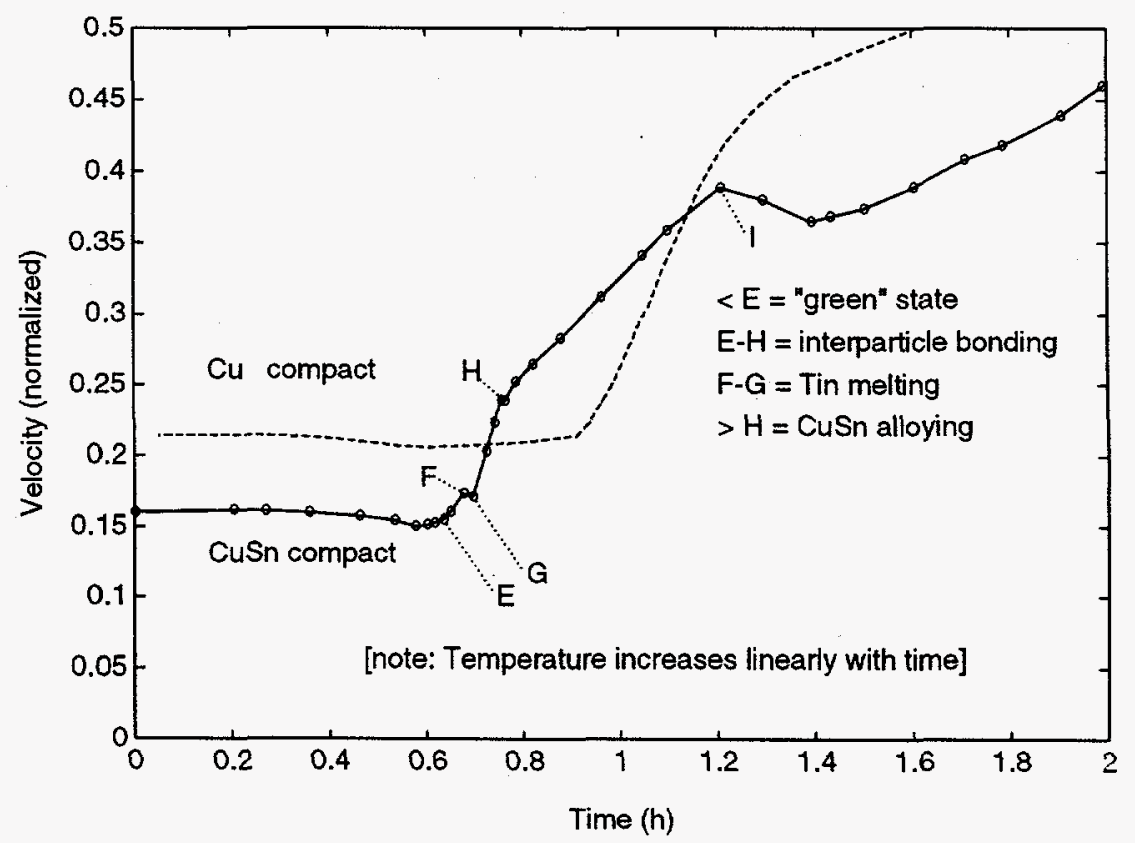

Figure 16. Ultrasonic velocities measured during sintering for copper and copper $/ 10 \%$ tin compacts. The letters refer to specific regions in the sintering cycle.

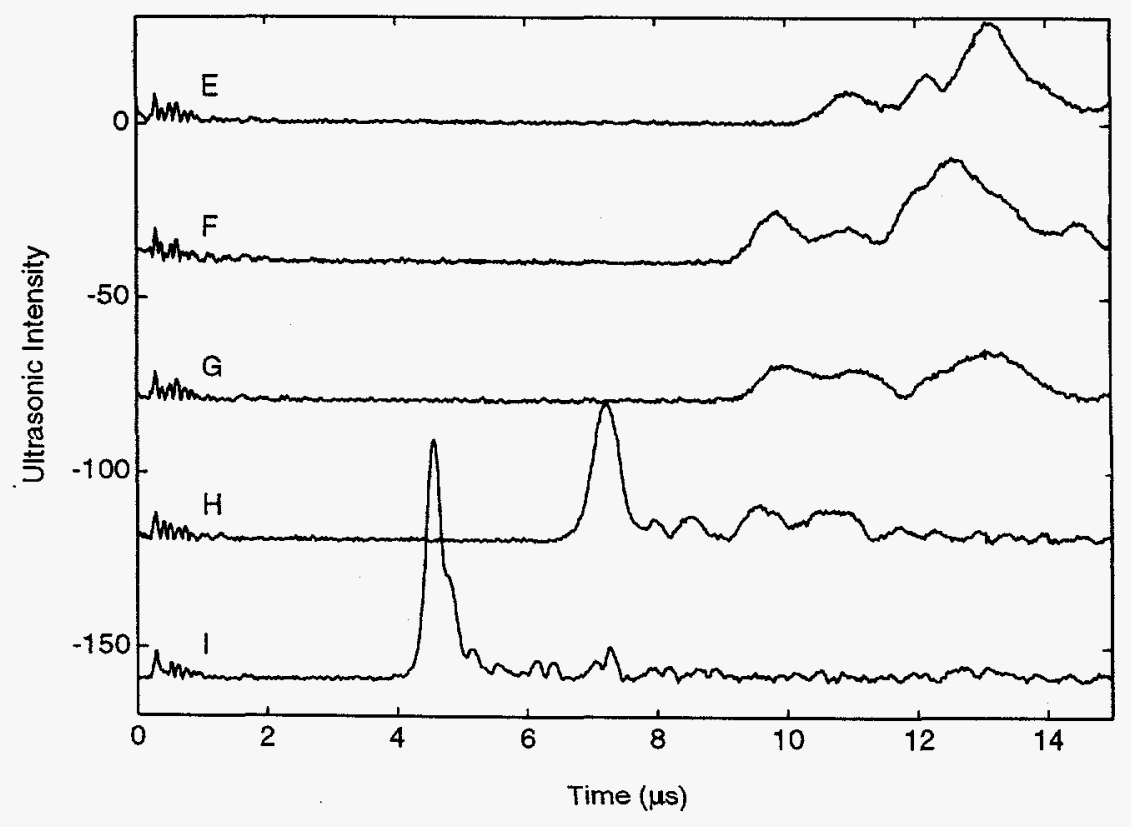

Figure 17. Ultrasonic signal magnitude waveforms taken at the points indicated in the text for the copper/10\%tin compact. 
multiple scattering is taking place. When the tin particles melt, the ultrasonic signals first begin to drop in amplitude, as shown by \#G. Immediately after melting is complete, the ultrasonic signal develops into a well-defined localized pulse as seen in \#H. Subsequently, as the compact sinters, the pulse becomes even more localized and its velocity increases due to the increased elastic modulus and decreased scattering in the compact, \#I. These waveforms illustrate, very well, the various microstructural transformations occurring in the compact as sintering proceeds. These results also illustrate the potential for ultrasonic measurements to provide useful, and previously unobtainable, information about the sintering consolidation process. 


\section{CARBON STEEL PHASE TRANSITION MEASUREMENTS}

Monitoring of microstructure changes and phase transformations that occur during the high temperature heat treatment of metal alloys is an important potential use for laser ultrasonics. ASTM A108 carbon steel (grade G10450, 0.43-0.50\% carbon) was chosen as a test material because it exhibits a phase transformation from the ferrite body center cubic (bcc) to the austenite face centered cubic (fcc) phase over a temperature range of $\sim 740$ to $765^{\circ} \mathrm{C}$. The phase transformation dynamics have been recorded for different heating and cooling rates. The measured longitudinal ultrasonic velocity in this material as the sample was heated from 600 to $800^{\circ} \mathrm{C}$ and then cooled at different rates is shown in Figure 18. On heating, the longitudinal velocity decreases rapidly above $\sim 730^{\circ} \mathrm{C}$, indicating a change in microstructure as the austenite phase is nucleated and grown. On cooling, the ferrite phase appears to be nucleated and grown below $\sim 680^{\circ} \mathrm{C}$-the longitudinal velocity rapidly increases. Due to the phase transformation, there is a lag between the sample and furnace temperatures. The sample temperature was recorded directly with a contact thermocouple. The phase transition is evident in the sample temperature's lag behind the furnace temperature, which increases and decreases linearly. The direct sample temperature measurements agree quite closely with the temperatures indicated by the longitudinal velocity measurements. These results indicate that between these temperatures the sample is in a two-phase region in which one phase is increasing and one is decreasing. The nucleation and growth or reduction of these phases result in the observed hysteresis. The transition region is also marked by a higher level of noise in the ultrasonic measurements, especially for the slower heating and cooling rates. This may be a direct result of the two phases present in the sample and the corresponding microstructural changes occurring during the measurement period. These data are a good example of how laser ultrasonics can provide a method for the determination of phase equilibria of materials in a noninvasive manner.

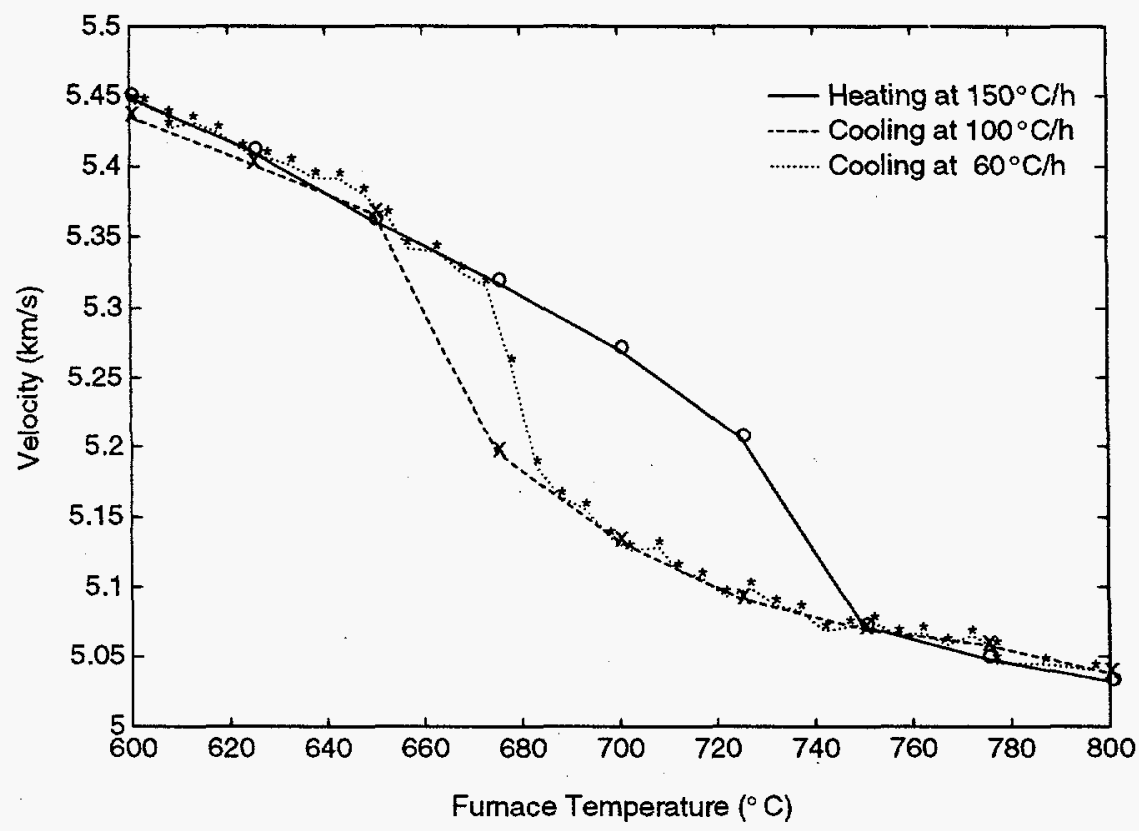

Figure 18. Ultrasonic wave velocity hysteresis recorded during the microstructural phase transition in carbon steel. 


\section{SURFACE WAVES IN SHEETS/FOILS AND SPHERES}

Many products are thin sections formed by processes such as hot and cold rolling, thin strip casting, and spin casting. The noncontacting technique presents opportunities to interrogate such product forms during processing. In-process inspection of such forms is virtually impossible with other techniques. Measurements on thin plates and foils of both ceramic and metal have been made using laser techniques. A graduate student from Montana State University ${ }^{43}$ worked with INEL personnel on determining the effects of material properties on the laser generation mechanism and the ability of the ultrasonic measurements to determine elastic properties of materials in this form. This is an extension of earlier work concerning the effects of optical penetration on the generation of elastic waves in solids. The experimental setup is shown in Figure 19. The results showed how these types of measurements can be made in a totally noncontacting manner with the laser technique, and are very encouraging. Both symmetric and antisymmetric Lamb (plate) waves can be generated in the plates and detected experimentally as shown in Figure 20. The waveforms agree with the calculations, and the dispersion curves can be obtained from the measurements by signal analysis. These measurements would be useful for on-line determination of microstructure, via the elastic properties, during the processing of sheets and foils.

Another research area concerned with sample geometry was the application of laser ultrasonics to materials with complex shapes, such as those with curved surfaces. Due to its noncontacting and point source/detector characteristics, laser ultrasonics offers a potential capability that conventional techniques do not. Conventional ultrasonic techniques are limited to bodies with simple, regular shapes and their curved surfaces must have relatively large radii. The potential of the noncontacting techniques was

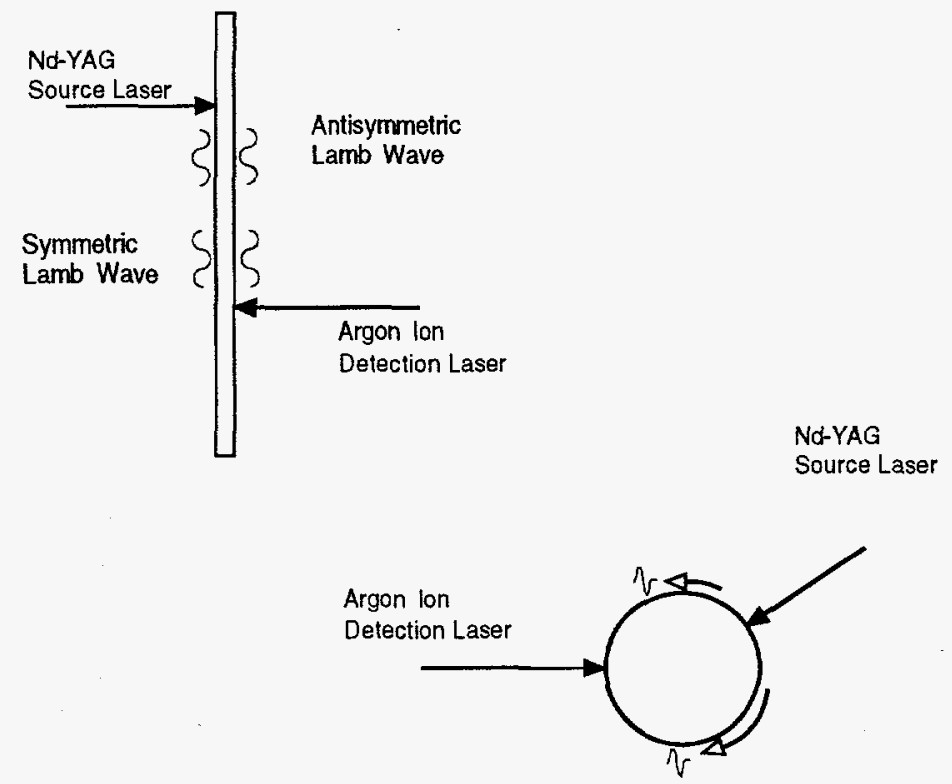

Figure 19. Block diagram of the experimental setup for recording surface waves on plates and spheres using laser ultrasonics.

investigated by measuring the elastic properties of spheres, which have all the potential problems of materials with curved surfaces and yet can be studied analytically. Both metallic and ceramic spheres were 
investigated using the experimental geometry shown in Figure 19. Detection of the surface motion takes place at one point, as shown. The source point is then rotated about the polar axis determined by the detection point. Both thermoelastic and ablation source mechanisms were studied, and both bulk and surface wave modes have been detected. ${ }^{44}$ From these data, elastic properties can be determined using a single sample shape and measurement. Very interesting effects due to the sample surface curvature can be seen. Figure 21 shows the measured waveforms for different angular positions of the source point with respect to the polar axis. Two large surface waves are seen, the first is the direct wave from the source and the other is the wave reflected from the pole directly opposite the source point. Two effects of curvature are seen in these data: focusing of the wave at the pole, which gives the large amplitude wave seen when the source and detector are on the same polar axis (angle $=0$ in the figure), and dispersion of the waves due to the surface curvature, such that the lower frequency components travel faster than the higher frequency components. This latter effect is a general property of wave motion on curved surfaces, but it is only apparent in the multiple reflection data (not shown). These two effects occur in any curved surface situation and must be accounted for if these signals are to be used for determining material properties through propagation characteristics. Understanding this type of wave motion is essential for using laser ultrasonics to investigate materials in complex shapes, e.g., turbine blades

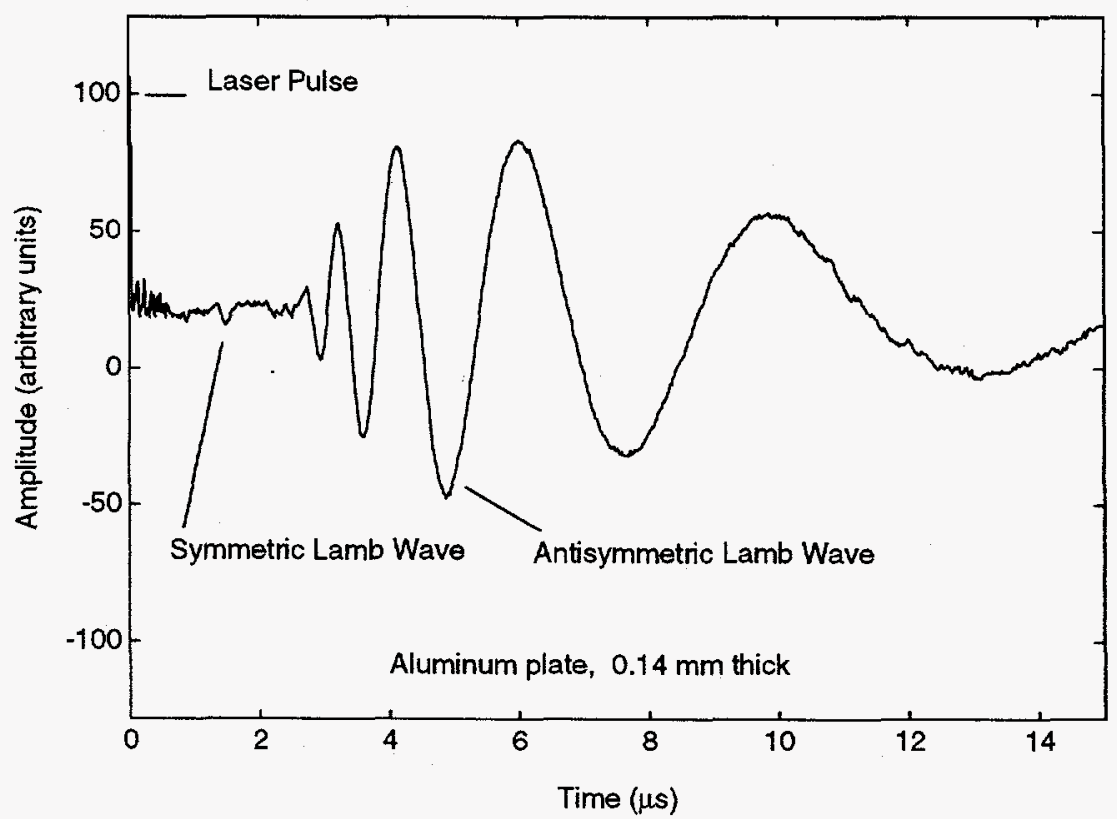

Figure 20. Lamb waves measured by the laser ultrasonic technique in aluminum. Both the symmetric and antisymmetric modes are easily observed; the laser pulse occurs near the origin. 


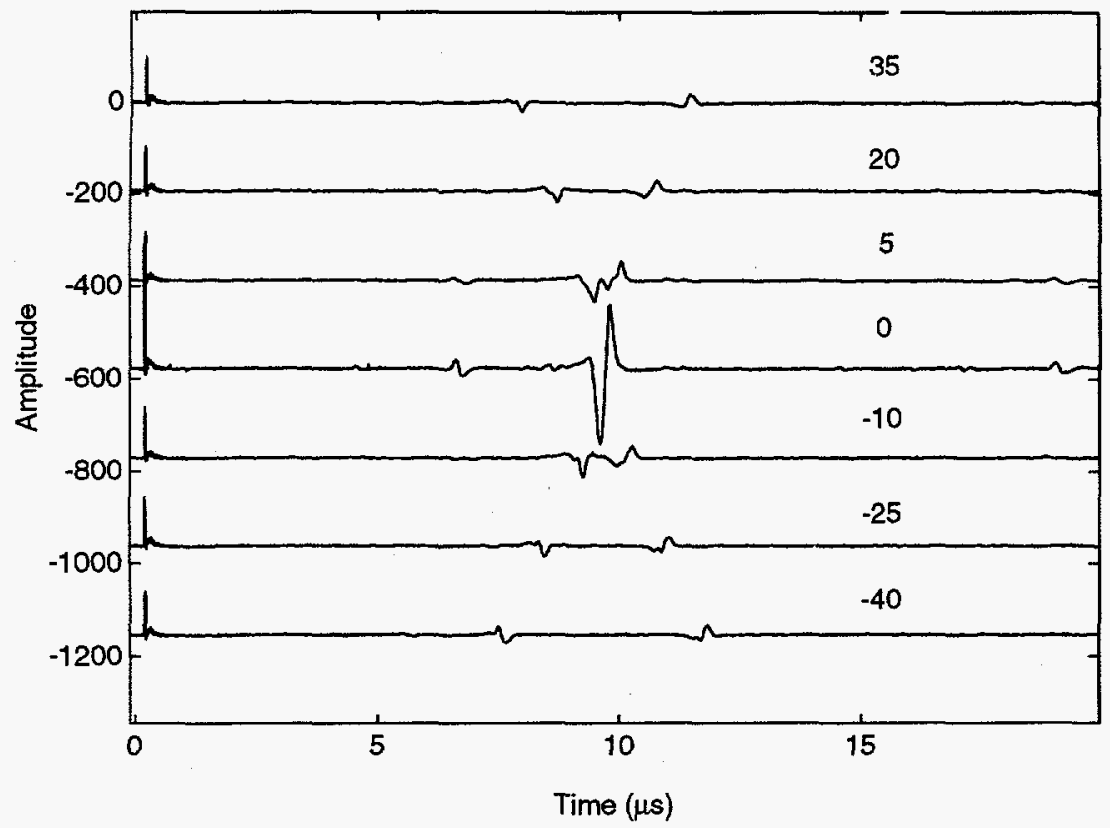

Figure 21. Surface waves recorded on a $17.5 \mathrm{~mm}$ diameter stainless steel sphere using laser ultrasonics. Shown are both the direct and the pole reflected waves received at the detector for various source angular positions from the detector polar axis, given by the numbers on the right. 


\section{MICROELECTRONIC APPLICATIONS OF LASER ULTRASONICS}

A cooperative research and development agreement (CRADA) was established between the INEL and a company that manufactures microelectronic circuit testing equipment to investigate the ability of laser ultrasonics to provide a noncontacting inspection method for microelectronic applications. This task is complicated by the requirements for small dimensions and high focusing of laser energy. Laser ultrasonic measurements were adapted to a microscope that can focus both generation and detection laser spots to sizes on the order of $10 \mu \mathrm{m}$. Acceptable signal-to-noise measurements of surface waves have been obtained for pulse energy levels as low as $50 \mu \mathrm{J}$ focused to a spot size of about $75 \mu \mathrm{m}$ diameter and with detection power levels of a few milliwatts on the samples, see Figures $22 \& 23$. These levels cause no surface damage on metals. Higher pulse energy levels and/or higher focusing can ablate the sample.

The results have shown that noncontacting ultrasonic measurements can be performed even on the scale of 10 to $100 \mu \mathrm{m}$. Since the propagation distances are so small, very high frequency bandwidth detection must be maintained throughout the complete generation and detection system. To date, response bandwidths of 10 to $50 \mathrm{MHz}$ have been achieved.

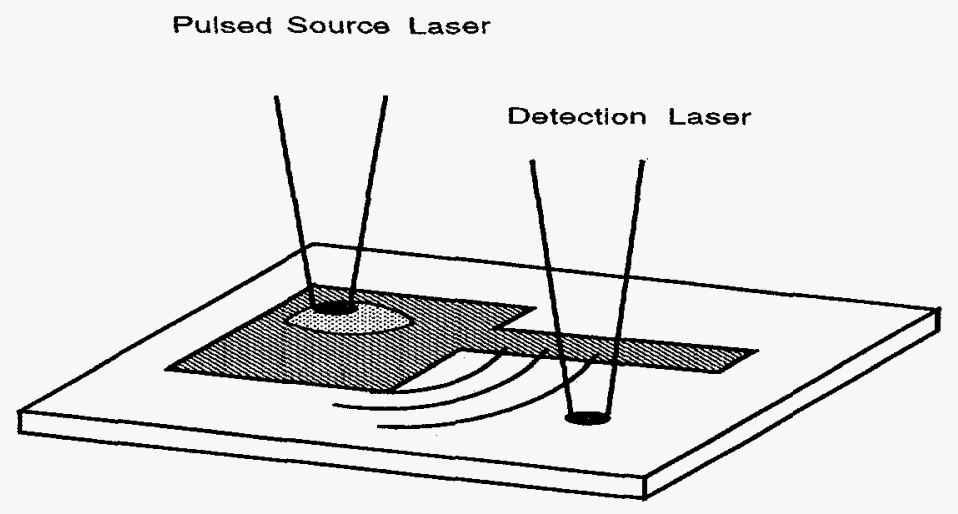

Figure 22. Setup for high frequency surface wave measurements to evaluate bonding in microelectronic applications. 


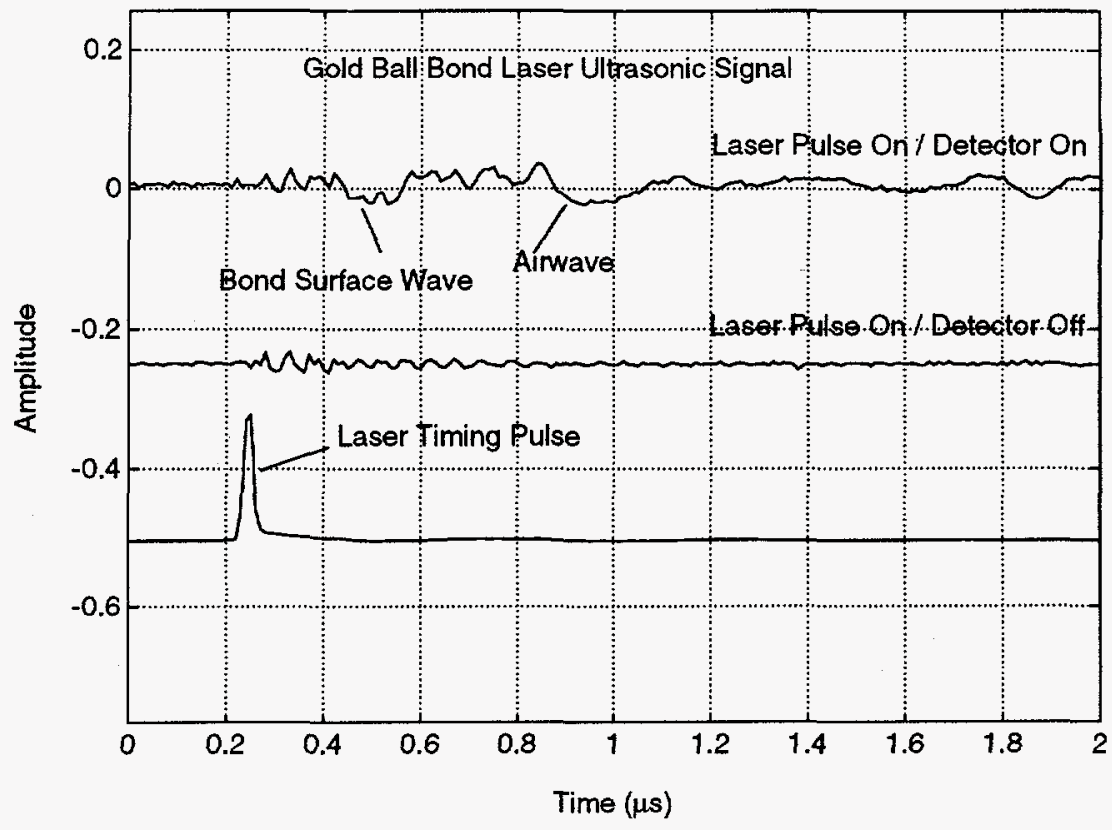

Figure 23. Surface wave measurement at high frequencies for a source-to-detector distance of $100 \mu \mathrm{m}$. 


\section{MOLTEN METAL SOLIDIFICATION MONITORING}

Melting and casting of metal alloys occur in a severe environment. The processing parameters of interest, such as temperature, melt depth, solidification boundary, and composition, are difficult to measure in situ. However, laser ultrasonic techniques offer the potential for monitoring the properties of molten metals in a noninvasive manner. Supported by this project, INEL became a participant in the National Institute of Standards and Technology Consortium on the Casting of Aerospace Alloys. INEL performed the laser ultrasonic portion of this research. Experimental measurements were made at INEL and theoretical modeling of laser generation and propagation of ultrasonic waves in molten metals was performed at Montana State University (MSU) through subcontract.

\section{Depth Measurements on Molten Tin}

The first measurements were concerned with determining the molten pool depth in tin, which was chosen since it melts at a low temperature. ${ }^{45}$ The experimental setup was similar to that used for the sintering experiments. Both surface and bulk longitudinal waves were produced in the liquid by the pulsed laser. Generation and detection of the ultrasonic waves were done at the same surface location to allow sufficient time for the surface waves to travel away before the longitudinal waves returned after reflecting off the liquid bottom. The pool depth was also measured by a contact vernier caliper after cooling. Figure 24 shows the measurement geometry and Figure 25 the ultrasonic echoes detected at the surface for various liquid depths. At the left is the initial pulse due to the laser. Following this pulse are echoes of the longitudinal waves reflecting off the bottom. As can be seen, transit time increases with pool depth. Excellent correlation of transit time with depth was found for depths from 6 to $25 \mathrm{~mm}$ using a mean wave speed of $2.44 \mathrm{~mm} / \mu \mathrm{s}$. These results showed that laser ultrasonics could be effectively used to monitor conditions in molten metal pools.

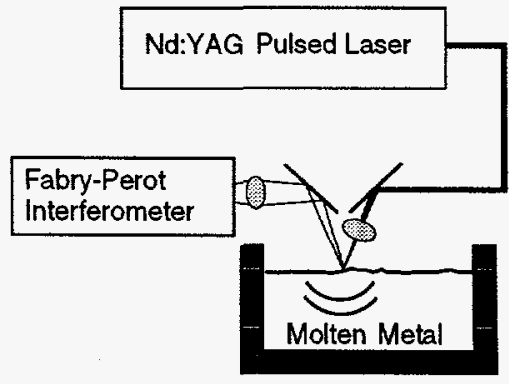

Figure 24. Laser ultrasonic measurement apparatus for acoustic wave generation and detection at the liquid metal surface. 


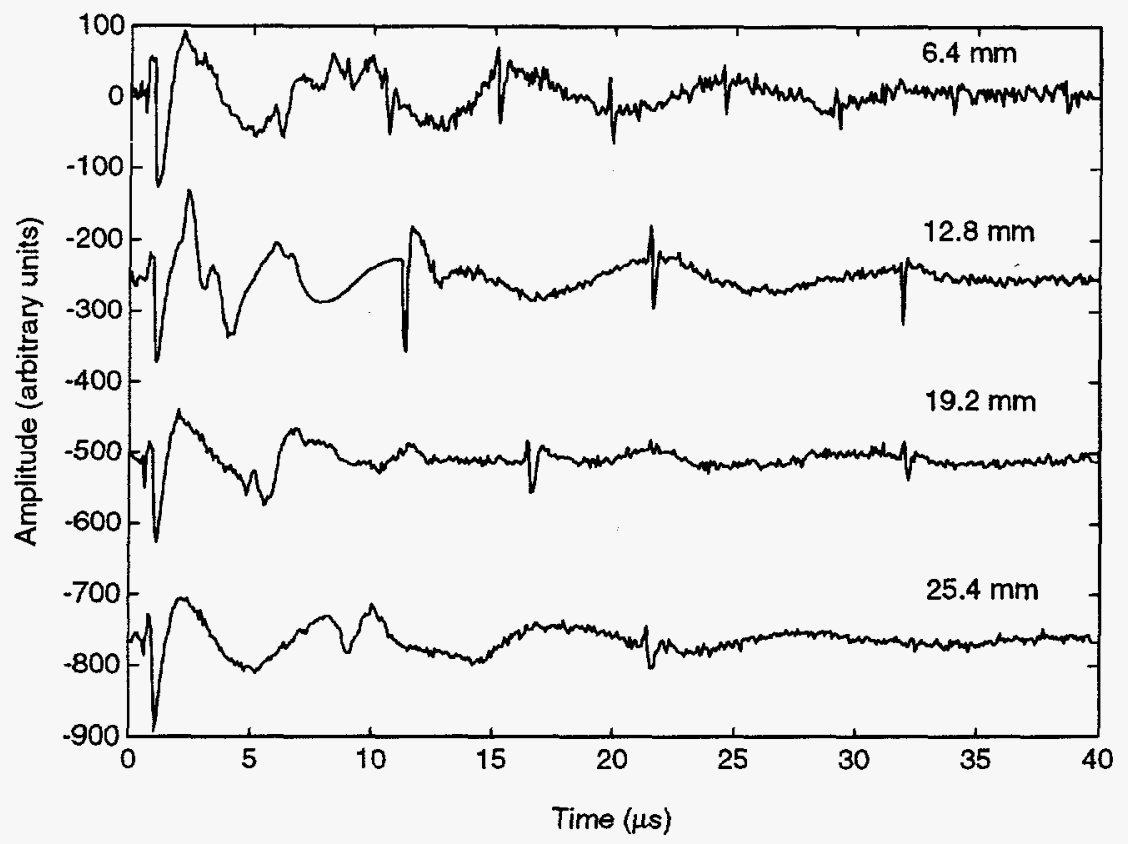

Figure 25. Ultrasonic waveforms detected for different molten pool depths in tin. The sharp pulses appearing at regular time intervals are reflections from the bottom of the pool.

\section{Liquid Mercury Laser Source Characterization}

\section{Radiation Pattern}

To better understand ultrasound generation and detection from the free surface, experiments measuring the radiation efficiency were initiated using liquid mercury. This allowed different measurement geometries and source conditions to be explored without the complications of heating and temperature gradients. Radiation efficiency from laser generation at the molten metal surface was the first characteristic determined. The radiation pattern from a small surface source was measured by placing mercury in a glass cylinder with an inside radius of $1 \mathrm{in}$. and a length of $6 \mathrm{in}$. The source laser was directed at the free surface with a spot size of about $3 \mathrm{~mm}$ diameter, while the detection laser, incident at a known angle, was below the source at the mercury/glass interface. The experimental arrangement is shown in Figure 26. The pulsed laser generates bulk acoustic waves in the liquid, and surface waves and acoustic waves in air above the liquid. Both thermoelastic and ablation source conditions were explored. The results show a substantial directionality to the radiation pattern that narrows as the source spot size is increased, see Figure 27. No noticeable changes in directionality or waveshape were observed for laser pulse energies in the thermoelastic or ablation regimes. This is consistent with expectations for generation at fluid surfaces. Most of the ultrasonic energy is directed perpendicular to the liquid surface, similar to an ablative source in a solid metal. Concentration of the ultrasonic energy normal to the surface could prove to be a significant factor in effectively using this source on surfaces undergoing vibration. 


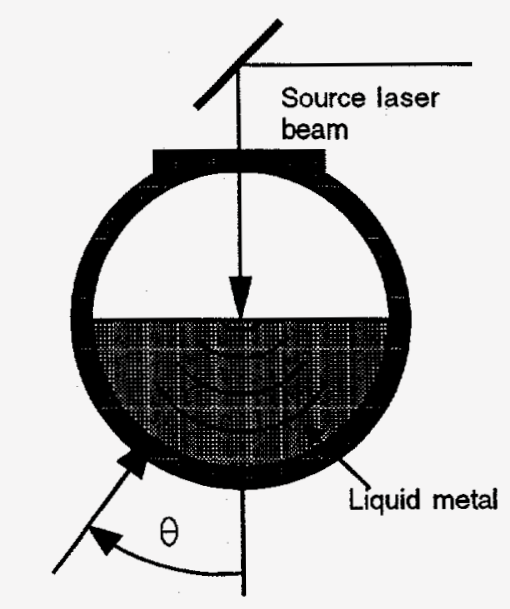

Detection laser beam

Figure 26. Angular radiation measurement geometry for liquid mercury.

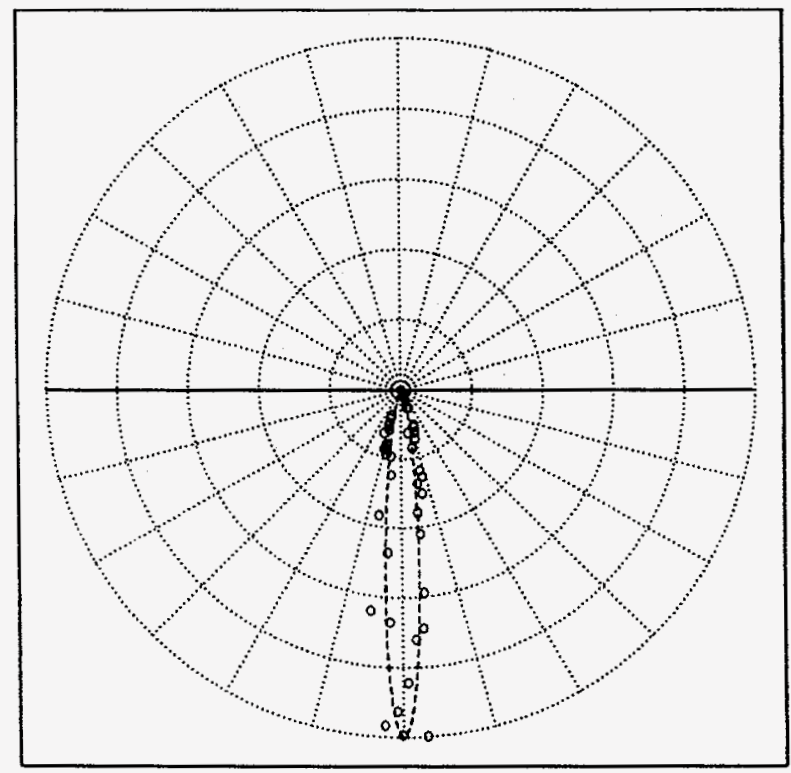

Figure 27. Laser source angular radiation pattern in mercury

Substantial surface wave motion is readily generated in the fluid. Direct measurements were obtained by redirecting the detection beam on the surface a distance of $7.5 \mathrm{~mm}$ away from the source spot. 


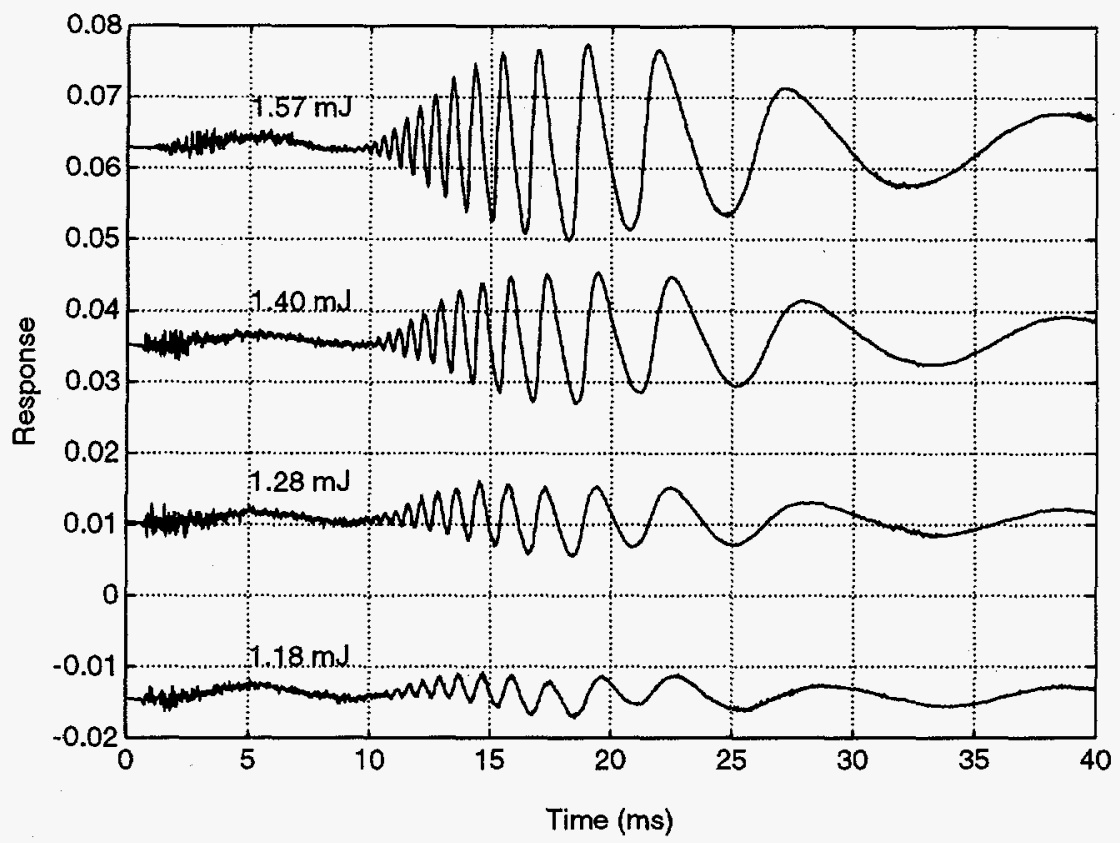

Figure 28. Surface waves on mercury for a source-to-detector separation of 7.5 $\mathrm{mm}$.

This allowed simultaneous detection of surface waves, acoustic waves in the air above, and ultrasonic bulk waves reflected back to the surface. Figure 28 shows several surface wave amplitudes for different laser pulse energies. The surface motion is complicated by the effects of gravity and surface tension, producing a highly dispersive wave. This is readily seen in the waveforms. The preliminary results indicate that a considerable tradeoff occurs between bulk and surface waves regarding generation efficiency as a function of laser pulse energy. More work is needed to accurately determine the partition of laser pulse energy between bulk, surface, and air waves in order to optimize bulk wave generation.

Theoretical work at Montana State University under the direction of Professor R. J. Conant has concentrated on mathematical modeling of bulk and surface waves generated by a pulsed laser source. The goal is to predict the generation efficiency of the thermoelastic and ablation mechanisms while including the effects of the free liquid surface (i.e. surface wave generation from surface tension, gravity, and compression effects). Previous work calculated the radiation pattern for thermoelastic generation (neglecting surface waves) and shows a radiation pattern much like that observed in the current measurements. ${ }^{46}$ Ablation can be considered, in a simple model, as an impulsive normal point force on the surface. This leads to a radiation pattern similar to that obtained for the thermoelastic case. ${ }^{47}$ Therefore, no abrupt change in radiation pattern is expected as the laser power is increased from the thermoelastic to the ablation regime, which agrees with the experimental observations so far. As indicated, the effects of surface wave generation may be important for the overall laser generation process because this is another path for energy dissipation. Surface waves were modeled, taking into account the properties of the material, including compressibility. A dispersion relation was developed that describes the surface waves, accounts for compressibility, and reduces to the well-known results for incompressible fluids as the speed of sound in the liquid becomes very large. The challenge in developing a realistic model is to properly account for the buoyancy force resulting from the laser-induced temperature change upon absorption and the appropriate surface boundary condition. ${ }^{48}$ 


\section{Energy Dependence}

The dependence of the ultrasonic amplitude on the Nd-YAG pulse energy was measured by directing the laser source on the surface of the liquid mercury. Both thermoelastic and ablation source conditions were explored. The ultrasonic wave was detected with a $10 \mathrm{MHz}, 1 \mathrm{~mm}$ diameter, piezoelectric transducer. The mercury depth was $13 \mathrm{~mm}$, with the transducer $11 \mathrm{~mm}$ below the surface, so the ultrasonic amplitude measurements represent an average over a reception solid angle of about 3 degrees. The laser energy, adjusted by sliding thin glass plates in and out of the beam, was measured at each point. The spot size was measured photographically.

The ultrasonic amplitude is expected to vary linearly with laser pulse energy for thermoelastic generation, and also for ablative generation at low energies. For thermoelastic generation, the amplitude scales with the thermal expansion, and, therefore, with the absorbed pulse energy. For ablation, it will scale with the momentum of the ejected material, which is proportional to the mass ejected and the absorbed pulse energy above the ablation threshold. Figure 29 shows the measured ultrasonic amplitudes for two spot sizes vs. incident laser pulse energy. The dashed lines show the expected slope for a linear dependence. Both data sets exhibit two linear regions, corresponding to thermoelastic expansion at lower energies and ablation at higher energies. A visible "spark" and an audible "snap" were observed for data points near the higher dashed line. For low laser energies, the absorbed incident light causes thermoelastic expansion. At high energies, ablation causes material to be ejected. This material can absorb or scatter the incident light, resulting in a lower fraction of incident laser pulse energy actually being absorbed. Consequently, the ultrasonic amplitude is expected to saturate at sufficiently high laser pulse energies; however, no perceptible saturation was observed over the range employed. The most striking feature is the rapid increase of the ultrasonic amplitude with laser energy in the transition region between thermoelastic and ablation source mechanisms.

A threshold model was found to explain the laser energy dependence. ${ }^{49}$ The incident pulse energy, up to a threshold energy density, heats the liquid to the point of vaporization, producing ultrasound by thermoelastic expansion. Absorbed pulse energy beyond the threshold ejects material from the pool, producing ultrasound by ablation. It is evident from the measurement results that the ablation mechanism is two orders of magnitude stronger than the thermoelastic mechanism in mercury. It is reasonable to assume that the amount of material ablated is proportional to the energy in the absorbed laser pulse that is above the threshold for ablation. Noting that the laser spot size enters as a multiplicative factor, this model suggested plotting the data as ultrasonic pulse amplitude per unit area illuminated vs. the incident pulse energy, as shown in Figure 30. The data for both spot sizes fall on a single curve as predicted by the model. There are two parameters in the model, the material's ablation threshold and a parameter that describes the strength of the ablation mechanism with respect to the thermoelastic mechanism. For mercury, the ablation threshold was found to be $6 \mathrm{MW} / \mathrm{cm}^{2}$ and the ablation mechanism to be about 100 times stronger than the thermoelastic mechanism. Both depend on the thermal and optical properties of the liquid metal. Both are calculable from detailed knowledge of material properties, in principle. Molten metals offer a good medium for studying ablation, since the surface is always refreshed and ablation, at least for mercury, dominates ultrasonic generation above the threshold 


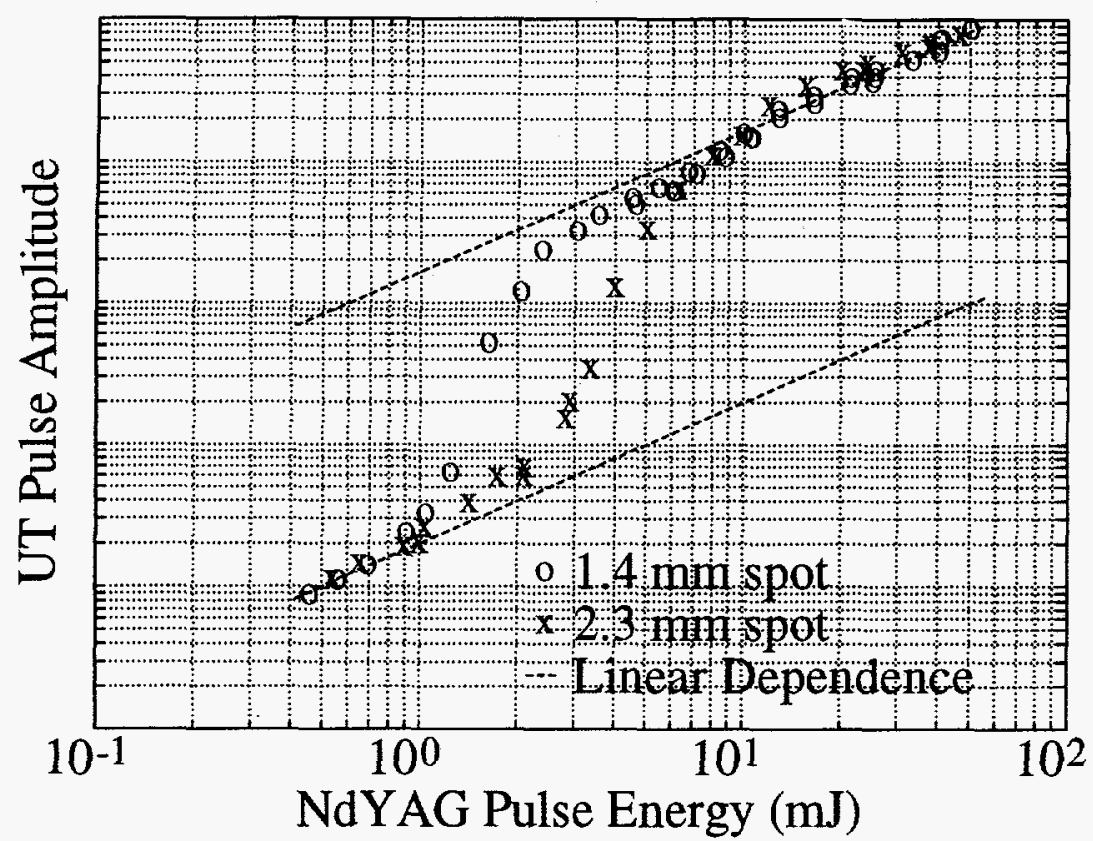

Figure 29. Ultrasonic amplitude as a function of the Nd-YAG pulse energy in both the thermoelastic and ablation regimes for two spot sizes.

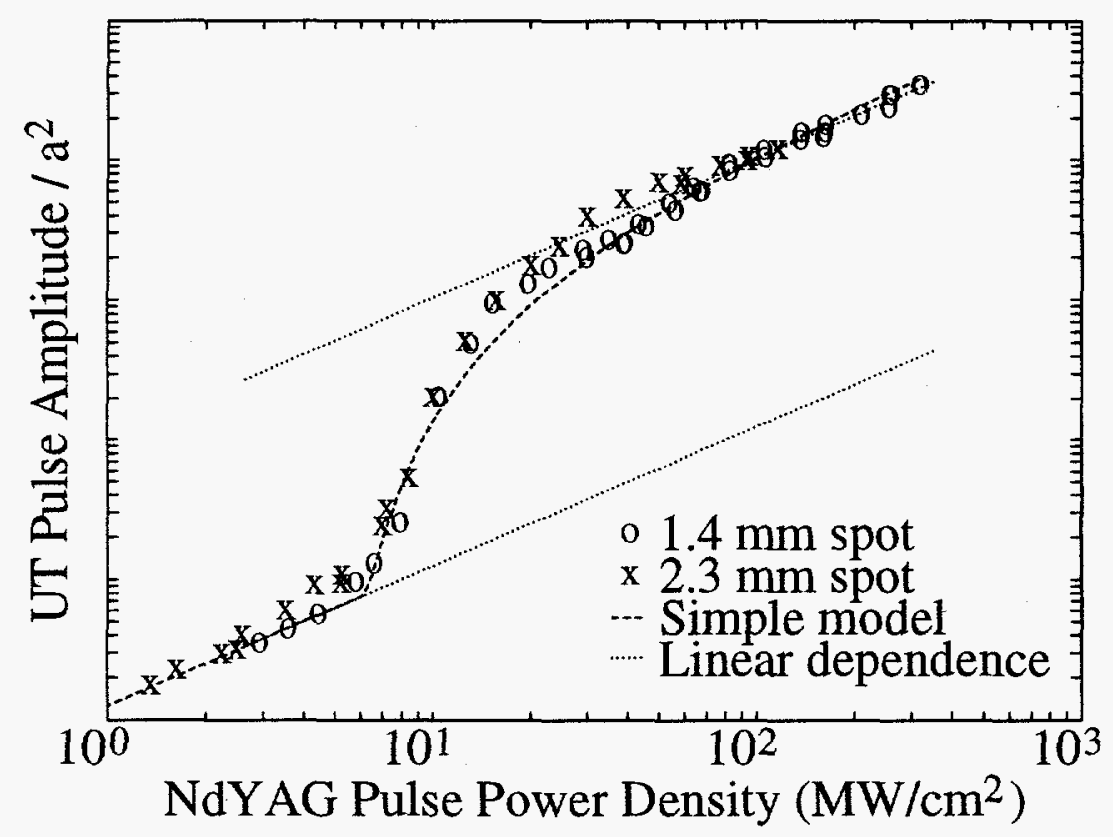

Figure 30. The ablation model, shown as the dashed curve, displays the essential physics for the transition from thermoelastic expansion to ablation ultrasound production mechanisms. 


\section{Molten Tin Liquid/Solid Interface Detection}

A real-time sensor that directly measures properties of the solidification front would be a valuable aid to the metal casting industry. Information needed includes solidification front location, shape, and growth dynamics. The use of contacting probes is often undesirable because it can cause contamination and probe deterioration. Noncontacting laser ultrasonics offers an attractive solution to these problems, particularly if access to the free liquid surface is available. Laser ultrasonic measurements of the solidification front in tin and a tin-lead alloy were successfully recorded. ${ }^{50}$ Tin was selected for its low melting point and the availability of a suitable furnace.

\section{Stationary Solidification Front Measurements}

A vertical tube furnace was used to maintain the metal with both liquid and solid phases as shown in Figure 31. The pulsed laser generation beam and the detection beam were focused on the liquid surface. The ultrasonic wave, generated at the surface, traveled down to the solidification front, reflected, and was detected at the liquid surface a small distance away from the source beam. Simultaneously, a piezoelectric transducer generated ultrasonic waves at the bottom of the furnace that traveled up through the impedance matching block and into the solid tin. These waves reflected from the solidification front and also from the liquid surface and were detected by the same piezoelectric transducer. Utilization of both the noncontacting laser and the contacting piezoelectric methods provided a cross check on the depth of the front and a comparison between methods.

Waveforms showing the solidification front echo are displayed in Figure 32. The upper trace shows the laser-generated echo with a travel time of about $37 \mu \mathrm{s}$. The lower trace shows the piezoelectricgenerated echo recorded at $195 \mu \mathrm{s}$ and the echo from the liquid surface at about $232 \mu \mathrm{s}$.

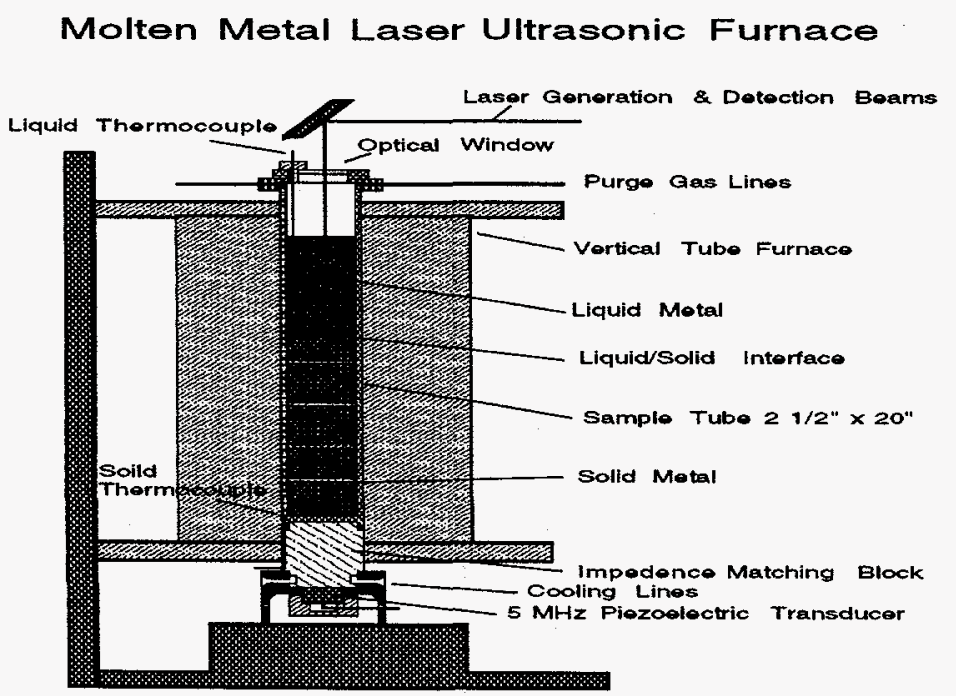

Figure 31. Molten metal casting furnace for laser/piezoelectric experiments. 

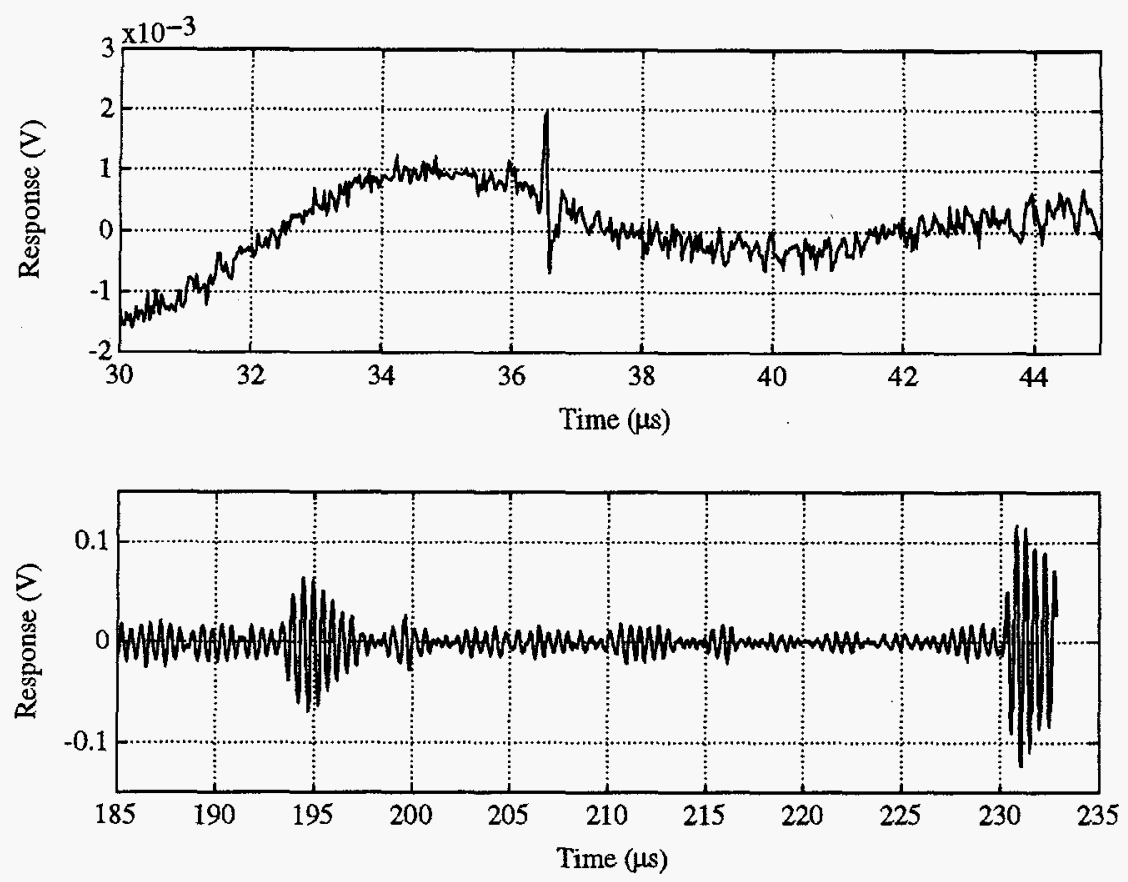

Figure 32. Solidification front reflection echoes recorded at the surface of the liquid with the laser technique (upper, at $37 \mu \mathrm{s}$ ) and at the bottom of the solid with the contact piezoelectric technique (lower, at $195 \mu \mathrm{s}$ ).

The time for the wave to travel from the solidification front to the surface and back is again seen to be about $37 \mu \mathrm{s}$. Both measurement techniques locate the interface about $45 \mathrm{~mm}$ below the liquid surface. Differences between the two ultrasonic techniques are also seen. The laser method is wideband, producing a narrow echo signal pulse, whereas the piezoelectric method is essentially narrowband, producing a signal characteristic of transducer ringing. The laser results are also free of spurious signals from internal reflections in the impedance matching block, such as are present in the piezoelectric recorded waveforms, that often complicate signal source identification.

The location of the solidification front was altered by changing the temperature gradient along the tin column. Figure 33 shows the laser-generated signal from the solidification front at various stationary depths. The sharp signature of the solidification front moves to longer times, from 31 to $88 \mu \mathrm{s}$, reflecting the longer path for the ultrasonic pulse through the molten metal. The solidification front echo recorded by the piezoelectric transducer moved to shorter times, from 211 to $160 \mu \mathrm{s}$, reflecting the shorter path for the pulse through the solid tin. The liquid surface echo moved to longer times, from 230 to $250 \mu \mathrm{s}$, because the sound speed is slower in the liquid. A strong, but slowly varying, additional waveform was found in the laser ultrasonic measurement. This is due to the acoustic wave generated by the ablation pulse. Liquid surface vibrations also degrade the laser detection process. All laser ultrasonic waveforms shown were single shot. Surface contamination effects on the molten metal also were a factor in determining the generation efficiency for the laser source; however, repetition of the high energy laser pulse was found to clean the surface. Some differences in solidification front echo signal amplitude were caused by conditions of the solidification front. As the heat flow was altered, a flat solidification front surface was not always found, resulting in decreased reflection signal amplitude. 


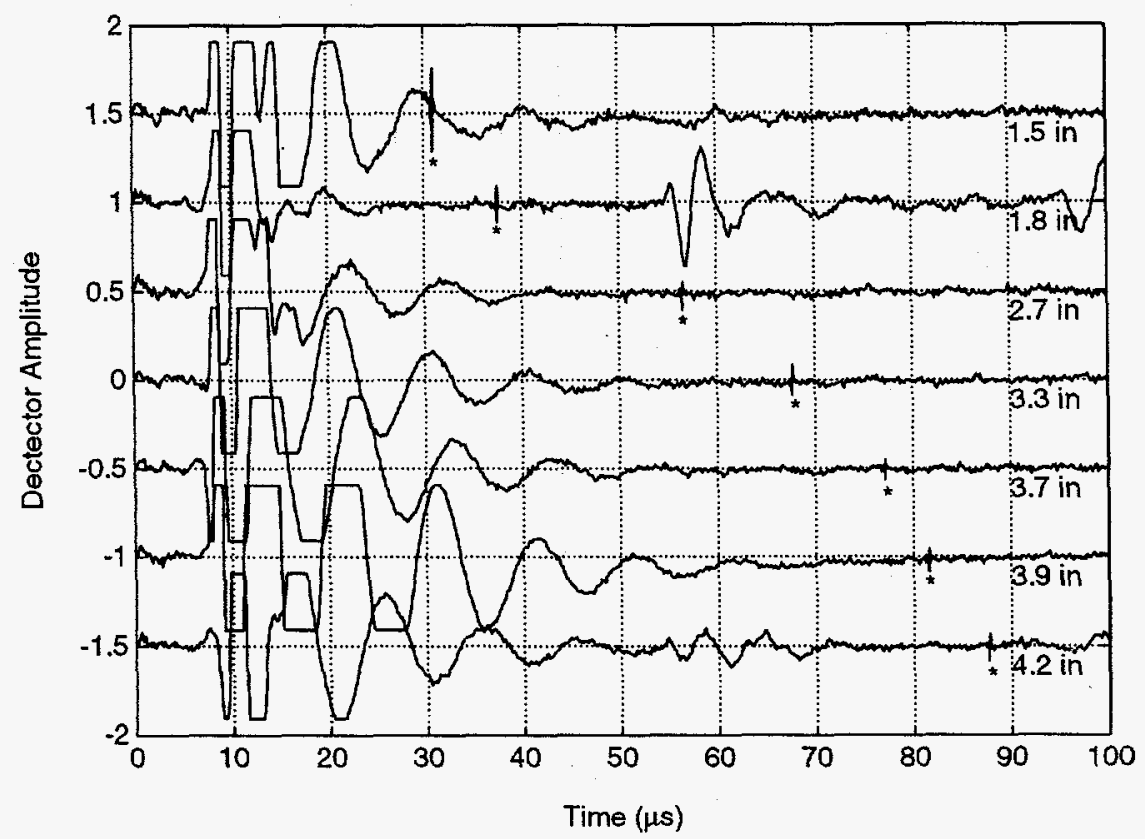

Figure 33. The solidification front in tin measured by the laser ultrasonic method $\left(^{*}\right)$. The large slow oscillations result from acoustic waves in gas above the liquid.

The front could be made more planar, increasing the reflection signal amplitude, by holding the temperature gradients constant to create local equilibrium. The reflection signal amplitude is an indication of the solidification front profile and structure.

\section{Moving Solidification Front}

Measurements on a moving solidification front were made with the furnace insert depicted in Figure 34. The tin column is considerably shorter than for the stationary front experiments and the piezoelectric transducer was eliminated. This improved control of the heat flow. As in the initial setup, the generation and detection laser beams were incident on the liquid surface. The first measurement with this setup was of a moving front in about $80 \mathrm{~mm}$ of pure tin. Laser ultrasonic signals, with the tin solidifying at about $1 \mathrm{~mm} / \mathrm{min}$, are displayed in Figure 35. Besides the usual "air wave" signals, the solidification front echo can be seen moving from about 52 to $26 \mu \mathrm{s}$, indicating the pool depth has shrunk from 64 to $32 \mathrm{~mm}$. The echo signal amplitude decreased for a solidification front evolving in time as compared to those for a stationary front, reflecting the irregularities of the front structure as growth occurs. 


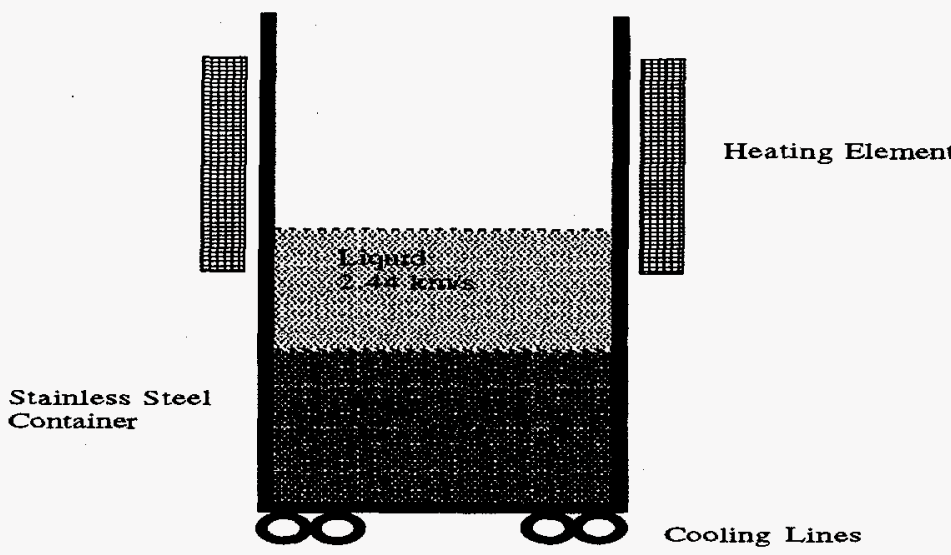

Figure 34. Furnace insert for moving solidification front experiments.

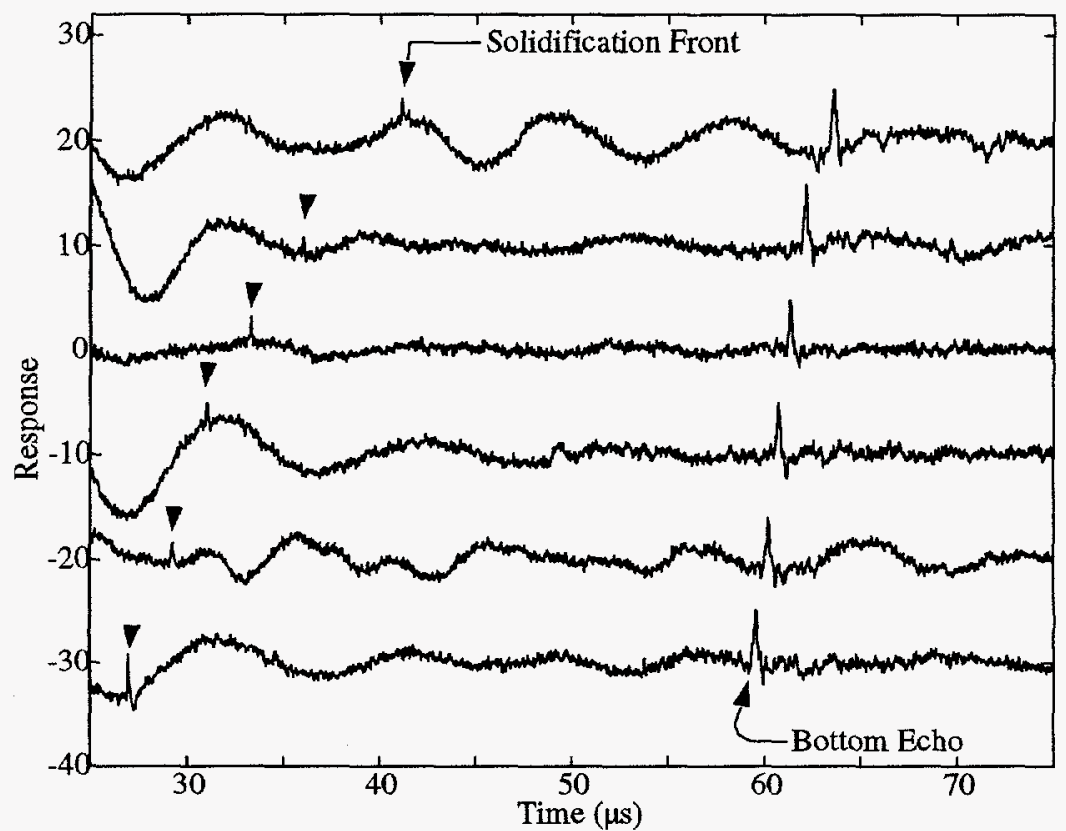

Figure 35. Laser signals for a moving solidification front $(1 \mathrm{~mm} / \mathrm{min})$ in tin. All waveforms are single shot; the data span $30 \mathrm{~min}$. 
Alloy Measurements

A set of thermocouples was inserted at fixed depths into the metal to measure the temperature as a function of depth. This permitted an estimation of the depths at which the liquidus and solidus temperatures from the tin-lead phase diagram were reached-the difference approximates the mushy zone thickness. ${ }^{b}$ Lead was selected to form an alloy with tin because only a small addition, $0.6 \%$, was needed to produce a significant mushy zone (solidus and liquidus at about 220 and $231^{\circ} \mathrm{C}$, respectively). The ultrasonic generation, detection, and propagation properties of the liquid and solid were still essentially the same as those for pure tin. Experiments with the $0.6 \% \mathrm{~Pb}$ alloy were more difficult, as expected. Geometry, particularly of the generation and detection spots relative to the solidification front, was important, consistent with earlier work on laser generation in molten metal. Both the solidification front and the bottom echoes were difficult to detect except when the solidification front moved at less than about $0.1 \mathrm{~mm} / \mathrm{min}$. Figure 36 shows data for the alloy. The mushy zone is about $8 \mathrm{~mm}$ thick, and is nearly stationary with the alloy solidifying at $0.1 \mathrm{~mm} / \mathrm{min}$. The solidification front echo appears in six of the traces at about $50 \mu \mathrm{s}$. The bottom echoes extend from about 67 to $73 \mu \mathrm{s}$, indicating a large amount of internal scattering taking place as the wave travels through the mushy zone. Figure 37 shows the solidification front signal acquired for an $8 \mathrm{~mm}$ and a $12 \mathrm{~mm}$ mushy zone, in both cases solidifying at about $0.05 \mathrm{~mm} / \mathrm{min}$. The moving solidification front signal for pure tin is shown for comparison. The signals are similar, with little additional scattering due to the mushy zone. This suggests that the recorded echo signal comes from scattering by local predominant features ratiler than from throughout the mushy zone.

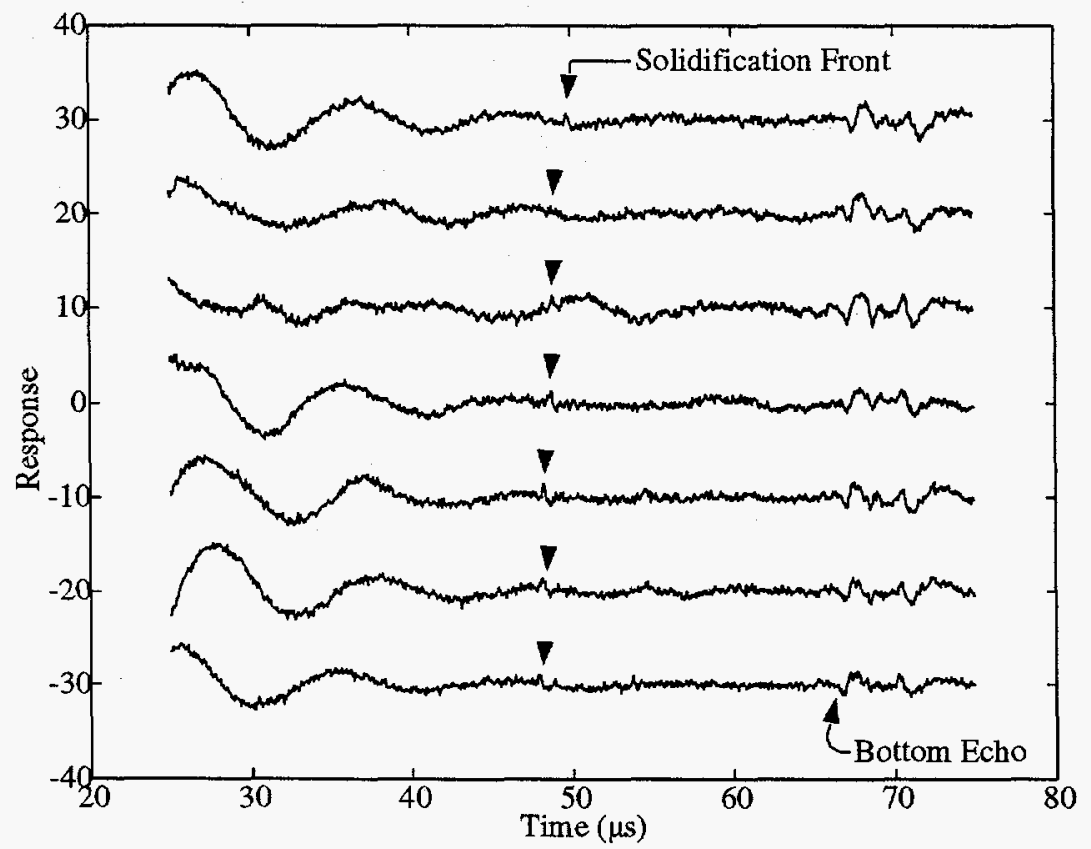

Figure 36. Laser signals from a moving solidification front $(\sim 0.1 \mathrm{~mm} / \mathrm{min})$ in a tin-lead $(0.6 \%)$ alloy. All waveforms are single shot; the data span about $30 \mathrm{~min}$.

b. Private communication from W. J. Boettinger and R. J. Schaefer of the Metallurgy division, Nationa! Institute of Standards and Technology, Gaithersburg, May 1995. 
The location of the solidification front in pure tin and also in a $0.6 \% \mathrm{~Pb}$ alloy with a mushy zone was successfully recorded using laser ultrasonic methods. Reflections from the stationary solidification fronts were considerably larger than those from moving fronts. The presence of a mushy zone in the alloy decreased the reflection signal amplitude. Averaging and other signal processing techniques could be used to significantly enhance the solidification front reflection signal. Laser ultrasonic methods show potential for studying solidification in metals via the reflected signal amplitude. Solidification front shape, growth structure, and growth rate all affect the signals measured.

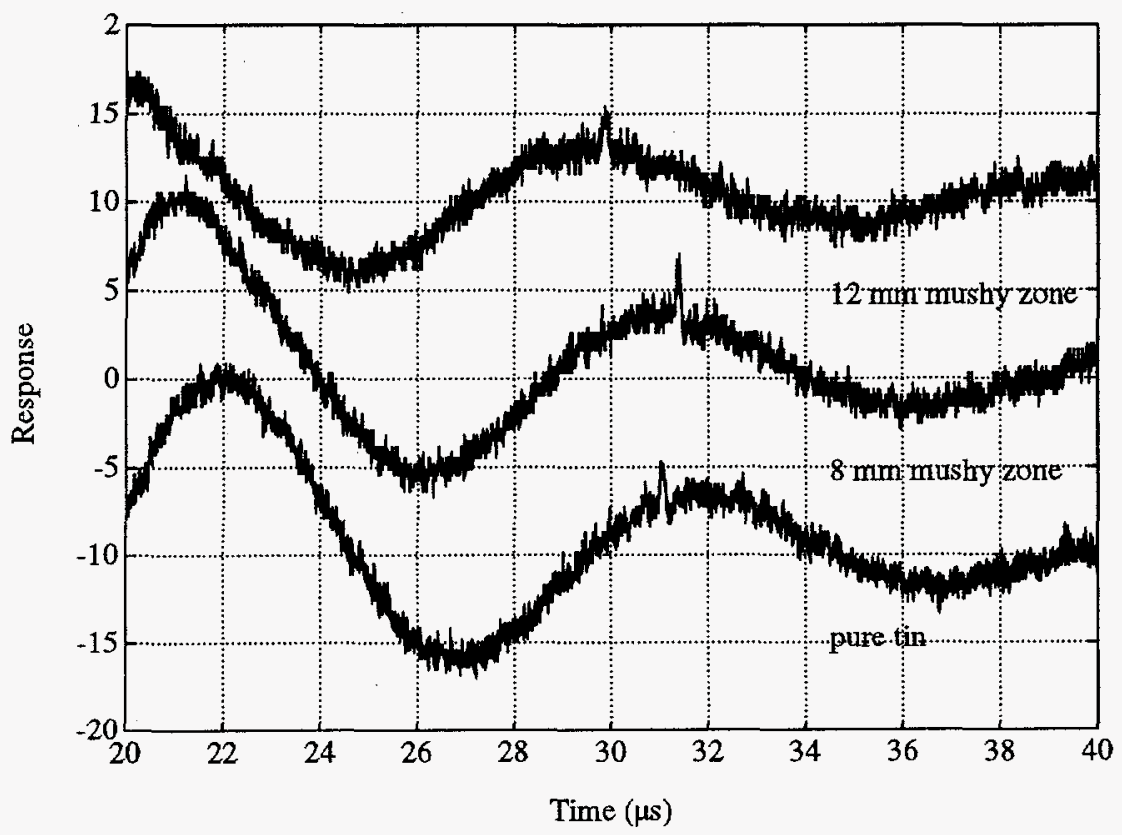

Figure 37. Comparison of solidification front echoes for 8 and 12 mm mushy zones with that of a moving front in pure tin. 


\section{WIRE ROPE MEASUREMENTS}

As a result of contacts with the USBM Pittsburgh Research Center (PRC), noncontacting ultrasonic techniques to inspect wire ropes were investigated. Ultrasonic wave propagation along ropes could provide a new inspection technique to complement the magnetic measurements already in use. Two distinct wave modes, longitudinal and torsional, would yield local measurement of Young's modulus and the shear modulus along the rope. Currently, only static measurements of these parameters are performed in the laboratory. High precision ultrasonic measurements could detect changes in the moduli as the rope wears, forming the basis of an in situ rope fatigue or wear condition inspection technique. Local measurements could provide spatial resolution of the order of $1 \mathrm{~m}$ or less, and the method is fast and could be made noncontacting.

Two 17-ft long, $1.25 \mathrm{in}$. diameter wire ropes were received from the PRC for assessment. The rope sections came from a long rope fatigued at the PRC on a special machine that forces it through many bending cycles. Long lengths of rope can be run on this machine such that different sections exhibit different amounts of fatigue. The various sections undergo 0 to 8 cycles of bending for every cycle of the machine. Both an unfatigued (dead wrap) section (Section F8T387) of rope and a section exhibiting the most fatigue (Section F8T21) were tested at INEL. A long mounting jig, consisting of an I-beam, was made that holds one rope horizontally in the air with a small amount of load. Magnetostrictive generation and piezoelectric detection were used to measure the longitudinal velocity, which is about $3.5 \mathrm{~km} / \mathrm{s}$. As expected, this is lower than a solid steel rod's velocity of $5.0 \mathrm{~km} / \mathrm{s}$ due to the lower density and Young's modulus of the rope. Figure 38 shows waveforms recorded along the rope for a single sine wave burst of the magnetic induction drive. The extended waveform after the first pulse is a reflection from the end nearest the drive coil. Evidence of other wave modes has also been observed. Figure 39 shows the results of low-load measurements on the two rope sections. A considerable increase in wave velocity was found for the fatigued rope over the unfatigued sample. This is consistent with expectations that fatigue increases the effective Young's modulus of the rope and, correspondingly, the wave velocity. 


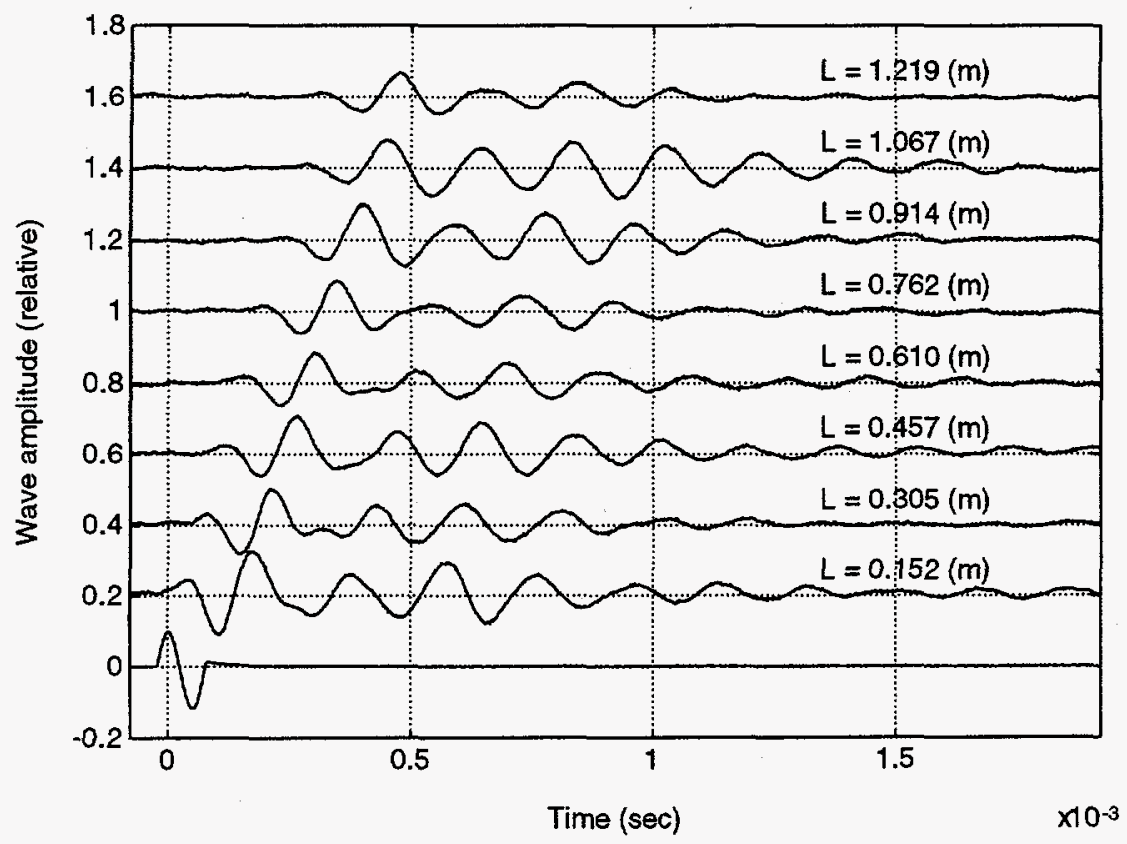

Figure 38. Waveforms recorded along the unfatigued rope. The bottom trace is the source current pulse.

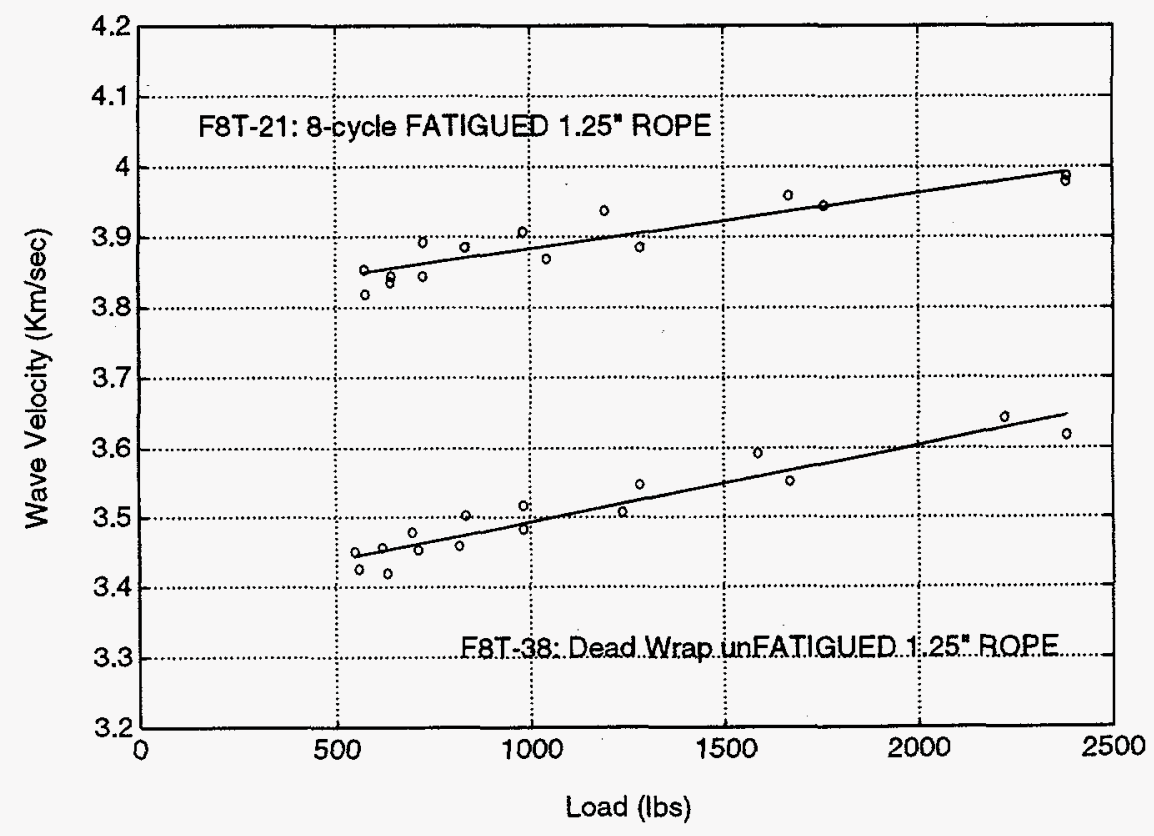

Figure 39. Wave velocity comparison between the two ropes tested at INEL. (The lines are only an aid to illustrate the general load dependence.) 
Wire ropes are normally used under much greater loads than that tested at the INEL. To determine if the same dependence of wave velocity on fatigue occurs at higher loads, wave velocity measurements were conducted at the PRC Wire Rope Research Laboratory using six sections of a rope with 0 to 8 fatigue cycles. This work was conducted in collaboration with Dr. William McKewan and his staff using their high load capacity tensile and axial fatigue testing machine. Rope sections were loaded up to 60 kips $(60,000 \mathrm{lbs})$ and wave velocity measurements were taken with a local two-detector cross-correlation technique for increasing and decreasing loads. Figure 40 shows the results for all six sections tested (F8T22, -24, -27, -29, -32, -36). All sections exhibited similar dependence of velocity on load. There is a rapid increase in velocity with load for loads less than approximately $10 \mathrm{kips}$. These results are similar to those at the low loads used in the INEL tests, where the velocity dependence on load is steep and a considerable difference exists between the dead wrap and highly fatigued sections. Further increasing the load causes the velocity to level off, approaching independence from load at the maximum tested. Generally, the rope sections exhibited increases in absolute velocity with fatigue. The section with the highest fatigue (F8T22) exhibited the highest velocity and the dead wrap section (F8t36) the lowest. The others were in between these two, approximately increasing with fatigue. Section F8T32 is a noted exception and warrants more attention. Figure 41 shows a comparison between the dead wrapped (F8T36) and most highly fatigued (F8T22) sections that is consistent with the INEL results. More rope sections need to be measured to improve the statistics concerning rope longitudinal wave velocity dependence on fatigue. However, these initial results do support the conclusion that wave velocity increases with fatigue. Problems arose concerning the coupling of the piezoelectric pickup transducers to the rope, partly due to different grease conditions on the rope and its construction. These problems brought out the need for fully noncontacting methods of measurement.
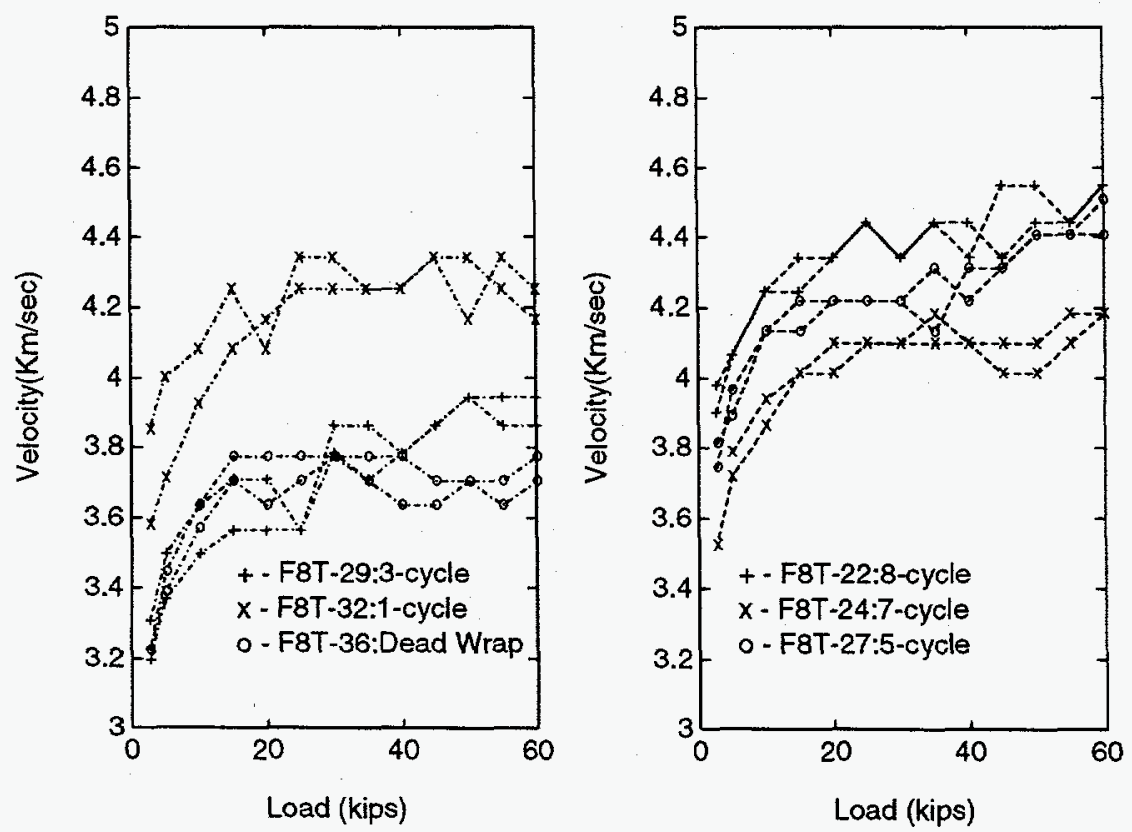

Figure 40. Wave velocities measured on six rope sections under high load. 


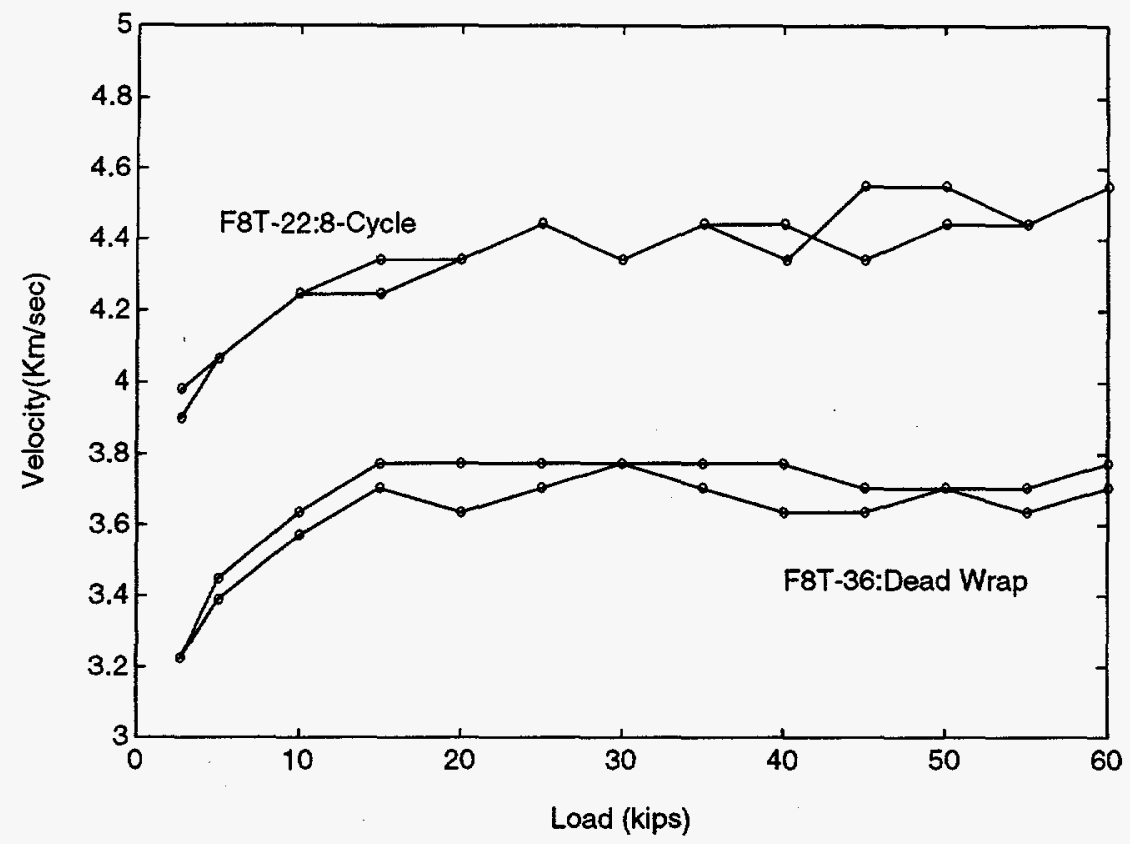

Figure 41. Wave velocity comparison between the least and most fatigued sections at high load.

Two noncontacting measurement approaches have been considered. With internal INEL funding, the laser ultrasonic detection system has been redesigned into a smaller, portable noncontacting detector; however, this was not completed in time to be applied to this project. The other approach utilizes electromagnetic induction on magnetized rope sections. This method is totally noncontacting and offers the potential for much improved longitudinal wave velocity measurement precision due to the lack of direct coupling. Preliminary results show significant interference sensitivity to this approach, which can be alleviated somewhat by using specially designed $1 \mathrm{st}$ or 2 nd derivative coil arrangements. Figure 42 shows measured signals due to a tone burst excitation recorded with both the magnetic and piezoelectric transducers. Further tests with this approach have brought out complicated signal signatures due to the complex nature of twisted wire ropes. Measurements made at frequencies from 10 to $50 \mathrm{kHz}$ indicate that either multi-modes were excited or that there is considerable dispersion in the elastic wave propagation. This is to be expected as the rope has characteristic lengths in the wire bundles and in the twist pitch. More work is needed to fully characterize the elastic wave modes propagating along wire ropes and to optimize the generation and detection process. A collaboration with Commercial Technologies Inc., of Metarie, LA, which makes magnetic flux linkage sensors for wire rope testing, was sought to allow the elastic wave measurements to be coupled to the flux linkage sensor to form a probe system usable for remote measurements. This approach appeared to be well matched but no CRADA agreement resulted. 


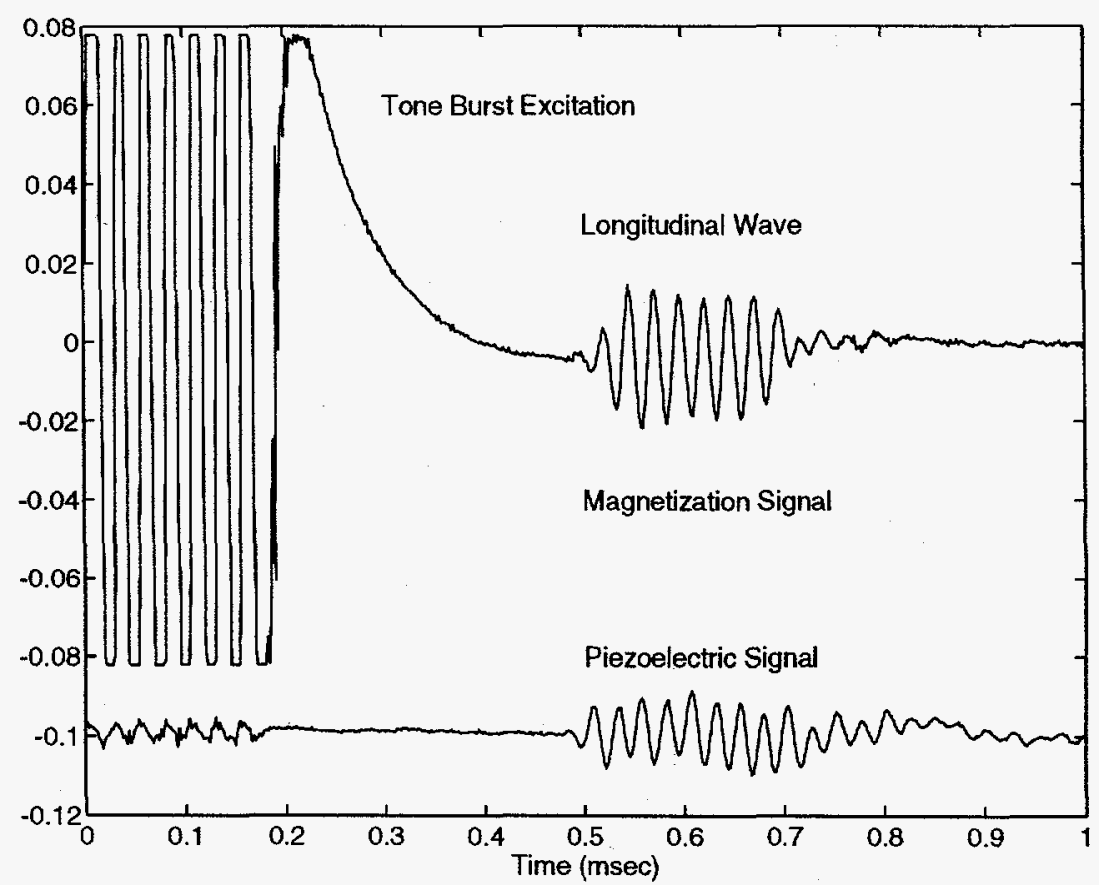

Figure 42. Longitudinal wave signals measured along the rope with magnetic and piezoelectric transducers. 


\section{RESEARCH SUMMARY}

This work has been instrumental in introducing industry to the capabilities of noncontacting ultrasonic measurements - Laser Ultrasonics - for in situ process monitoring and NDE. Although this project has drawn heavily on the research of others, especially from other parts of the world in laser detection technique development, it has made a major contribution by demonstrating laser ultrasonics' capability for material property measurement in diverse processing and NDE situations. This was necessary to bring laser ultrasonics into the materials analysis field. When this project began (1983) there were no companies in the U.S. using laser ultrasonics and no vendors producing equipment for the commercial market. Now, at the end of this project (1995), several companies (Rockwell, General Dynamics, Lockheed Martin) have set up or purchased equipment for this purpose. Vendors now exist in the U.S.: Hughes, Textron, and soon Simpex Technologies. INEL was the first national laboratory to investigate laser ultrasonics for materials processing and NDE in a manner suitable for industrial applications; similar efforts are now underway at Argonne National Laboratory, Lawrence Livermore National Laboratory, Sandia National Laboratory, NASA-Langley, and the National Institute of Standards and Technology. 


\section{TECHNOLOGY TRANSFER}

The experiments on both solid and liquid materials at high temperatures, as well as the demonstration of noncontacting capability, have resulted in much interest from private industry. In May 1992, an announcement was printed in the Commerce Business Daily (CBD) asking for potential industrial collaborators for this project. More than 30 responses were received from a large range of companies. The processes offered for collaboration included laser ablation measurement for drilling, fabrication of carbonepoxy composites, superplastic forging, high-pressure and high-temperature consolidation, microwave ceramic joining, and fabrication of metal matrix composites. Several applications for post-processing nondestructive evaluation were also suggested.

A cooperative research and development agreement (CRADA) has been signed with a company that manufactures microelectronic circuit-testing facilities, Simpex Technologies, to research the ability of laser ultrasonics for noncontacting circuit bonding inspection.

Not all industrial participants desired to establish a CRADA. Discussions were held with other industrial partners on (a) the application of laser ultrasonics to the consolidation of nanosize particles (resulted in a Department of Energy [DOE] Small Business Innovation Research proposal), (b) ceramic metal composite consolidation (resulted in a DOE proposal), and (c) applications to resin-based composite curing (resulted in a Department of Defense proposal).

This work resulted in the project "Molten Metal Depth Sensing", funded for FY94 through FY96 by the DOE Defense Programs Office, which is a CRADA involving six industrial partners involved in metal remelting and ingot fabrication.

This project is contributing to a CRADA between INEL and General Motors, Ford, and Chrysler, funded by DOE, to research applications for laser ultrasonics in the automotive industry.

Industrial companies that have collaborated with the INEL on evaluation of laser ultrasonics in a variety of materials processing and NDE applications include Pratt \& Whitney, Thiokol, Hercules, Howmet, B.F. Goodrich, and Simpex Technologies.

INEL has been a partner in the CRADA involving the National Institute of Standards and Technology Consortium on the Casting of Aerospace Alloys for sensor development. INEL performed the laser ultrasonic portion and provided basic knowledge concerning the generation and detection of ultrasonic waves in molten metals and laser ultrasonic location of the solidification front during the casting process. 


\section{PROJECT PUBLICATION LIST}

\section{Inconel Grain Scattering and the Single Scatterer Model}

K. L. Telschow and G. D. Lassahn, "Effects of Scatterer Spacing Statistics on Ultrasonic Backscatter Signal Spectra," Proceedings of the 1984 IEEE Ultrasonics Symposium, November 1984, Dallas, Texas, Vol. 2, B. R. McAvoy (ed.) IEEE, New York, 1984, 852

K. L. Telschow and G. D. Lassahn, Quantitative Backscatter for Microstructure Characterization, Idaho National Engineering Laboratory Report EGG-SCM-7218, August 1986

\section{Rapidly Solidified Materials}

K. L. Telschow and J. E. Flinn, "Ultrasonic Backscatter and Attenuation in Consolidated RSP Powder," Review of Progress in Quantitative NDE, Vol.5B, D. O. Thompson and D. E. Chimenti eds., Plenum Pub. Co., New York, 1986, 1355-1363

K. L. Telschow and J. E. Flinn, Ultrasonic Backscatter and Attenuation Measurements for Microstructure Characterization: Application to Consolidated Rapidly Solidified Type 304 Stainless Steel Powder, Idaho National Engineering Laboratory Report EGG-SCM-7198, March 1986

K. L. Telschow and J. E. Flinn, "Ultrasonic Characterization of Consolidated Rapidly Solidified Powders: Application to Type 304 Stainless Steel," Nondestructive Characterization of Materials II, ed. by J. F. Bussiere, J. Monchalin, C. O. Rudd and R. E. Green, Jr. (Plenum Press, New York, 1987) 149-157

\section{Porosity Distributions / Composites}

K. L. Telschow, J. B. Walter, and D. C. Kunerth, "Ultrasonic Characterization of Nonuniform Porosity Distributions in SiC Ceramic," Review of Progress in Quantitative NDE, Vol. $7 B$ edited by D. O. Thompson and D. E. Chimenti (Plenum Press, New York, 1988), 1285-1292

J. B. Walter, L. A. Lott and K. L. Telschow, "Ultrasonic Characterization of Ceramic-Ceramic Composites," Review of Progress in Quantitative NDE, Vol. $7 B$ edited by D. O. Thompson and D. E. Chimenti (Plenum Press, New York, 1988), 971-978

D. C. Kunerth, K. L. Telschow, and J. B. Walter, "Characterization of Porosity Distributions in Advanced Ceramics: A Comparison of Ultrasonic Methods," Materials Evaluation, 47 (5), 1989, 571-575

K. L. Telschow and J. B. Walter, Ceramic Joint Interface Diagnostics with Ultrasonic Reflection Signal Energies, Idaho National Engineering Laboratory Report EGG-SCM-8069, July 1988.

\section{Laser Generation}

K. L. Telschow, "Microstructure Characterization with a Pulsed Laser Ultrasonic Source," Review of Progress in Quantitative NDE, Vol.7B edited by D. O. Thompson and D. E. Chimenti (Plenum Press, New York, 1988), $1211-1218$ 
Master's Thesis, The Effects of Thermal Diffusion and Optical Absorption on Laser Generated Ultrasonic Waves in a Solid, by Amitava Roy. Department of Mechanical Engineering, Montana State University, June 1989. Professor R. J. Conant, advisor.

Master's Thesis, One-Dimensional Model for Laser Generated Elastic Waves in a Solid Layer, by Harischandra Prasad Cherukuri. Department of Mechanical Engineering, Montana State University, June 1989. Professor R. J. Conant, advisor.

R. J. Conant and K. L. Telschow, "Longitudinal Wave Precursor Signal for an Optically Penetrating Thermoelastic Laser Source," Review of Progress in Quantitative NDE, Vol. $8 A$ edited by D. O. Thompson and D. E. Chimenti (Plenum Press, New York, 1989), 497-504

K. L. Telschow and R. J. Conant, "Optical Parameter Effects on Laser Generated Ultrasound for Microstructure Characterization," Nondestructive Characterization of Materials, Proceedings of the 3rd International Symposium, Saarbrucken, West Germany, October 3-6, 1988, P. Hoeller, V. Hauk, G. Dobmann, C. O. Ruud, R. E. Green eds., (Springer-Verlag, New York, 1989) 799-806.

K. L. Telschow and R. J. Conant, "Optical and Thermal Parameter Effects on Laser Generated Ultrasound," J. Acoust. Soc. Am. 88(3), 1990, 1494-1502

Master's Thesis, Investigation of the Generation Mechanisms involved in Laser Generated Ultrasound and Estimation of Elastic Constants in Thin Plates, by David Hurley. Department of Mechanical Engineering, Montana State University, under Professor R. J. Conant June 21, 1991

\section{Process Monitoring}

K. L. Telschow, J. B. Walter, G. V. Garcia, and D. C. Kunerth, "Process Monitoring Using Optical Ultrasonic Wave Detection," Review of Progress in Quantitative NDE, Vol. 9 edited by D. O. Thompson and D. E. Chimenti (Plenum Press, New York, 1990) 2063-2068

K. L. Telschow, J. B. Walter, and G. V. Garcia, "Laser Ultrasonic Monitoring of Ceramic Sintering," $J$. Appl. Phys. 68(12), 1990, 6077-6082

K. L. Telschow, "Real-Time Monitoring of Ceramic Sintering with Laser Ultrasonics," Nondestructive Characterization of Materials IV, edited by C. O. Ruud, J. F. Bussiere and R. E. Green, Jr., (Plenum Press, New York, 1991) pp 97-104

\section{Rough Surface Materials}

J. B. Walter and K. L. Telschow, "Laser Ultrasonic Measurements on Ceramic Materials with Rough Surfaces," Extended Abstracts of the Conference on Nondestructive Evaluation of Modern Ceramics, (Am. Soc. Nondestructive Testing, Inc., Columbus, OH, July 9-12, 1990) 140-143

Ph.D. Thesis, Wave Scattering and Reflection from a Random Rough Interface Between Two Elastic Solids, by Hemin Yang. Department of Mechanical Engineering, Montana State University, under Professor R. J. Conant, May 7, 1991 
L. S. Koo and K. L. Telschow, "Analysis of Laser Ultrasonic Measurements of Surface Waves on Elastic Spheres," Review of Progress in Quantitative NDE, Vol. $11 \mathrm{~A}$ edited by D. O. Thompson and D. E. Chimenti (Plenum Press, New York, 1992) 609-615

M. H. O'Brien, K. L. Telschow, and J. R. Knibloe, "Analysis of As-Machined Nuclear Graphite Parts using Conventional and Laser Ultrasonic Techniques," J. Nuclear Science and Technology, 29(4), pp. 378$387,1992$.

\section{Molten Metals}

G. V. Garcia, N. M. Carlson, K. L. Telschow and J. A. Johnson, "Noncontacting Laser Ultrasonic Generation and Detection at the Surface of a Molten Metal," Review of Progress in Quantitative NDE, Vol. 9 edited by D. O. Thompson and D. E. Chimenti (Plenum Press, New York, 1990) 1981-1986

J. B. Walter, K. L. Telschow, and R. J. Conant, "Laser Ultrasonic Generation at the Surface of a Liquid Metal," Review of Progress in Quantitative NDE, Vol. 14 edited by D. O. Thompson and D. E. Chimenti (Plenum Press, New York, 1995) 507-512.

J. B. Walter and K. L. Telschow, "Laser Ultrasonic Detection of the Solidification Front during Casting," Review of Progress in Quantitative NDE, Vol. 15 edited by D. O. Thompson and D. E. Chimenti (Plenum Press, New York, 1996) to be published. 


\section{PATENTS}

\#4995260, "Nondestructive Material Characterization," EGG-PI-192, February 26,1991

\#5048969, "Piezoelectric Measurement of Laser Power," EGG-PI-191, September 17,1991

\#5103676, "A Method of Noncontacting Ultrasonic Process Monitoring," EGG-PI-407, April 14, 1992

"Method and Device for Optical Determination of Wire Ball, Wedge and Solder Pad Bond Quality for Interconnections in Integrated Electronic Circuits," EGG-PI-645, Filed Mar. 1994 


\section{REFERENCES}

1. K. L. Telschow and G. D. Lassahn, "Effects of Scatterer Spacing Statistics on Ultrasonic Backscatter Signal Spectra," Proceedings of the 1984 IEEE Ultrasonics Symposium, November 1984, Dallas, Texas, Vol. 2, B. R. McAvoy (ed.) IEEE, New York, 1984, p. 852.

2. R. Truell, C. Elbaum, and B. B. Chick, Ultrasonic Methods in Solid State Physics, Academic Press, New York, 1969.

3. K. L. Telschow and G. D. Lassahn, Quantitative Backscatter for Microstructure Characterization, Idaho National Engineering Laboratory Report EGG-SCM-7218, August 1986.

4. K. L. Telschow, et al., "Nondestructive Evaluation of Ceramic and RSA Joints and Materials," in Strategic and Critical Materials Program Annual Report-1985, May 1985.

5. D. C. Waterman and R. Truell, "Multiple Scattering of Waves," J. Math. Phys. 2, 512, (1961).

6. K. L. Telschow, et al., "Nondestructive Evaluation of Ceramic and RSA Joints and Materials," in Strategic and Critical Materials Program Annual Report-1986, May 1986.

7. K. L. Telschow and J. E. Flinn, "Ultrasonic Backscatter and Attenuation in Consolidated RSP Powder," Review of Progress in Quantitative NDE, Vol. 5B, D. O. Thompson and D. E. Chimenti eds., Plenum Pub. Co., New York, 1986, pp. 1355-1363.

8. K. L. Telschow and J. E. Flinn, "Ultrasonic Characterization of Consolidated Rapidly Solidified Powders: Application to Type 304 Stainless Steel," Nondestructive Characterization of Materials II, ed. by J. F. Bussiere, J. Monchalin, C. O. Rudd and R. E. Green Jr. (Plenum Press, New York, 1987) 149-157.

9. K. L. Telschow and J. E. Flinn, Ultrasonic Backscatter and Attenuation Measurements for Microstructure Characterization: Application to Consolidated Rapidly Solidified Type 304 Stainless Steel Powder, Idaho National Engineering Laboratory Report EGG-SCM-7198, March 1986.

10. K. L. Telschow, J. B. Walter and D. C. Kunerth, "Ultrasonic Characterization of Nonuniform Porosity Distributions in SiC Ceramic," Review of Progress in Quantitative NDE, Vol. $7 B$, ed. by D. O. Thompson and D. E. Chimenti (Plenum Press, New York, 1988), 1285-1292.

11. J. B. Walter, L. A. Lott, and K. L. Telschow, "Ultrasonic Characterization of Ceramic-Ceramic Composites," Review of Progress in Quantitative NDE, Vol. 7B, ed. by D. O. Thompson and D. E. Chimenti (Plenum Press, New York, 1988), 971-978.

12. D. C. Kunerth, K. L. Telschow and J. B. Walter, "Characterization of Porosity Distributions in Advanced Ceramics: A Comparison of Ultrasonic Methods," Materials Evaluation, 47(5), 1989, $571-575$.

13. D. C. Kunerth, J. B. Walter, and K. L. Telschow, Nondestructive Evaluation of Silicon Carbide Heat Exchanger Tubes, Idaho National Engineering Laboratory Report EGG-SD-7563, April 1987.

14. K. L. Telschow and J. B. Walter, Ceramic Joint Interface Diagnostics with Ultrasonic Reflection Signal Energies, Idaho National Engineering Laboratory Report EGG-SCM-8069, July 1988. 
15. S. A. Suarez, R. F. Gibson, and L. R. Deobald, "Random and Impulse Techniques for Measurement of Damping in Composite Materials," Exp. Tech., 8 (10), Oct. 1984, pp. 19-24.

16. J.-P. Monchalin and R. Hěon, "Laser Ultrasonic Generation and Detection with a Confocal Fabry-Perot Interferometer," Materials Evaluation, 44, 1231 (1986).

17. J.-P. Monchalin, "Optical Detection of Ultrasound," IEEE Trans. on UFFC, 33, 485-490, (1986).

18. R. J. Conant and K. L. Telschow, "Longitudinal Wave Precursor Signal for an Optically Penetrating Thermoelastic Laser Source," Review of Progress in Quantitative NDE, Vol. 8A, edited by D. O. Thompson and D. E. Chimenti (Plenum Press, New York, 1989), pp. 497-504.

19. K. L. Telschow and R. J. Conant, "Optical Parameter Effects on Laser Generated Ultrasound for Microstructure Characterization," Nondestructive Characterization of Materials, Proceedings of the 3rd International Symposium, Saarbrucken, West Germany, October 3-6, 1988, P. Hoeller, V. Hauk, G. Dobmann, C. O. Ruud, R. E. Green eds., (Springer-Verlag, New York, 1989) pp. 799806.

20. K. L. Telschow and R. J. Conant, "Optical and Thermal Parameter Effects on Laser Generated Ultrasound," J. Acoust. Soc. Am., 88(3), 1990, 1494-1502.

21. K. L. Telschow, "Microstructure Characterization with a Pulsed Laser Ultrasonic Source," Review of Progress in Quantitative NDE, Vol.7B, edited by D. O. Thompson and D. E. Chimenti (Plenum Press, New York, 1988), pp. 1211-1218.

22. C. M. Sayers and R. L. Smith, "The Propagation of Ultrasound in Porous Media," Ultrasonics 20, 201-205 (1982).

23. E. P. Papadakis and B. W. Petersen, "Ultrasonic Velocity as a Predictor of Density in Sintered Powder Metal Parts," Mater. Eval. 37(5), 76-80 (1979).

24. S. J. Klima et al., "Ultrasonic Velocity for Estimating Density in Structural Ceramics," NASA TM-82765, (1981).

25. C. B. Scruby, R. L. Smith and B. C. Moss, "Microstructural Monitoring by Laser-Ultrasonic Attenuation and Forward Scattering," NDT International 19(5), 307-313 (1986).

26. J.-P. Monchalin, et al., "Laser-Ultrasonics Developments Towards Industrial Applications," Proceedings of the IEEE 1988 Ultrasonics Symposium (IEEE, N.Y., 1988) 1041-1044.

27. C. B. Scruby, "Some Applications of Laser Ultrasound," Ultrasonics, 27, 195-209 (1989).

28. C. B. Scruby, R. J. Dewhurst, D. A. Hutchins, and S. B. Palmer, "Laser Generation of Ultrasound in Metals," Research Techniques in Nondestructive Testing, vol. 2, R. S. Sharp editor (Academic press, N.Y., 1982), 281-327.

29. D. A. Hutchins, "Ultrasonic Generation by pulsed Lasers," Physical Acoustics, vol. XVIII, W. P. Mason editor (Academic Press, N.Y., 1988), 21-123.

30. J. D. Aussel, A. Le Brun and J. C. Baboux, "Generating Acoustic Waves by Laser: Theoretical and Experimental Study of the Emission Source," Ultrasonics, 26, 245-255, 1988. 
31. U. Schleichert, K. J. Langenberg, W. Arnold, and S. Fassbender, "A Quantitative Theory of Laser-Generated Ultrasound," Review of Progress in Quantitative Nondestructive Evaluation, Vol. 8A, D. O. Thompson and D. E. Chimenti eds., Plenum Press, New York, 489-496 (1989).

32. L. Piche, B. Champagne, and J.-P. Monchalin, "Laser Ultrasonics Measurements of Elastic Constants of Composites," Materials Evaluation, 45, 74 (1987).

33. L. F. Bresse, D. A. Hutchins, and K. Lundgren, "Elastic Constant Determination using Generation by Pulsed Lasers," J. Acoust. Soc. Am., 84(5), 1751-1757, (1988).

34. J.-D. Aussel and J.-P. Monchalin, "Precision Laser-Ultrasonic Velocity Measurement and Elastic Constant Determination," Ultrasonics, 27, 165-177 (1989).

35. J.-D. Aussel and J.-P. Monchalin, "Measurement of Ultrasound Attenuation by Laser Ultrasonics," J. Appl. Phys., 65(8), 2918-2922, (1989).

36. R. J. Dewhurst et al., "A Remote Laser System for Ultrasonic Velocity Measurement at High Temperatures," J. Appl. Phys., 63(4), 1225 (1988).

37. M. W. Griggs, et al., "Elastic Moduli of Solids--A Method Suitable for High Temperature Measurements," J. Phys. E: Sci. Instrum., 19, 1059-1063, (1986).

38. F. Duvant et al., "Ultrasonic Control of Ceramic Products Cracking During Their Making Between 20 and $1400^{\circ} \mathrm{C}$," Proceedings of the Second International Symposium of Ceramic Materials and Components for Engines, Verlag Deutsche Keramische Gesellschaft, Bad Honnef, West Germany, 849 (1986).

39. J. H. Gieske and H. M. Frost, "Sound Velocity Measurements in Green-Body Ceramics as a Function of Sintering Temperatures," Review of Progress in Quantitative Nondestructive Evaluation, Vol. 8B, D. O. Thompson and D. E. Chimenti eds., Plenum Press, New York, 1709 (1989).

40. K. L. Telschow et al., "Process Monitoring Using Optical Ultrasonic Wave Detection," Review of Progress in Quantitative NDE, Vol. 9, edited by D. O. Thompson and D. E. Chimenti (Plenum Press, New York, 1990) 2063-2068.

41. K. L. Telschow, J. B. Walter, G. V. Garcia, "Laser Ultrasonic Monitoring of Ceramic Sintering," J. Appl. Phys,. 68(12), 1990, 6077-6082.

42. K. L. Telschow, "Real-Time Monitoring of Ceramic Sintering with Laser Ultrasonics," Nondestructive Characterization of Materials $I V$, edited by C. O. Ruud, J. F. Bussiere and R. E. Green, Jr., (Plenum Press, New York, 1991) pp. 97-104.

43. D. Hurley, Investigation of the Generation Mechanisms involved in Laser Generated Utrasound and Estimation of Elastic Constants in Thin Plates, Master's Thesis, Department of Mechanical Engineering, Montana State University, under Professor R. J. Conant, June, 1991.

44. L. S. Koo and K. L. Telschow, "Analysis of Laser Ultrasonic Measurements of Surface Waves on Elastic Spheres," Review of Progress in Quantitative NDE, Vol. 11, edited by D. O. Thompson and D. E. Chimenti (Plenum Press, New York, 1992) 609-615. 
45. G. V. Garcia et al., "Noncontacting Laser Ultrasonic Generation and Detection at the Surface of a Molten Metal," Review of Progress in Quantitative NDE, Vol. 9, edited by D. O. Thompson and D. E. Chimenti (Plenum Press, New York, 1990) pp. 1981-1986.

46. F. V. Bunkin, Al. A. Kolomensky, and V. G. Mikhalevich, Lasers in Acoustics, (Harwood Publisher Academic GmbH, Chur, Switzerland, 1991) chapter 1.

47. S. Temkin, Elements of Acoustics, (John Wiley \& Sons, Inc., New York, 1981) chapter 5.

48. Al. A. Kolominski, Sov. Tech. Phys. Lett. 12, (2), February 1986, pp. 100-101.

49. J. B. Walter and K. L. Telschow, "Laser Ultrasonic Generation at the Surface of a Liquid Metal," Review of Progress in Quantitative NDE, Vol. 14, edited by D. O. Thompson and D. E. Chimenti (Plenum Press, New York, 1995) 507-512.

50. J. B. Walter and K. L. Telschow, "Laser Ultrasonic Detection of the Solidification Front during Casting," Review of Progress in Quantitative NDE, Vol. 15, edited by D. O. Thompson and D. E. Chimenti (Plenum Press, New York, 1996) to be published. 